$3_{8^{1}}^{8^{9}}$
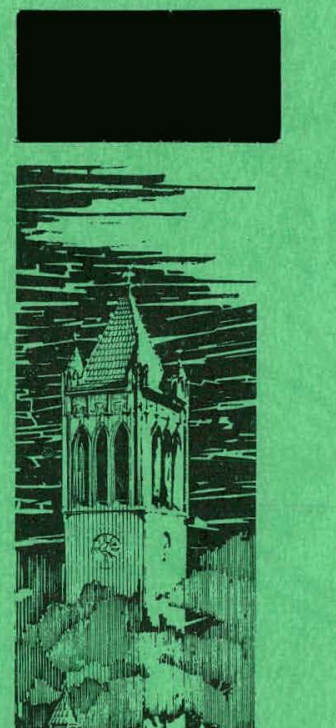

(1)

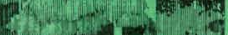
4ta $=1 \mathrm{rll}$

$-12=$
RETEASED FOR ANWUNCEWE?

IN NUCLEAR SCIENCE ABSTRACTS

IOWA STATE UNIVERSITY

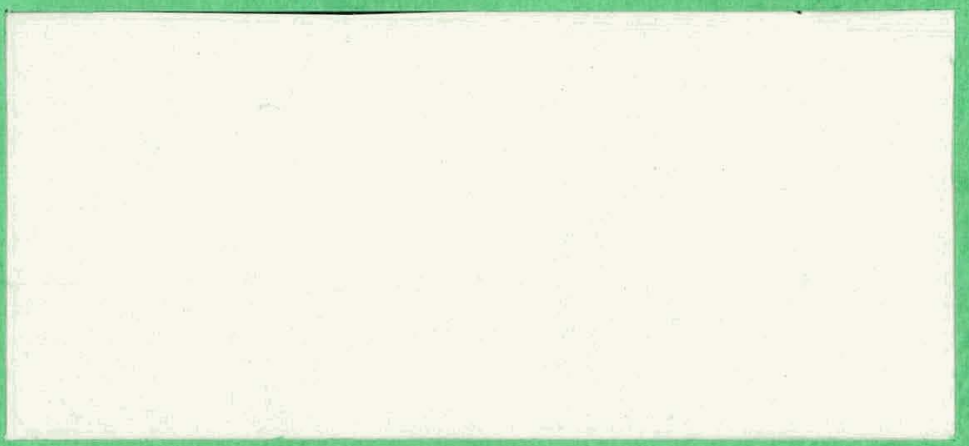

AMES LABORATORY

RESEARCH AND

DEVELOPMENT

REPORT

U.S.A.E.C. 


\section{DISCLAIMER}

This report was prepared as an account of work sponsored by an agency of the United States Government. Neither the United States Government nor any agency Thereof, nor any of their employees, makes any warranty, express or implied, or assumes any legal liability or responsibility for the accuracy, completeness, or usefulness of any information, apparatus, product, or process disclosed, or represents that its use would not infringe privately owned rights. Reference herein to any specific commercial product, process, or service by trade name, trademark, manufacturer, or otherwise does not necessarily constitute or imply its endorsement, recommendation, or favoring by the United States Government or any agency thereof. The views and opinions of authors expressed herein do not necessarily state or reflect those of the United States Government or any agency thereof. 


\section{DISCLAIMER}

Portions of this document may be illegible in electronic image products. Images are produced from the best available original document. 

IS -1356

This report is distributed according to the category Chemistry (UC-4) as listed in TID-4500, March 1, 1966.

\section{LEGAL NOTICE}

This report was prepared as an account of Government sponsored work. Neither the United States, nor the Commission, nor any person acting on behalf of the Commission:

A. Makes any warranty or representation, expressed or implied, with respect to the accuracy, completeness, or usefulness of the information contained in this report, or that the use of any information, apparatus, method, or process disclosed in this report may not infringe privately owned rights; or

B. Assumes any liabilities with respect to the use of, or for damages resulting from the use of any information, apparatus, method, or process disclosed in this report.

As used in the above, "person acting on behalf of the Commission" includes any employee or contractor of the Commission, or employee of such contractor, to the extent that such employee or contractor of the Commission, or employee of such contractor preparcs, disseminates, or provides access to, any information pursuant to his employment or contract with the Commission, or his employment with such contractor.

Printed in USA. Price \$5.00. Available from the Clearinghouse for Federal Scientific and Technical Information, National

Bureau of Standards, U. S. Department of

Commerce, Springfield, Virginia 
ABSTRACT

I. INTRODUCTION

II. HISTORICAL REVIEW 6

A. Theoretical 6

B. Experimental 15

I. Microcalorimetry 15

2. Comparison of experiment with theory 18

III. THEORY 23

A. General Thermodynamics 23

B. Partial Molal Heat Contents 28

1. Definitions and properties 28

2. From heats of dilution 32

3. From heats of solution 33

4. From theory 35

IV. EXPERIMENTAL 39

A. Preparation of Materials 39

B. Apparatus 45

1. Water bath 47

2. Submarine jacket 48

3. Calorimeter containers 49

4. Calorimeter stirrers 50

5. Sample holders 52

6. Calorimeter heaters and circuit 55 
7. Thermopile and circuit 59

8. Adiabatic control 61

C. Experimental Procedure. 62

D. Calorimeter Tests 72

1. Electrical 72

2. Chemical 75

E. Treatment of latá 80

F. Heats of Dilution 90

1. Lanthanum chloride 92

2. Praseodymium chloride 96

3. Terbium chloride 107

4. Holmium chloride 115

5. Ytterbium chloride. 119

G. Heats of Solution of Terbium Chloride Hexahydrate and Holmium Chloride Hexahydrate $\quad 130$

H. Error Analysis $\quad 131$

V. DISCUSSION 134

$\begin{array}{ll}\text { VI. BIBLIOGRAPHY } & 157\end{array}$ 


\title{
HEATS OF DILUTION OF SOME AQUEOUS RARE-EARTH CHLORIDE SOLUTIONS AT $25^{\circ} \mathrm{C}^{*}$ \\ C. W. De Kock and F. H. Spedding
}

\begin{abstract}
The heats of dilution of aqueous $\mathrm{PrCl}_{3}, \mathrm{TbCl}_{3}$, and $\mathrm{YbCl}_{3}$ solutions
\end{abstract} were determined from zero molal to saturation, and aqueous $\mathrm{LaCl}_{3}$ and $\mathrm{HoCl}_{3}$ solutions from 0.25 molal to saturation at $25^{\circ} \mathrm{C}$. In addition, aqueous heats of solution of $\mathrm{TbCl}_{3} \cdot 6 \mathrm{H}_{2} \mathrm{O}$ and $\mathrm{HoCl}_{3} \cdot 6 \mathrm{H}_{2} \mathrm{O}$ were determined at $25^{\circ} \mathrm{C}$.

From these data empirical least square equations for the relative apparent molal heat contents, $\emptyset_{L}$, were determined as a function of $\mathrm{m}^{1 / 2}$ using an IBM 7074 computer. Expressions for the relative partial molal heat content of the water, $\overline{\mathrm{L}}_{1}$, and of the salt, $\overline{\mathrm{L}}_{2}$, were determined from these empirical equations. The relative partial molal excess entropies of the water $\left(\bar{S}_{1}-\bar{S}_{1}{ }^{\circ}\right)$ and of the salt $\left(\bar{S}_{2}-\bar{S}_{2}{ }^{\circ}\right)$ were determined from the $\overline{\mathrm{L}}_{1}$ and $\overline{\mathrm{L}}_{2}$ data and from the activity coefficient data of these electrolytes. Values for $\bar{L}_{1}, \bar{L}_{2}, T\left(\bar{S}_{1}-\bar{S}_{1}{ }^{\circ}\right)$ and $T\left(\bar{S}_{2}-\bar{S}_{2}{ }^{\circ}\right)$ were calculated at rounded concentrations.

The data show that aqueous $\mathrm{PrCl}_{3}$ and $\mathrm{TbCl}_{3}$ solutions obey the Debye-Hückel limiting law and there is strong indication that aqueous $\mathrm{YbCl}_{3}$ solutions also obey the limiting law. It is postulated that the heat of dilution data below 0.15 molal for all the aqueous rare-earth chloride

\footnotetext{
This report is based on a Ph. D. thesis submitted by C. W. DeKock, Novcmbcr, 1965 to Iowa State University, Ames, Iowa.
} 
solutions which have been studied can be understood in terms of two series within the rare earths. These two series have different water coordination numbers with a gradual shift in the equilibrium between these two coordination numbers occurring from beyond $\mathrm{Nd}$ to a round $\mathrm{Tb}$ or Dy. The lighter rare earths, from La to $\mathrm{Nd}$, favor the higher coordination number, while the heavier rare earths, from around $\mathrm{Tb}$ or Dy to $\mathrm{Yb}$, favor the lower water coordination number. The data for $\mathrm{PrCl}_{3}$ indicate that for this salt the equilibrium between two water coordination numbers shifts toward the lower coordination number with increasing concentration above 2.0 molal. 


\section{INTRODUCTION}

The study of electrolytic solutions has been a major field of interest ever since the time of Van't Hoff (78) and Arrhenius (3). The principle reason for this interest is the large number of processes which involve ions in solution. Another reason is that a theory of electrolytic solutions, for a wide range of concentrations, remains as one of the major unsolved problems of physical chemistry.

One of the oldest and most useful tools for the study of electrolytic solutions is classical thermodynamics. From a study of the macroscopic properties of electrolytic solutions, the chemist attempts to infer the microscopic structure of the solution. The thermodynamic properties of very dilute solutions of electrolytes are correctly predicted by the Debye-Hückel (9) theory. However, extensions of this theory to moderate concentrations (ionic strength equals 0.1 molal or higher) have been largely unsuccessful.

The heat of dilution of an electrolyte provides a very critical test of the Debye-Hückel (9) theory since this property can be measured accurately to very low concentrations.

The heat of dilution also provides valuable information about the energy changes due to dissociation, hydrolysis, hydration, modification of the solvent due to the presence 
of hydrated ions, and electrical work which accompany dilution. A brief study of the effect of association and hydrolysis on the heat of dilution was made during the course of this research. Heats of dilution are also valuable because they are needed to correct the heat of any reaction involving that electrolyte to its standard state which is usually infinite dilution. The derived quantities, the partial molal heat contents, are needed to calculate the activity coefficients of the electrolyte at different temperatures.

Since the rare earths are now avallable in high purity and in kilogram quantities, they provide a natural choice for the study of electrolytic solutions. They are readily avallable due to the advances in ion-exchange technology at the Amoo Laboratory during the past is to 20 years, Powell (54) has given an excellent review of this work.

The choice of the lanthanides, with the group III B elements $Y$ and La, for the study of electrolytic solutions is dictated by a number of almost ideal properties exhibited by these elements. They each form a number of salts which are very soluble in water. In aqueous media the rare-earth rations tend to hydrolyze and aoooolate much less then other tripositive cations. They form tripositive ions in aqueous solution and therefore provide a strenuous test for 
any theory of dilute electrolytes, since the physical properties of electrolytes in dilute solution are proportional to the square of their ionic charge. Since their salts are soluble over a wide concentration range, the physical properties of their solutions would provide a test of any theory which would be advanced for moderate to concentrated solutions of electrolytes. In fact, the avallability of precise thermodynamic data for solutions of rare-earth salts over wide concentration ranges should be very valuable for indicating new theoretical approaches to this problem. Chemically the rare-earths are very simllar. Their chemical properties are determined primarily by the outer three valency electrons common to all the rare earths. In aqueous solution they usually exist as strongly hydrated trivalent lons, and in crystals they also usually exist in the trivalent state. Their very close chemical similarity can be seen from the fact that they form isomorphic crystals and mixed crystals and compounds over wide ranges of atomic number from La to $\mathrm{Lu}$. This similarity is due to the unique electronic structure of the rare earths. As the atomic number increases, electrons fill the incompleted $4 \mathrm{f}$ subshell which is well shlelded by the completed 5s 5p subshells. Since the $4 f$ electrons are screened by these outer orbitals they exert very little influence on the chemical properties of these elements, However, as the nuclear charge increases, 
the $4 f$ orbital is attracted inward, resulting in the familiar lanthanide contraction. These factors make the rare-earth series an almost ideal series for studying the properties of electrolytes as a function of the fonic radius.

This thesis is a report of the measurement of the heats of dilution of $\mathrm{PrCl}_{3}, \mathrm{TbCl}_{3}$, and $\mathrm{YbCl}_{3}$ from $0.0 \mathrm{molal}$ to saturation, and of $\mathrm{LaCl}_{3}$ and $\mathrm{HoCl}_{3}$ from 0.3 molal to saturation. The heats of solution of $\mathrm{TbCl}_{3} \cdot 6 \mathrm{H}_{2} \mathrm{O}$ and $\mathrm{HoCl}_{3} \cdot 6 \mathrm{H}_{2} \mathrm{O}$ were also measured. The heat of dilution data in the very dilute concentration range provides an excellent test of the Debye-Hückel theory (9) for 3-1 electrolytes. Although the heat of dilution of $\mathrm{YbCl}_{3}$ solutions from 0.0 molal to 0.25 molal had previously been measured by Eberts (10), it was remeasured because his points scattered widely in the dilute region and led to an apparent discrepancy with the Debye-Hückel theory (9) for his most dilute points. It seemed desirable to extend the heat of dilution data to saturation. This was prompted by the fact that the enthalpy and entropy play a major role in determining the properties of electrolytic solutions. Previous work had shown a correlation (8) between the apparent inolal heat contents and the apparent molal volumes at very dilute concentrations, and it was of great interest to see how this correlation would be modified as the concentration increased. Since the activity coefficients for these rare-earth chlorides 
were available for the entire concentration range, precise data for the heats of dilution would make it possible to calculate the excess entropy of dilution and would thus round out a major area of interest in this laboratory. The excess entropy of dilution for lower valence electrolytes has been interpreted in terms of structure making and structure breaking effects (15). The highly charged rare-earth cation would certainly modify these effects, and the regular behavior of the rare-earth series should provide a check on the interpretation of the excess entropy of dilution. 


\section{HISTORICAL REVIEW}

\section{A. Theoretical}

In its simplest form, theoretical solution chemists are faced with the following problem: the thermal motions of ions in solution tend to give a completely random distribution of the ions throughout the solution, opposing this random distribution will be the ordering effects arising from the electronic charges carried by the ions. In a more rigorous treatment, particularly in more concentrated solutions, the theoretician must also consider ion-solvent interactions, short-range forces between ions, ion association, hydrolysis, and the physical size of ions. If the distribution of the lons is known, it is possible to calculate the electrical potential arising from this distribution; but in order to calculate the ionic distribution, the electrical potential is required. Milner (44), in 1912, was the first to successfully give a quantitative solution to this problem. His solution was too complex to be of any practical value at the time, but he was able to show that the deviations from ideality of dilute electrolytic solutions should be proportional to the square root of the concentration.

The basis of the modern theory of very dilute 
electrolytic solutions is the now famous paper published by Debye and Hückel (9) in 1923. They were able to quantitatively predict the behavior of the activity coefficient for very dilute solutions of an electrolyte using the following assumptions:

1. Strong electrolytes are completely dissociated into ions in solution.

2. All deviations from ideal solutions are attributed to the electrostatic forces between the lons.

3. The ions are rigid spheres, having a mean distance of closest approach.

4. The solvent is a continuous medium of uniform dielectric constant.

5. If any particular ion, say an i-ion, is chosen as the center of the coordinate system, then from the condition of electroneutrality there must be a net charge of $-z_{i} e$ throughout the whole solution outside this ion. This is the "ionic atmosphere" of the i-ion, and 1 s spherically symmetric in the absence of external forces.

7. The principle of the linear superposition of fields is not violated.

Using the above assumptions, Debye and Hückel (9) obtained the following expression for the mean lonic activity coefficient in very dilute solutions: 


$$
\log \gamma \pm=\frac{-A(f) \sqrt{I}}{1+B a \circ \sqrt{I}}
$$

where

$$
\begin{aligned}
& A(f)=\frac{1}{2 \cdot 303 v}\left[\sum_{i=1}^{p} v_{1} z_{i}^{2}\right]\left[\frac{2 \pi N \varepsilon^{6}}{1000(D k T)^{3}}\right]^{1 / 2} \\
& B=\left[\frac{8 \pi \varepsilon^{2} N}{1000 D k T}\right]^{1 / 2}
\end{aligned}
$$

and $I=1 / 2 \sum_{i=1}^{p} c_{i} z_{i}^{2}$ is the ionic strength. The total number of ions produced by the dissoctation of one molecule of the electrolyte is $v=\sum_{i=1}^{p} \nu_{1}$ where $\nu_{1}$ is the number of i-lons with charge $z_{i} ; c_{1}$ is the concentration in moles per liter of the ith ion; $N$ is Avogadro's number; $\varepsilon$ is the electronic charge; $D$ is the dielectric constant of the solvent; $k$ is Boltzmann's constant; $T$ is the absolute temperature, and $a^{0}$ is the mean distance of closest approach. In very dilute solutions, the ionic strength is small compared to untty, and since the numerical value of $\mathrm{Ba}^{\circ}$ for aqueous electrolytes is to an order of magnitude one, the term $\mathrm{Ba}^{\circ} \sqrt{\mathrm{I}}$ becomes negligible compared to one, and equation 2.1 reduces to the Debye-Hückel limiting law 


$$
\log Y \pm=-A_{f} \sqrt{I}
$$

In 1926, Bjerrum (6) and Adams (1) independently showed that the heat of dilution of strong electrolytes in dilute aqueous solutions could be predicted from an application of the Debye-Hückel (9) theory. Bjerrum showed that all salts dissolved in dilute aqueous solution should liberate heat on infinite dilution. He pointed out that the quantity of heat and the sign of the heat depended on the dielectric properties of the solvent and the valence type of the salt. However, it was not until 1931 that the correct limiting law for the heat of dilution was obtained. Scatchard (64) then showed that the limiting law for the heat of dilution also depended on the thermal expansibility of the solvent. He obtained the equation

$\Phi_{L}=-\sqrt{\frac{\pi N^{3} \varepsilon^{6}}{1000 k}}\left(1+\frac{d \ln D}{d \ln T}+\frac{1}{3} a T\right) \frac{\left(2 v_{i} z_{i}^{2}\right)^{3 / 2}}{D^{3 / 2} T^{1 / 2}} c^{1 / 2},(2 \cdot 3)$

which is the limiting law for the relative apparent molal heat content of a single strong electrolyte at low concentrations, equal to the heat evolved when one mole is diluted from concentration $\mathrm{C}$ to infinite dilution. Here $\alpha$ equals the coefficient of thermal expansibility of the solvent, and the remainder of the symbols have the same 
meaning as in equation 2.1. A more detailed treatment of equation 2.3 will be given in the following section.

The success of the Debye-Hückel theory (9) soon led to a critical evaluation of its statistical basis. The contributions of Fowler (13), Onsager (50), Kramers (35), K1rkwood (33), and Kirkwood and Poirier (34) have proved the validity of the limiting law al very low concentrations.

Since the Debye-Hückel theory (9.) predicted the behavior of electrolytes very well at low concentrations, it was natural that many workers would attempt to modify and extend it to higher concentrations. A very brief review of some of this work will be given here.

Bjerrum (5), in 1926, was the first to present a simple, yet very useful modification of the Debye-Hückel theory (9). By assuming that all oppositely charged ions within a certain distance of one another were associated, he was able to calculate the number of ion-pairs in the solution. He proposed that the critical distance should be $r=\left|z_{1} z_{2}\right| \varepsilon^{2} / 2 D k T$. By taking into account the number of associated spectes, and by assuming that all ions, complex or simple, obeyed the Debye-Hückel theory (9), he was able to account for the behavior of many electrolytes in solvents of low dielectric medium. Fuoss and Kraus (20) have extended this theory to include triple and quadruple ions. Fuoss (19) has recently modified the equation for the equilibrium 
constant of ion pairs. This theory has been used extensively to explain conductance data in solvents of different dielectric constants.

In developing equation 2.1 Debye and Hückel (9) retained only the first two terms in the expansion of the Poisson-Boltzmann equation, since if the higher terms were retained, the principle of the linear superposition of fields would be violated. Gronwall, La Mer, and Sandved (24) recognized this problem, but accepted terms through the sixth order and solved for the electrical potential by numerical integration. La Mer, Gronwall, and Greiff (36), by similar methods, obtained the solution for unsymmetrical electrolytes. These solutions do lead to more reasonable $a^{0}$ values than those given by the simple Debye-Hückel solution (9), but they are mathematically inconsistent as pointed out by Fowler and Guggenheim (14, Chapter 9). Also, recent work by other contributors indicates that any more exact solution of the Poisson-Boltzmann equation than that given by Debye and Hückel (9) is futile for obtaining a solution which will be valid at higher concentrations. Frank and Thompson (16) have concluded that the validity of the Poisson-Boltzmann equation is assured only for $I<10^{-3}$ for 1-l electrolytes. Guggenheim (26), using an electronic computer, has found that the numerlcal inconsistency of the Poisson-Boltzmann equation is appreciable for unsymmetrical 
electrolytes at non-zero concentrations. Fuoss and Onsager (21), by dividing the electrical potential into two parts, obtained a more exact solution to the Poisson-Boltzmann equation for symmetrical electrolytes. They divided the electrical potential at the Bjerrum distance, $r=$ $\left|z_{1} z_{2}\right| \varepsilon^{2} / D k T$ and called the electrical potential inside this radius ts, and outside this radius $\mathrm{L}$. By forcing the electrical potential and its first derivative to be continuous at the Bjerrum distance, they obtained a continuous solution for the Polsson-Boltzmann equation. Using this method, they obtained a solution which includes short-range forces between the ions. Their results show that this more exact solution of the Poisson-Boltzmann equation leads to deviations from equation 2.2 opposite to that found for real electrolytic solutions. They conclude that "the properties of electrolytes, specific for each electrolyte at non-zero concentrations, do not appear to be derivable by extension of the limiting solution of the Poisson-Boltzmann equation to higher concentrations, but rather must be sought in the projection of a theory of fused salts into and through the region of concentrated solutions".

A number of workers have attacked the problem from the viewpoint of ion-solvent interactions. Hückel (32), and later Scatchard $(65,66)$, treated the lon-solvent interactions in terms of an electrostatic salting-out effect 
arising from the fact that the electrolyte lowers the dielectric constant. Stokes and Robinson (72), and later Glueckauf (22), have assumed that the Debye-Hückel theory (9) gives the activity coefficient of the hydrated ion, and not the activity coefficient of the ion itself. Robinson and Stokes, using mole fraction statistics, and Glueckauf, using volume fraction statistics, obtained an equation for the activity coefficient of a single electrolyte which contains two arbitrary parameters: the mean distance of closest approach, $a^{\circ}$; and the hydration number of the lons, h. With this equation, they were able to fit the activity coefficients of many electrolytes at moderate concentrations, and some 1-1 electrolytes to five molal. Friedman (17) has recently observed that the basic assumption of this theory is that the entropy of mixing is ideal if it is expressed in mole fraction, or volume fraction statistics, provided that one does not count, as part of the solvent, those solvent molecules that form the solvation layer of the lons. He pointed out for this theory to give a correct equation for the activity coefficient it must be that the excess heat of dilution, $v m \emptyset_{L}$, conforms to the Debye-Hückel limiting law, but in fact the deviations of $v m \emptyset_{L}$ from the limiting law are as great as those of the activity coefficient. The only completely new approach to the theory of electrolytic solutions since the advent of the Debye-Hückel 
theory (9) has been that of Mayer (43). By adapting his cluster theory of Imperfect gases to solutions of electrolytes, he was able to derive the limiting Debye-Hückel square-root law for the osmotic and activity coefficlents of dilute electrolytes. In 1953, Poirier (53), from Mayer's complex results, developed expressions for the mean ionic molar activity coefficient, apparent and partial molal volumes, and relative apparent and partial molal heat contents. He also calculated the activity coefficients of $\mathrm{NaCl}$, $\mathrm{CaCl}_{2}, \mathrm{ZnSO}_{4}$ and $\mathrm{LaCl}_{3}$ using only $a^{\circ}$ as an adjustable parameter. The agreement between theory and experiment was good to concentrations slightly higher than the Debye-Hückel theory (9) can be used. Friedman (18, Chapter 1) states that although the derivation of the theory appears completely rigorous, it may still be limited to low concentrations. This is due to the fact that all of the results are expressed in series, and although mathematically convergent, may converge so slowly that the numerical results will be of little practical value at other than low concentrations. Friedman's book gives an excellent treatment of Mayer's theory, and his contributions to the theory.

Al though the above discussion does not cover all of the existing theories of electrolytic solutions, it does serve to emphasize two points:

1. That the Debye-Hückel theory gives the correct analysis 
for the behavior of an electrolytic solution as the concentration of the electrolyte approaches infinite. dilution.

2. That no adequate theory exists to explain the individual behavior of electrolytes at non-zero concentrations.

For a more complete theoretical treatment, the reader is referred to the excellent monograph of Harned and Owen (29) and to the treatise of Robinson and Stokes (59).

\section{B. Experimental}

\section{Microcalorimetry}

The verification of the Debye-Hückel limiting law for heats of dilution of strong electrolytes is a classic example of theory preceding experimental proof by many years. In 1926, when Bjerrum (6) and Adams (1) simultaneously showed that heats of dilution could be predicted. from an application of the Debye-Hückel theory (9), the only data available of sufficient accuracy to test the theory were those of Richards and Rowe $(55,56)$. Richards and Rowe had measured the heats of dilution of several 1-1 valence electrolytes to a final concentration of 0.139 molal. Since they were using a Beckmann thermometer to measure the temperature change, they could go no lower. At this concen- 
tration some of the heats of dilution were positive and some negative, and Bjerrum could find no support for his prediction that all electrolytes should liberate heat when diluted from some low concentration to infinite dilution. Clearly, a test of the predictions of the DebyeHückel theory required more sensitive calorimeters. In 1926, Nernst and Orthmann (48), using a double calorimeter, measured the heats of dilution of several salts to a final concentration of 0.1 molal, and in some cases to 0.03 molal. The temperature change was measured with a 20 junction ironconstantan thermopile, which had a sensitivity of ten microdegrees per millimeter galvanometer deflection. Even at these final concentrations they could find no agreement with theory. The next year, however, Nernst and Orthmann (49), by replacing their 20-junction thermoplle with a 100-junction thermopile, and Lange and Messner (38), using a very precise microcalorimeter, obtained qualitative agreement with theory. Lange and Messner designed the first accurate microcalorimeter for the measurement of heats of dilution at high dilution. It consists of an unsilvered two-liter Dewar flask, divided into two similar calorimeters. The partition consists of a 1000 to 1500-junction iron-constantan thermopile, the signal of which is fed to a sensitive galvanometer. Temperature changes of $2 \times 10^{-7{ }^{\circ}} \mathrm{C}$ can be detected, so that heats of dilution can be measured to 0.0001 molal. The 
Dewar is immersed in an outer bath, the temperature of which is controlled adiabatically to better than $0.001^{\circ} \mathrm{C}$. Details of the calorimeter, and data for a number of $1-1$, $1-2,2-1$, and $2-2$ valence electrolytes are given in a review by Lange and Robinson (39).

Another microcalorimeter, of somewhat different design, was developed by Gucker, Pickard, and Planck (25). This microcalorimeter consists of two 1dentical one-liter twin calorimeters, made of tantalum. These calorimeters are suspended inside a submarine jacket, which is immersed in a water bath. By means of adiabatic thermels and an automatic controlling device, the water bath can be controlled to $0.0003^{\circ} \mathrm{C}$. The calorimeters are separated by a distance of three centimeters, which reduces the coefficient of thermal conduction between the calorimeters to 0.0011 degrees per degree per minute. This is the maln advantage of this microcalorimeter over the Lange type. The Lange calorimeter had a coefficlent of thermal conduction between the calorimeters which was approximately twenty-five times larger. The temperature differences were measured with a 60-junction copper-constantan thermopile connected to a special low resistance potentiometer, with a Paschen astatic galvanometer as a null instrument. The calorimeter had a sensitivity of one microdegree per millimeter galvanometer deflection. The microcalorimeter used in this work has been 
patterned after that of Gucker, Plckard, and Planck (25). The above discussion has covered only those calorimeters used to measure heats of dilution at high dilution. A more complete description of microcalorimetry is given by Swiestoslawsk1 (75). Excellent treatments of microcalorimeters and other types of calorimeters are given by Skinner $(67)$, Hossini $(60)$, and Sturtevant (73).

2. Comparison of experiment with theory

It was noted that Nernst and Orthmann (49), and Lange and Messner (38), were able to obtain only qualitative agreement with the Debye-Hückel (9) theory. There were two reasons for this: their method of extrapolation did not lend itself to a correct determination of the limiting slope, and many different values for $\frac{\mathrm{d} l n D}{\mathrm{~d} n \mathrm{~T} T}$ existed in the literature.

Gulbransen and Robinson (27), in an attempt to obtain quantitative agreement with theory, made a careful series of measurements on the heats of dilution of sodium chloride at $10^{\circ}, 15^{\circ}, 20^{\circ}$, and $25^{\circ} \mathrm{C}$. They found an average deviation of 18 per cent from the theoretical limiting slope calculated from the Debye-Hückel theory (9) using Wyman's data (81) for the dielectric constant of water. In order to determine whether the data of Gulbransen and Robinson were in conflict with the Debye-Hückel theory, Young and Groenier (83). 
in 1936, introduced a new method of analyzing the data. By applying the chord-area method of Young and Vogel (85) to the sodium chloride data of Gulbransen and Robinson, they obtained limiting slopes which deviated only 2.3 per cent from the theoretical slopes. A period of ten years separated the prediction of Bjerrum (6) and Adams (1), and this quantitative verification of the limiting law for 1-1 valence electrolytes. Later, Young and Seligmann (84) applied the same method to all of the $1-1$ and $1-2$ electrolytes for which sufficient data were avallable. The average deviation from the theoretical slope, calculated using Wyman's data (81), for these eleven $1-1$ and five $1-2$ electrolytes was 0.5 per cent. They concluded that the Debye-hückel limiting law was completely verified for these salts.

The agreement between theory and experiment is not as satisfactory for higher-valence electrolytes. Young and Seligmann (84) applied the method of Young and Gronier (83) to 2-2 valence electrolytes, but found that the lowest experimental slopes were two to three times greater than the theoretical value. Robinson and Wallace (58), analyzing their data.for the sulfates of calcium, magnesium, cadmium, zinc, and copper by their short-chord method, found a maximum in the slope between 0.001 molal and 0.0001 molal. Although they could not determine the limiting slopes, they reported that this was strong indication that better agree- 
ment with theory existed than had previously been reported for these electrolytes. The agreement with theory for 1-3 and $1-4$ valence electrolytes is good. The agreement for 3-1 electrolytes will be covered in the discussion of the results of this work. For 2-3, 3-3, and 2-4 valence electrolytes the agreement between theory and experiment is far. from satisfactory. Lange (37) has given a review of the data for these high valence electrolytes.

The reason for the discrepancy between the observed limiting slope and the theoretical limiting slope for highervalence electrolytes is not yet clear. There are two factors which, if present, can contribute significantly to this discrepancy. These are ionic association and hydrolysis. If a metal ion forms complexes with the anion, but its salts are not hydrolyzed, the following behavior can be expected: on dilution there will be a heat effect due to the dissociation of the complex, which may be large compared to the actual heat of dilution; but as the concentration is lowered there is less association, and hence the contribution to the observed heat of dilution is reduced, and eventually becomes insignificant. If this vehavior uccurs, then the short-chord plots will show a maximum or minimum, depending on the sign of the heat of dissociation, at some concentration, depending on the stability constant of the complex ion. The smaller the dissociation constant, the lower the concentra- 
tion will be at which the maximum or minimum occurs. At sufficiently low concentrations, the short chords should approach the theoretical limiting slope. It is possible that this would occur at such low concentrations that present experimental methods could not detect it. The short-chord plots show a different behevior if the salts of the metal hydrolyze, but the metal ion does not form complexes with the anion. As the concentration of the electrolyte is lowered, hydrolysis will increase, so that the contribution to the heat of dilution from hydrolysis will increase as the concentration decreases. In this case, the short-chord plots will approach the axis asymptotically (positively or negatively, depending on the sign of the heat of hydrolysis).

The heats of dilution of the halldes of cadmium (58), and the sulfates of magnesium, calcium, and cadmium have been studied (57). Since these salts do not hydrolyze, and there is a large amount of evidence that they form complexes (7), they are excellent examples of the first type of behavior. Robinson and Wallace (58) found maxima in the shortchord plots of the halides of cadmium, and good evidence for maxima in the short-chord plots of magnestum, calcium and cadmium sulfates.

Sodium acetate and aluminum chloride are good examples of the second type of behavior. These salts are known to hydrolyze, but if they form complexes, the complexes 
are very weak, and as the concentration is lowered, hydrolysis will predominate. Lange (37) has shown the effect of hydrolysis on the heat of dilution of these salts. By diluting sodium acetate into very dilute sodium hydroxide $(\mathrm{pH}=10)$, and aluminum chloride into very dilute hydrochloric acid ( $\mathrm{pH}=3$ and 4$)$, he was able to. show that the asymptotic behavior of the short chords disappeared completely. The heats of dilution of thorium nitrate and uranyl nitrate have been measured by Lange (37), and the heat of dilution of uranyl acetate has been measured by Salman and White (63). These salts are known to both hydrolyze and associate $(2,7$, $30 \mathrm{a}, 30 \mathrm{~b})$. However, at sufficlently low concentrations the effect of hydrolysis predominates, and the short-chord plots approach the axis asymtotically.

The above discussion has server to lllustrate that although the Debye-Hückel theory (9) has been confirmed for low-valence electrolytes, the picture is not as sharply defined for higher-valence salts. It is not clear, at this time, whether the theory must be modifled for these salts, or whether the deviations occur due to ion association and hydrolysis. It is certain, however, that to verify the theory for higher-valence electrolytes, excellent experimental data at very high dilutions will be required. 


\section{THEORY}

\section{A. General Thermodynamics}

It is difficult and often impossible for a chemist to describe all the different microscopic entities present in an electrolytic solution. For this reason he needs a tool which will allow him to investigate such systems with only a minimum number of independent variables specified. Thermodynamics is such a tool. It often affords the chemist with an insight into the microscopic nature of the system by defining the macroscopic state of the system in terms of a minimum number of independent variables.

The properties of a homogeneous system at equilibrium define the macroscopic state of that system. Those propertles of the system which can be measured, either directly or indirectly by experiment, determine the state of the system. These properties give no record of the previous history of the system, and depend solely on the present state of the system. Therefore, the difference in any property between two states depends only on the states themselves, and is Independent of the path used to pass from one state to the other. Functions which define these properties are called thermodynamic state functions. The differentials of these functions possess the important property of being exact 
differentials. This is another way of stating that the difference in a property between two states is independent of the path used to pass from one state to the other. The properties of a homogeneous system can be divided into two classes; extensive and intensive properties. Intensive properties are those which are independent of the mass of the system, 1.e. their value 18 the same for the whole system as for any macroscopic portion of it. Pressure, temperature, density and composition are all examples of intensive variables. Extensive properties are those which are directly proportional to the masses or numbers of moles present in the system. Rigorously defined, an extensive property is a homogeneous function of first degree in the numbers of moles of material present in the system, while the intensive variables are held constant. For example, if $G$ is an extensive property, say

$$
G=G\left(T, P, n_{1}, n_{2} \ldots n_{k}\right)
$$

then multiplying each of the extensive independent variables by some constant $b$ produces the same effect as multiplying the entire function by $b$. That is,

$$
b G=G\left(T, P, b n_{1}, b n_{2}, \ldots b n_{k}\right) \text {. }
$$


If Euler's theorem of homogeneous functions is applied to $G$, then $G$ can be expressed as follows:

$$
G=\sum_{i=1}^{k} n_{i}\left(\frac{\partial G_{i}}{\partial n_{i}}\right)_{T, P, n_{j}} \text {. }
$$

The quantity

$$
\left(\frac{\partial G}{\partial n_{1}}\right)_{T, P, n_{j}}=\bar{G}_{1}
$$

and is called the partial molal G.

By differentiation equation 3.3 yields

$$
d G=\sum_{i=1}^{k} n_{i} d \bar{G}_{1}+\sum_{i=1}^{k} \bar{G}_{i} d n_{i}
$$

The total differential of equation 3.1 at constant temperature and pressure is

$$
\mathrm{dG}=\sum_{i=1}^{k} \bar{G}_{i} \mathrm{dn}
$$

Equating the right hand sides of equations 3.5 and 3.6 gives 


$$
\sum_{1=1}^{k} n_{1} d \bar{G}_{1}=0
$$

which is a-general form of the Gibbs-Duhem equation. Partial molal quantities are valuable in the study of homogeneous systems of more than one component, since $\bar{G}_{1}$ is the total change in $G$ when one mole of $i$ is added to an infinite amount of the system, all the other variables being held constant.

The first and second laws of thermodynamics state that the internal energy and entropy of a system are properties of the state of the system. These two laws can be expressed by the following exact differential equation

$$
d E=\operatorname{TdS}-\operatorname{PdV}+\sum_{1=1}^{k} \mu_{1} d n_{1}
$$

where E, S, T, P, V, and $n_{1}$ are the internal energy, entropy, absolute temperature, pressure, volume, and number of moles of each component 1 in a homogeneous system of $k$ components. The quantity $\mu_{1}$ is $\left(\partial E / \partial n_{1}\right)_{S, V, n_{j}}$ and is called the chenical potential of component 1. The chemical potential is an important measurable property of the system, but experimental measurements are never carrled out at constant entropy and volume while changing the number of moles of a 
component 1. For this reason, it is convenient to define three other state functions:

$$
\begin{aligned}
& \text { Enthalpy }=H=E+P V \\
& \text { Work content }=A=E-T S \\
& \text { Free energy }=F=H-T S .
\end{aligned}
$$

Differentiating equations $3.9,3.10$ and 3.11 , and substituting into equation 3.8 , leads to the following relations:

$$
\begin{aligned}
& \mathrm{dH}=\mathrm{TdS}+\mathrm{VdP}+\sum_{i=1}^{k} \mu_{i} \mathrm{dn} n_{i} \\
& \mathrm{dA}=-\mathrm{SdT}-\mathrm{PdV}+\sum_{i=1}^{k} \mu_{1} d n_{1} \\
& \mathrm{dF}=-\mathrm{SdT}+\mathrm{VdP}+\sum_{i=1}^{k} \mu_{1} d n_{i} .
\end{aligned}
$$

The above equations emphasize the importance of $\mu_{i}$, since 


$$
\begin{aligned}
\mu_{1} & =\left(\frac{\partial E}{\partial n_{1}}\right)_{S, V, n_{j}}=\left(\frac{\partial H}{\partial n_{1}}\right)_{S, P, n_{j}}=\left(\frac{\partial A}{\partial n_{1}}\right)_{T, V, n_{j}} \\
& =\left(\frac{\partial P}{\partial n_{1}}\right)_{T, P, n_{j}} .
\end{aligned}
$$

From the last equality it is seen that the chemical potential is simply the partial molal free energy.

\section{B. Partial Molal Heat Contents}

\section{Definitions and properties}

This research was concerned with the measurement of the amount of heat evolved or absorbed when a rare-earth chloride solution was diluted, or when crystals of rareearth chloride hexahydrates were dissolved in water. Since the measurements were conducted at constant pressure and composition, and since the changes of state were reversible, equation 3.12, with the use of the second law of thermodynamics, becomes

$$
\mathrm{dH}=\mathrm{TdS}=\delta \mathrm{q} .
$$

The enthalpy of a two-component system, say rareearth chloride and water, can be expressed by means of the 
partial molal heat contents of lts components. Thus,

$$
H^{1}\left(n_{1}, n_{2}\right)=n_{1} \bar{H}_{1}^{1}+n_{2} \bar{H}_{2}^{1}
$$

gives the total enthalpy of a solution containing $n_{1}$ moles of solvent and $n_{2}$ moles of solute, called state 1 , in terms of the partial molal heat contents, $\overline{\mathrm{H}}_{1}{ }^{1}$ and $\overline{\mathrm{H}}_{2} 1$, of the solvent and solute respectively.

Only differences in enthalpy can be measured. This requires a standard state which is chosen to be infinite dilution. The enthalpy $\mathrm{H}^{\circ}$ in the standard state can be written

$$
H^{\circ}\left(n_{1}, n_{2}\right)=n_{1} \bar{H}_{1}^{\circ}+n_{2} \bar{H}_{2}^{\circ}
$$

The enthalpy change, $\Delta H$, from infinite dilution to state $i$ 1s

$\Delta H=H^{1}\left(n_{1}, n_{2}\right)-H^{0}\left(n_{1}, n_{2}\right)=n_{1}\left(\bar{H}_{1}^{1}-H_{1}^{0}\right)+n_{2}\left(\bar{H}_{2}^{1}-\bar{H}_{2}^{0}\right)$ (3.19)

It is convenient to define a new quantity, $L$, called the relative heat content, such that

$$
\Delta H=L=H^{1}-H^{\circ} \text {. }
$$


Then 3.19 becomes

$$
L=n_{1} \bar{L}_{1}+n_{2} \bar{L}_{2}
$$

where $\bar{L}_{1}$ and $\bar{L}_{2}$ are the relative partial molal heat contents of solvent and solute respectively.

The partial molal heat contents of the solvent and solute cannot be determined from a single measurement. For this reason, it is convenient to introduce a quantity $\varnothing_{G}$ called the apparent molal $G$ and defined

$$
\emptyset_{G}=\frac{G-n_{1} \bar{G}_{1}^{\circ}}{n_{2}}
$$

where $\bar{G}_{1}{ }^{\circ}$ is the value of the extensive property $G$ for the solvent in the standard state. The relative apparent moial heat content is then written

$$
\emptyset_{L}=\frac{L\left(n_{1}, n_{2}\right)-n_{1} \bar{L}_{1}^{0}}{n_{2}}
$$

but

$$
\overline{\mathrm{L}}_{1}{ }^{\circ}=\overline{\mathrm{H}}_{1}{ }^{\circ}-\overline{\mathrm{H}}_{1}^{0}
$$

so that

$$
n_{2} \emptyset_{L}=L\left(n_{1}, n_{2}\right)=n_{1} \bar{L}_{1}+n_{2} \bar{L}_{2} .
$$


If $\emptyset_{L}$ is determined as a function of concentration, then $\bar{L}_{1}$ and $\bar{L}_{2}$ can be calculated from equations 3.4 and 3.25

$$
\bar{L}_{2}=n_{2}\left(\frac{\partial \phi_{L}}{\partial n_{2}}\right)_{T, P, n_{I}}+\varnothing_{L}
$$

and.

$$
\bar{L}_{1}=\frac{-n_{2}^{2}}{n_{1}}\left(\frac{\partial \phi_{L}}{\partial n_{2}}\right)_{T, P, n_{1}} \text {. }
$$

In this research $\emptyset_{L}$ was determined as a function of $\mathrm{m}^{1 / 2}$, where $\mathrm{m}$ is the molality of the solution. It follows that

$$
n_{2}=\left(m^{1 / 2}\right)^{2}
$$

and

$$
n_{1}=\frac{1000}{M_{1}}
$$

where $M_{i}$ is the molality of the solvent. Equations 3.26 and 3.27 then become

$$
\bar{I}_{2}=\frac{m^{1 / 2}}{2}\left(\frac{\partial \emptyset_{L}}{\partial_{m}{ }^{1 / 2}}\right)+\phi_{L},
$$

and 


$$
\bar{L}_{1}=\frac{-m^{3 / 2} M_{1}}{2000}\left(\frac{\partial \phi_{L}}{\partial m^{1 / 2}}\right) \text {. }
$$

\section{From heats of dilution}

The utility of the previous definitions and derivations can be seen by applying them to a dilution experiment. Suppose a solution of $n_{1}$ moles of solvent and $n_{2}$ moles of solute is diluted into $n_{1}$ * moles of pure solvent. The relative heat content of the initial state is given by

$$
I^{1}\left(n_{1}, n_{2}\right)=n_{1} \bar{L}_{1}^{1}+n_{2} \bar{I}_{2}^{1}+n_{1} * \bar{L}_{1}^{\circ}
$$

and that of the final state is

$$
L^{f}\left(n_{1}, n_{2}\right)=\left(n_{1}+n_{1}^{*}\right) \bar{L}_{1}^{f}+n_{2} \cdot \bar{\tau}_{\cdot 2}^{f} \text {. }
$$

The heat of dilution, $\Delta H_{d i l}$, is then given by the difference in relative heat contents between the initial and final states, and remembering that $\overline{\mathrm{L}}_{1}^{0}=0$,

$$
\Delta H_{d i 1}=\left(n_{1}+n_{1}^{*}\right) \bar{L}_{1}^{\prime}+n_{2} \bar{L}_{2}^{f}-n_{1} \bar{L}_{1}^{1}-n_{2} \bar{L}_{2}^{1}
$$

or using equation 3.25 


$$
\Delta H_{d i I}=n_{2}\left(\phi_{L}^{f}-\phi_{L}^{i}\right) \text {. }
$$

It is customary to report heats of dilution per mole of solute, so dividing equation 3.34 by $n_{2}$ gives

$$
\Delta H_{D}=\emptyset_{L}{ }^{\mathbf{P}}-\emptyset_{L}^{1}
$$

where $\Delta H_{D}$ is the heat of dilution per mole of solute.

3. From heats of solution

Suppose $n_{2}$ moles of pure solute is dissolved into $n_{1}$ moles of pure solvent. The relative heat content of the initial state is

$$
I^{i}\left(n_{1}, n_{2}\right)=n_{2} \bar{L}_{2}^{\cdot}+\left(n_{1} \bar{L}_{1}^{0}=0\right)
$$

where $\overline{\mathrm{I}}_{2} \cdot$ is the heat of solution per mole of pure solute with respect to infinite dilution. The relative heat content of the final state is

$$
L^{f}=n_{1} \bar{I}_{1}+n_{2} \bar{L}_{2}=n_{2} \emptyset_{L}^{f} \text {. }
$$

The change in relative heat content is 


\section{4}

$$
\Delta H_{S O 1}=L_{L}^{f} \cdot-L^{i}=n_{2}\left(\phi_{L}^{f}-\bar{L}_{2} \cdot\right)
$$

and again the heat of solution per mole is

$$
\Delta H_{S}=\emptyset_{L}^{f}-\bar{L}_{2} \cdot
$$

Since

$$
\lim _{m \rightarrow 0} \emptyset_{L}=0
$$

equation 3.39 becomes at infinite dilution

$$
\Delta H_{S}(\text { infinite dilution })=-\overline{\mathrm{E}}_{2} \cdot
$$

Thus if the heat of solution at infinite dilution is known, $\emptyset_{\mathrm{L}}$ ean be determined from equation 3.39. However, $\overline{\mathrm{L}}_{\dot{2}} \cdot$ can only be determined by an extrapolation procedure similar to that used to determine absolute values of $\emptyset_{\bar{L}}$. Usually $\bar{\Sigma}_{2}$. cannot be determined as accurately as absolute values of $\emptyset_{L}$, because often $\Delta H_{S}$ is large and it becomes difficult to make precise extrapolations to infinite dilution. Hence, it is difficult to obtain accurate values of $\phi_{\mathrm{L}}$ from this method. Conversely, however, if values of $\emptyset_{\mathrm{L}}$ have been determined from heats of dilution, $\overline{\mathrm{L}}_{2} \cdot$ can be determined using equation 3.39 . 
4. From theory

For a solution containing $n_{1}$ moles of solvent and $n_{2}$ moles of solute, Debye and Hïckel (9) have shown that the coulomb forces between lons contributes an amount

$$
\Delta F(e 1)=\frac{-n_{2} N \varepsilon^{2}}{3 D} \tau \times \nu_{1} z_{1}^{2}
$$

Here,

$$
x=\left(\pi_{i} z_{i}^{2}\right)^{1 / 2}\left(\frac{4 \pi N \varepsilon^{2}}{1000 D k T}\right)^{i / 2} c^{1 / 2}
$$

and

$$
\tau=\left[\frac{3}{(K a)^{3}}\right]\left[\frac{K^{2} a^{2}}{2}-k a+\ln (1+K a)\right], \text { (3.44) }
$$

while the remaining symbols have their usual meaning.

The enthalpy change accompanying a dilution from some concentration $C_{1}$ to some final concentration $C_{f}$ is given hy equation 3.34. If the initial concentration is chosen to be infinite dilution equation 3.34 becomes

$$
\Delta H_{d 11}=n_{2}{ }_{L}^{f} .
$$

Applying the familiar Gibbs-Helmholtz relation

$$
-\frac{\Delta H}{T^{2}}=\frac{\partial}{\partial T}\left(\frac{\Delta F}{T}\right)_{P}
$$


to equation 3.42 , the temperature dependent variable being $D, \tau, K$, and $a$, gives

$\emptyset_{L}=-A\left[\frac{I}{1+K a}\left(\frac{\partial \ln D}{\partial T}+\frac{1}{T}\right)+\frac{\sigma a}{3}\right] C^{1 / 2}+A\left[0-\frac{1}{1+\gamma a}\right]\left[\frac{\partial \ln a}{\partial T}\right]_{P} C^{1 / 2}$ (3.47)

per mole solute. The function 0 is given by

$$
0=\left[\frac{3}{\left(x_{a}\right)^{3}}\right]\left[1+x a-\frac{1}{1+x_{a}}-2 \ln (1+x a)\right]
$$

and

$$
A=R T^{2}\left[\frac{\pi N \varepsilon^{6}}{1000(D k T) 3}\right]^{1 / 2}\left[\Sigma v_{1} z_{1}^{2}\right]^{3 / 2}
$$

To obtain the limiting form of equation 3.47 we allow the concentration to approach zero. As the concentration approaches zero, $K$ approaches zero and $\sigma$ approaches one. This gives for the limiting law

$$
\emptyset_{L}=-A\left[\frac{\partial \ln D}{\partial T}+\frac{1}{T}+\frac{\alpha}{3}\right] C^{1 / 2}
$$

and is identical with equation 2.3. Equation 3.50 is often written

$$
\emptyset_{\mathrm{L}}=\mathrm{A}_{\mathrm{H}} \mathrm{C}^{1 / 2} \text {. }
$$


In the region where the limiting la: applies, C may he replaced by $d_{0} m$ where $d_{0}$ is the density of the sol ent ard $n$ is the milality of the solution, giving

$$
\emptyset_{\mathrm{L}}=\mathrm{A}_{\mathrm{H}^{\mathrm{d}}}{ }^{1 / a_{\mathrm{m}}} \mathrm{m}^{1 / z}
$$

To obtain the limiting forms of $\overline{\mathrm{L}}_{1}$ anc: $\overline{\mathrm{L}}_{2}$, equations 3.29 and 3.30 may be used giving

$$
\overrightarrow{\mathrm{L}}_{1}=\frac{-\mathrm{m}^{3 / 2} \mathrm{M}_{1}}{2000} \mathrm{~A}_{\mathrm{H}} \mathrm{d}_{\mathrm{O}}{ }^{1 / 2}
$$

and

$$
\bar{L}_{2}=3 / 2 A_{H} \alpha_{0}^{1 / 2} m^{1 / 2} \text {. }
$$

Valies of $3 / 2 A_{H}$ for aqueous $1-1$ electrolytes are tabulated by Harned and Owen (29). They use the values of idyman and Ingalls (82), measured in 1938, for $\left(\frac{\partial 2 n D}{\partial T}\right)_{p}$ for water. The value of Wyman and Ingalls for $\left(\frac{\partial \ln D}{\partial T}\right)_{p}$ for water at $25^{\circ} \mathrm{C}$ is 0.2 per cent below that of a recent measurement by Owen et al. (51), but about one por cent above that of Malmberg and Maryott. (1956) (41). The recent work (1962) of Vidulich and Kay (79) supports the data 
of Owen et al. Therefore, it was felt that the values of $3 / 2 A_{H}$ given by Harned and Owen represent the best values. The value which they give for $A_{H}$ is 6925 for aqueous 3-1 electrolytes at $25^{\circ} \mathrm{C}$. 
IV. EXPERIMENTAI

\section{A. Preparation of Materials}

For the neat of dilution measurements of $\mathrm{PrCl}_{3}$, $\mathrm{TbCl}_{3}$, and $\mathrm{YbCl}_{3}$ from zero molal to 0.25 molal, a stock solution of each rare-earth chloride between 0.7 and 1.0 molal was prepared and analyzed. For the heat of dilution measurements between 0.25 molal and saturation a concentrated stock solution between 3.3 molal and saturation was prepared and analyzed. The other concentrations were prepared by weight dilution of these stock solutions with conductivity water. The saturated solutions were prepared by allowing the concentrated stock solutions to evaporate in a desiccator until rare-earth chloride hydrate crystals former. About ' 30 milliliters of this saturated solution with some of the crystals were then placed in a $25^{\circ} \mathrm{C}$ constant temperature bath and continuously agitated. The saturated solution was left in the constant temperature bath with agitation for two weeks before the solution was used. The concentration of the saturated solutions was taken from the nata of Saeger (62). Spediling. Brown and Gray ${ }^{l}$.

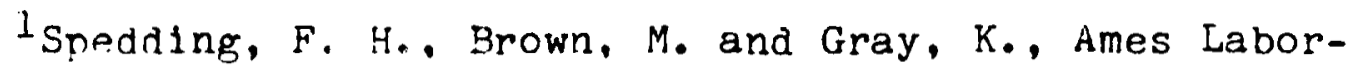
atory of the A.E.C.. Ames, Iowa. Apparent molal volumes of some aqueous rare-earth chloride solutions. Private communication. 1964. 
The conductivity water used in this research had a specific conductance of less than $1 \times 10^{-6}$ mho per centimeter. It was made by distilling tap distilled water from an alkaline potassium permanganate solution in a Barnsted Conductivity Still.

The rare-earth oxides used to prepare the stock solutions were obtained from the rare-earth separation group of the Ames Laboratory of the Atomic Energy Commission. The oxides were analyzed for certain metallic impurities by emission spectrography. The results of these analyses are given in Table 1.

A rare-earth chloride stock solution was prepared by dissolving a slight excess of the oxide in hot C. P. hydrochloric acid. The excess oxide was removed by filtration through a sintered glass filter. The filtered solution contained some colloidal oxide and other basic species from the hydrolysis of the rare-earth cation. Most of the colloidal oxide and other basic species were destroyed by adding C. P. hydrochloric acid until a pre-determined $\mathrm{pH}$ was attained, and then heating for several hours.

In order to destroy all the basic species and to obtain a stoichiometric solution, the solution was titrated to its equivalence point. The equivalence point was determined by titrating several aliquots of the solution with $0.05 \mathrm{~N} \mathrm{HCl}$. The titration was made with a Sargent 
Table 1. Spectrographic analysis of rare-earth oxides

\begin{tabular}{|c|c|c|c|c|c|}
\hline \multirow{2}{*}{$\frac{\mathrm{Oxide}}{\mathrm{La}_{2} \mathrm{O}_{3}}$} & \multicolumn{5}{|c|}{ Analysis (per cent) } \\
\hline & Rare-earth & $\begin{array}{r}\text { impurities: } \\
\mathrm{Ca}: \\
\mathrm{Fe}:\end{array}$ & $\begin{array}{l}\text { less } \\
\text { less } \\
\text { less }\end{array}$ & $\begin{array}{l}\text { than } \\
\text { than } \\
\text { than }\end{array}$ & $\begin{array}{l}.03^{2} \\
.01 \\
.007\end{array}$ \\
\hline $\operatorname{Pr}_{6}{ }^{0} 11$ & Rare-earth & $\begin{array}{r}\text { impurities: } \\
\mathrm{Ca}: \\
\mathrm{Fe}:\end{array}$ & $\begin{array}{l}\text { les:s } \\
\text { less } \\
.01\end{array}$ & $\begin{array}{l}\text { than } \\
\text { than }\end{array}$ & $\begin{array}{l}.15 \\
.03\end{array}$ \\
\hline $\mathrm{Tb}_{4} \mathrm{O}_{7}$ & Rare-earth & $\begin{array}{r}\text { impurities: } \\
\mathrm{Ca}: \\
\mathrm{Fe}:\end{array}$ & $\begin{array}{l}\text { less } \\
.025 \\
\text { less }\end{array}$ & $\begin{array}{l}\text { than } \\
\text { than }\end{array}$ & $\begin{array}{l}.05 \\
.003\end{array}$ \\
\hline $\mathrm{Ho}_{2} \mathrm{O}_{3}$ & Pare-earth & $\begin{array}{r}\text { impurities: } \\
\mathrm{Fe}: \\
\mathrm{Ca}:\end{array}$ & $\begin{array}{l}\text { less } \\
\text { less } \\
.05\end{array}$ & $\begin{array}{l}\text { than } \\
\text { than }\end{array}$ & .06 \\
\hline $\mathrm{Yb}_{2} \mathrm{O}_{3}$ & Rare-earth & $\begin{array}{r}\text { impurities: } \\
\mathrm{Fe}: \\
\mathrm{Ca}: \\
\mathrm{Th}:\end{array}$ & $\begin{array}{l}\text { less } \\
.01 \\
.01 \\
\text { not }\end{array}$ & $\begin{array}{l}\text { than } \\
\text { detect. }\end{array}$ & $\begin{array}{l}.03 \\
.0 d\end{array}$ \\
\hline
\end{tabular}

a The total amount of rare-earth impurities was probarily less than this amount, since in many cases the amount of rare-earth impurity present represented the lower limits of the quantitative analyses. In any case this amount of impurity would not affect the measured results.

Model D Recording Titrator, using a glass pH indicating electrode and a calomel reference electrode. The equivalence point was chosen at the inflection point of the titration curve. The bulk stock solution was then titrated to the equivalence point with approximately $6 \mathrm{~N} \backsim \mathrm{P}$. hydrochloric acid and heated for several hours. The pH would usually rise after the first heating period because the acid 
had reacted with some basic species in the solution. If this happened, the solution would be brought to its original volume by adding conductivity water and again titrated to the equivalence $\mathrm{pH}$. This procedure was repeated until the $\mathrm{pH}$ remained constant. The solution was then filtered through a sintered glass filter and stored in a tightly stoppered flask.

To determine the concentration of the stock solution, two analyses were made; one to determine the rare-earth ion content and the other to determine the chloride ion content. The rare-earth ion content of lanthanum, holmium and ytterbium chloride solutions was determined by precipitating the appropriate rare-earth ion as the oxalate and igniting it to the oxide.

The rare-earth chloride solutions were welghed into porcelain crucibles and the rare-earth ions were precipitated by adding a 15 per cent excess of twice recrystallized oxalic acid. The crucibles were then placed under infrared lamps until the rare-earth oxalate was completely dry. They were then ignited in a muffle furnace at $900^{\circ} \mathrm{C}$ for 12 to 18 hours. The rare-earth ion content was determined from the weight of the oxide. All analyses were made in triplicate, and a precision of better than 0.1 per cent was obtained. The rare-earth ion content of praseodymium and terbium chloride solutions was determined by a sulfate 
analysis. The appropriate rare-earth chloride solution was weighed into rorcelain crucibles and a 15 per cent excess of three molar sulfurlc acid wis added. The rare-earth sulfate crystals were allowed to grow slowly while being warmed under infrared lamps. After the crystals had grown, they were dried under infrared lamps and then heated with a Meeker burner to drive of the excess sulfuric acid. The crucibles were then ignited in a muffle furnace at $550^{\circ} \mathrm{C}$ for 12 hours. The rare-earth ion content was determined from the weight of the sulfate. The rare-earth sulfates were weighed very rapidy to avoid absorption of moisture. Triplicate analyses were made, and a precision of 0.1 per cent was obtained.

The chloride ion content of the rare-earth chloride solutions was determined potentiometrically using a Sargent Model D Recording Titrator. Fifty grams of approximately 0.1 normal silver nitrate solution were weighed into a beaker. The electrodes and titrating assembly were placed in the beaker and the rare-earth chloride solution was anded until an excess of chloride ion was recorded. The excess chloride ion was then back-titrated with the silver nitrate solution, using the recording titrator. The silver nitrate used as titrant was standardized before each analysis with a standard potassium chloride solution using this same procedure. The indirating electrode was a silver-silver 
chloride electrode, and the reference electrode was a sleevetype calomel electrode with the potassium chloride solution in the sleeve replaced by an ammonium nitrate solution. Triplicate analyses were again made on all solutions, and a precision of 0.05 per cent was obtained.

The average molality of the oxide and chloride analyses, or sulfate and chloride analyses, was used as the molality. of the solution. The mean of these two values was always within 0.1 per cent of either analysis.

The concentrated lanthanum chloride stock solution was prepared and analyzed by $\mathrm{Mr}$. K. Jones, the concentrated terbium and holmium chloride stock solutions by Mrs. K. Gray, and the concentrated ytterbium chloride stock solution was prepared by Mr. H. Weber, all of the Ames Laboratory of the A. E. C., Ames, Iowa.

The $\mathrm{HoCl}_{3} \cdot 6 \mathrm{H}_{2} \mathrm{O}$ and $\mathrm{TbCl} \cdot 6 \mathrm{H}_{2} \mathrm{O}$ crystals were prepared by allowing the crystals to grow very slowly in a saturated solution. The crystals were then placed in a desiccator over $\mathrm{BaCl}_{2}$ and the excess water was removed. They were then powdered and again placed in the desiccator for at least two weeks. To determine the composition of the crystals a solution was made from a welghed amount of the crystals and water. This solution was analyzed by the procedures given above. The analyses gave a $\mathrm{H}_{2} \mathrm{O} / \mathrm{TbCl}_{3}$. ratio of $6.04 \pm 0.02$ and $a \mathrm{H}_{2} \mathrm{O} / \mathrm{HoCl}_{3}$ ratio of $5.98 \pm 0.02$. 


\section{E. Apparatus}

The calorimeter used in this risearch was built by Naumann (4i), and subsequent modificat: ons and improvements were nade hy ibarts (10) and isejka (8). Furthey improvements were made in the course of this research to increase the eccuracy and precision of the calorimeter. The changes made improved the performance of the calorimeter in the

\section{following ways:}

1. The heat of stirring in the calorimeter containers was reduced.

2. The response time of the calorimeter was decreased.

3. The openlng of the sample holders produced no noticeable neat effect.

4. The adiabatlo control wis improved from $\pm 0.003^{\circ} \mathrm{C}$ to $\pm 0.0005^{\circ} \%$

5. Stray heat efferts were eliminated by constructing cumporints external to th: calorimeter containers from non-degenerative materials.

A schematic diagram of the calorimeter is given in Figure 1, and of the electricil circuits in Figures 2 and 3. Reference to the figures will be designated $(1-X)$ where $i$ refers to the figure and $x$ to the alphabetically labelled parts. 


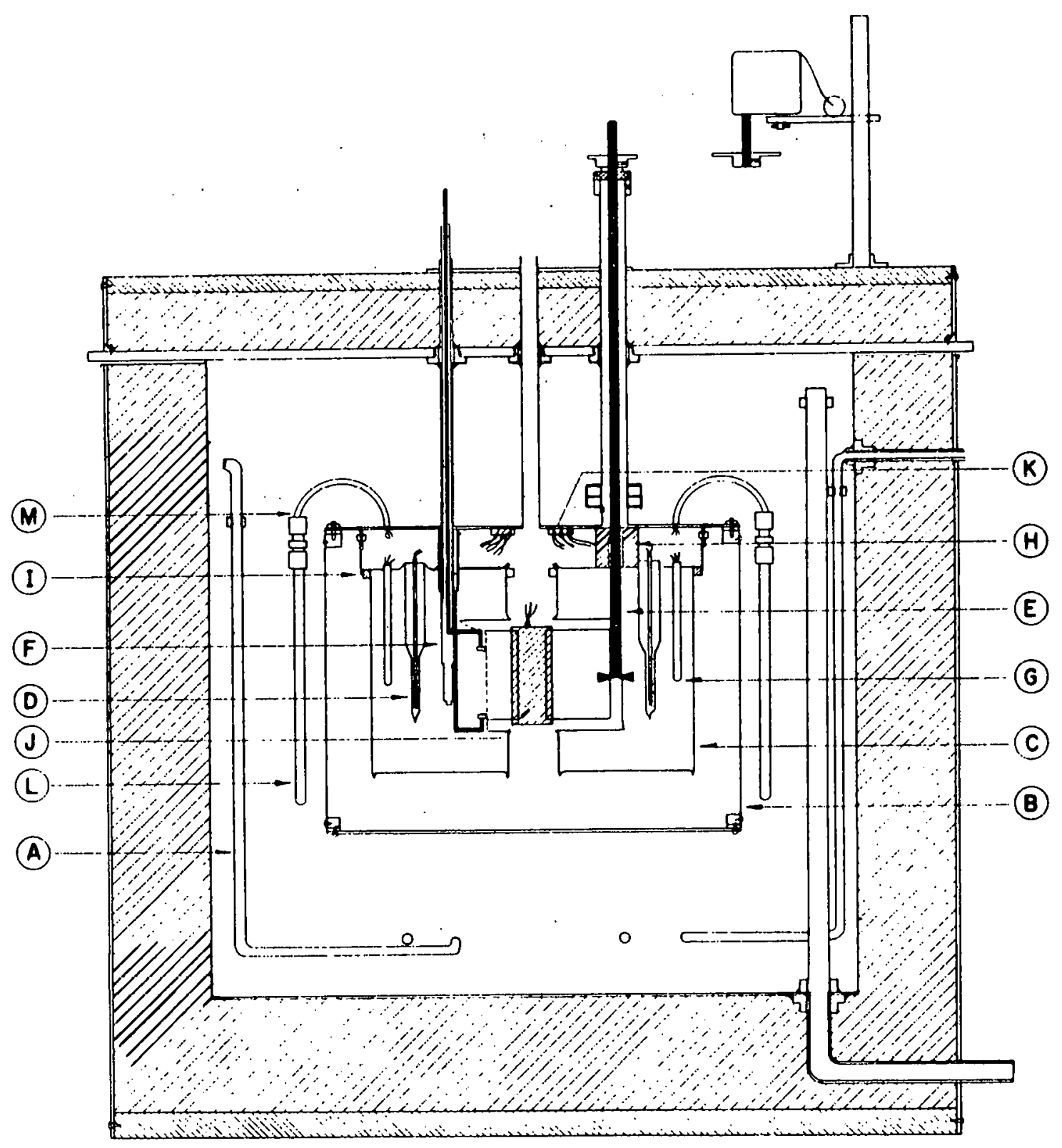

Figure 1. Adiabatic differential calorimeter 
1. Water bath

A 22-galion insulated water bath, mounted on a moveable angle iron platform, served as an adiabatic jacket for the calorimeter. Located inside the bath was a cooling coil $(1-A)$ of $1 / 4-$ inch copper tubing, an overflow pipe, and a 500-watt Calrod auxilliary heater. This heater was operated manually and was used only for bringing the bath to $25^{\circ} \mathrm{C}$.

The centrifuge pump which had previously been used to circulate the water was replaced by a centrifuge stirrer (Central Scientific Company Catalogue number 18850). This stirrer was mounted through the bath lid which was suspended 54 inches above the floor by an angle iron frame. There were two advantages to the centrifugal stirrer; its capacity was 100 gallons per minute compared to 35 gallons per minute for the centrifuge pump, and it heated the water less while stirring. Directly opposite the stirrer a small perforated copper baffle, 4 inches by 3 inches by $1 / 16$ inch, was soldered at a 30-degree angle to the side of the bath. The two 500-watt knife heaters previously used for bath control were also replaced by a 500-watt Calrod heater which was mounted to the bath Iid, and completely encircled the submarine. These two improvements greatly reduced the magnitude of the thermal gradients in the bath, which resulted in much better bath control. 
Detalis of the construction of the bath and bath $11 d$ are given by Naumann (46).

\section{Submarine jacket}

A submarine:jacket $(1-B), 6-5 / 8$ inches wide, $12-3 / 8$ inches long and $8-3 / 4$ inches deep surrounded the calorimeter containers. Its sides were of $16 \mathrm{~B}$ and $\mathrm{S}$ gauge monel, and its bottom of $1 / 4$-inch brass plate. It had straight parallel sides and semicircular ends. Brass flanges were soldered around the top and bottom inside wall, and the bottom brass plate was soldered to this brass flange on the inside and to the monel on the outside. All the seams of the submarine jacket, both inside and outside, were coated with a layer of Apiezon W wax to insure a leak-proof system. The top brass flange contained 20 brass studs which were used to fasten the jacket to 1ts 11d. Around the inside of the top flange was soldered a thin narrow copper strip which extended $1 / 16$ inch above the flange. A 1/8-inch 0-ring was placed between this copper strip and the brass studs, and served as the seal between the jacket and its 11d. The soft rubber gasket used previously was replaced by the 0 -ring because it was found that the rubber slowly decomposed with age, evolving significant quantities of heat.

The 1/4-1nch chromium plated copper 11d was fastened 5 inches below the bath lid by elght brass tubes, three of 
which are shown in Figure 1. These brass tubes were soldered to the 1/4-inch copper $11 d$, and also to brass collars which were threaded into the aluminum bath 11d. Two $1 / 2$-inch 0 . D. tubes served as access ports for the six conductor shielded cable for the calorimeter heaters, two 7/16-inch 0 . D. tubes for the four conductor shiclded cables of the main thermopile and the control thermels, two 5/16-inch 0 . D. tubes for the breaker rods, and two 1/2-inch 0 . D. tubes for the calorimeter stirrers and their bearing holders.

\section{Calorimeter containers}

The calorimeter containers (1-C) were made from 15-mil tantalum because of its chemical inertness and structural strength. Each one was 4 inches in diameter, 6 inches deep and had a well 2-1/4 inches deep with an opening of $3-3 / 8$ inches by 5/16 inch to accomodate the main thermopile (see Figure 1). A 1/4-inch, 45-degree flange was turned on the rim of the containers to match a similar flange on the container 11ds. Three 1/4-inch holes were drilled into each lid to accommodate the stirrer shaft $(1-E)$, only one shown, the sample holder support $(1-F)$, only one shown, and the control thermel $(1-G)$, both shown. A heater well (1-D) of 5/8-inch seamless tantalum tubing, flattened and sealed at the end, was also welded into each lid. Naumann (46) gives the construction details of the containers and lids. 
Each container lid was suspended from the bottom of the submarine lid by a 3-centimeter teflon spacer $(1-H)$, and a 3-centimeter 1/4-inch teflon tube. The teflon spacer was fastened to the bottom of the submarine lid by two small machine screws. The teflon tube was simply forced into its brass tube to make the connection at the submarine Iid, and Aplezon $W$ wax was used to fasten the tantalum container lid to the teflon tube. General Electrics Glyptal Enamel was painted on the joints between the teflon spacer and the container and submarine lids. In the past, lucite spacers had been used to suspend the container lids from the submarine lid, but it was found that lucite reacted with solvents in the Glyptal.

Each calorimeter container was held against its lid by an aluminum ring ( $1-I)$, which was suspended from the submarine lid by three loops of 10-pound nylon flshing line. The loops were hung from the bottom of ball-bearing swivels which were soldered to large brass nuts. The brass nuts were threaded onto studs projecting downward from the submarine lid.

4. Calorimeter stirrers

Each calorimeter stirrer (1-E) consisted of a 1/4inch stainless steel rod 14 inches long, then a $1 / 4-$ inch by 1-inch nylon spacer, and finally another 1/4-inch stain- 
less steel rod four inches long to the end of which were attached two stainless steel vanes, set at a 30 -degree angle to one another. Each vane was the shape of a semicircle with a 5/8-inch radius. Each stirrer was mounted so that the nylon spacer was immediately below the lower bearing. A bakelite pulley was mounted on the top of each stirrer rod, and the stirrers were powered at $325 \mathrm{r} . \mathrm{p} . \mathrm{m}$. by a $325 \mathrm{r} \cdot \mathrm{p} . \mathrm{m}$. synchronous motor. An 0-ring served as the pulley belt.

The stirrer shafts rotated in New Departure number 77R4A sealed bearings. Two bearings were used for each stirrer shaft, one mounted in a holder at the top of the brass tube, and the other mounted in a holder just above the submarine lid (see Figure 1). The lower bearing holder was made from a solld brass cylinder $1-1 / 2$ inches in diameter and one inch long. A $3 / 8$ inch hole was drilled through the cylinder to accommodate the stirrer shaft. Four small holes large enough for 6-32 machine screws were drilled through the cylinder at 90 degrees to one another near the edge of the cylinder. The cylinder was then cut into two sections, the top section was $3 / 4$ inch long, and the bottom section was $1 / 4$ inch long. A hole, just large enough to accommodate a bearing, was machined into the top section. A groove for a 7/8-inch diameter, 1/8-inch 0 -ring was cut in the bottom section. The four small holes in the bottom section were tapped with 6-32 machine threads, and then each section was 
soldered to its respective end of the brass tube. Four 6-32 machine screws were used to force the two sections together, the 0-ring making a water tight seal.

Placing the bearing outside the submarlne jacket, Instead of inside the jacket in the lucite spacer, and placing a spacer in the stirring rod resulted in an improved performance of the calorimeter. These two changes significantly reduced the amount of heat flowing from the bearing directly to the calorimeter container, resulting in a more stable thermal base line.

5. Sample holders

During the course of this research, three types of sample holders were used. For the heats of dilution of $\mathrm{YbCl}_{3}, \mathrm{PrCl}_{3}$, and $\mathrm{TbCl}_{3}$ from zero molal up to and including 0.25 molal, the sample holders used were those described by Spedding, Naumann and Eberts (70). Each sample holder consisted of two thin-walled stainless steel tubes, two centimeters in diameter and four centimeters long, held together by a stainless steel cross arm.

The ends of the tubes were threaded so that stainless steel caps could be screwed onto the ends. Dow Chemical Company Saran Wrap was placed in the caps to seal the end of the tubes. The method of breaking these seals was modified slightly in this research so that a zero heat of opening could 
be obtained. The breaker device consisted of a 5/16-inch stainless steel cone to which were attached four pieces of a stainless steel razor blade with Armstrong Adhesive A-6. The pieces of blade were attached to the cone at 90 degrees to one another in such a way that they came to a sharp point at the end of the cone. The stainless steel blades were kept lightly greased with Dow Corning Stopcock Grease. The cone was threaded onto a 0.035 -1nch stainless steel rod which passed through a snug-fitting teflon guide placed in the sample holder support at the container iid. The 0.035-inch rod was attached to a one-inch bakelite spacer which in turn was attached to a $1 / 8$-inch stainless steel rod which led to the outside. With this breaker arrangement, no detectable heat of opening of the sample holders was observed for eight openings. The snug-fitting teflon guide also decreased the evaporation from the calorimeter containers and resulted in a more stable thermal base line.

For more concentrated solutions, it was felt that the stainless steel sample holders could not be used. The first type of sample holder used for concentrated solutions was similar to the sample holder described by Vander Zee and Myers (76). It was made from 20 -millimeter glass tubing which was slightly pushed in on one end, and was four centlmeters long. Round glass plates, ground against the top rim of the cylinder, and against the inside bottom rim, 
served as the sample holder seals. The glass plates were coated with a layer of vaseline to insure a leak-proof seal. The glass cylinder was supported in the container by placing it in a snug-fitting teflon collar and attaching the collar to the sample holder support. A platinum wire attached to small glass hooks on the glass plates connected the two seals. A 10-pound nylon fishing. string was attached to the top seal and led to the outside via a brass tube. A light pull on the string, by means of a small hand wench to provide an even force, opened the sample holder. No detectable heat of opening. was observed for a number of blank openings. The heats of dilution. of $\mathrm{HoCl}_{3}$ from 0.25 molal to saturation, and $\mathrm{TbCl}_{3}$ from 0.49 molal to 1.69 molal were measured using this sample holder, and it was then discontinued. It was discontinued because $1 t$ was difficult to make good seals, and. because the thermal base. line was not. as steady when this sample holder was used. It was found, using blank runs, that the thermal base line was steadier when. these sample holders were taken out of the calorimeter containers.- This was not true of the stainless steel. sample holders, or of the glass bulbs to be described next.

A thin-walled glass bulb, blown from four-millimeter glass tubing, was the third. type of sample holder used. Glass. bulbs were used for the remalnder of the runs of $\mathrm{TbCl}_{3}$, and. for $\mathrm{LaCl}_{3}, \mathrm{PrCl}_{3}$, and $\mathrm{YbCl}_{3}$ from above $0.25 \mathrm{molal}$ to. 
saturation, and for the heats of solution of $\mathrm{TbCl}_{3} \cdot 6 \mathrm{H}_{2} \mathrm{O}$ and $\mathrm{HoCl}_{3} \cdot 6 \mathrm{H}_{2} \mathrm{O}$. For higher concentrations, where less than 4.0 milliliters of solution were required, bulbs having a capacity of 4.5 milliliters were used. For more dilute solutions, bulbs having a capacity of 10 milliliters were used.

Two bulbs of the smaller size, only one if the larger size was used, were mounted in the calorimeter container. The necks of the bulbs were mounted in a tefion support, and this teflon support was threaded directly onto the breaker rod. The bulbs were opened by slowly pushing the breaker rod down, thus forcing the glass bulb against a stainless steel anvil mounted in the bottom of the calorimeter container with Armstrong Adhesive A-6.

\section{Calorimeter heaters and circuit}

Two 50-ohm calorimeter heaters $\left(2-A, 2-A^{\circ}\right)$ were used for the measurement of the heats of dilution of $\mathrm{PrCl}_{3}, \mathrm{I}^{\prime} \mathrm{bCl} \mathrm{C}_{3}$, and $\mathrm{YbCl}_{3}$ solutions below $0.25 \mathrm{molal}$, while two 100 -ohm calorimeter heaters were used for all the other measurements. The primary reason for the replacement of the 50-ohm heaters by the $100-0 h m$ heaters was to reduce the ratio of lead resistance to heater resistance.

The heaters consisted of $38 \mathrm{~B}$ and $\mathrm{S}$ gauge manganin wire noninductively wound around a thin mica support. A 


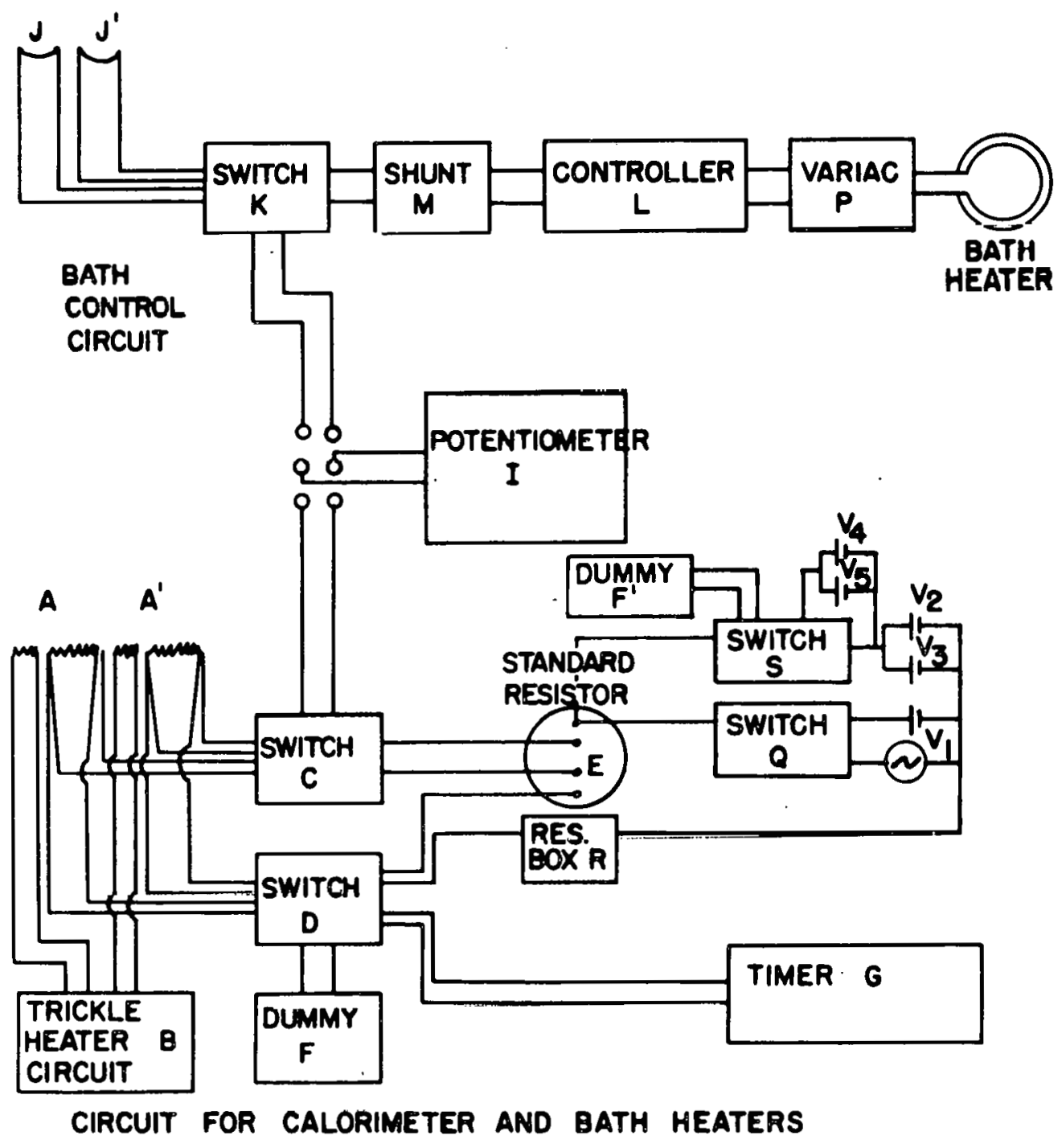

Figure 2. Schematic diagram of calorimeter circuits 
1.5-ohm trickle heater of $30 \mathrm{~B}$ and $\mathrm{S}$ gauge constantan was wound around each main heater. All heater leads, and the potentiometer leads for the 50 -ohm heaters, were $30 \mathrm{~B}$ and $\mathrm{S}$ gauge copper wire. The potentiometer leads for the 100-ohm heaters were $36 \mathrm{~B}$ and $S$ gauge copper wire, and were soldered to the midpoints of the heater leads. All heaters were annealed at $145^{\circ} \mathrm{C}$ for 48 hours and placed in the heater wells. The six leads from each heater were connected to a six conductor shielded cable at a junction block which was fastened to the underside of the submarine 11d. The conductor leads were soldered to various external rotary switches (see Figure 2), and to the trickle heater c1rcuit (see Figure 3). Switch (2-D) was a Leeds and Northrup 31-3$0-3,12-$ position silver contact rotary switch. Switch (2-C) was wired so that the potential drop could be measured across any of the following as desired elther heater; both heaters in series; the standard resistor $(2-E)$; or the dummy heater $(2-F)$. Switch $(2-D)$ was wired so that the ourrent cnuld be passed through either heater, through the heaters in series, or through the dummy heater. When switch $(2-D)$ was set to allow current to pass through elther heater, or through the heaters in series, it also engaged an electronic timer (2-G). Current from the following sources could be used;

a two-volt battery $\left(2-V_{1}\right)$; two six-volt batteries in parallel $\left(2-V_{2}, 2-V_{3}\right)$; or four six-volt batteries $\left(2-v_{2}\right.$, 
$2-\mathrm{V}_{3}, 2-\mathrm{V}_{4}, 2-\mathrm{V}_{5}$ ) which gave a 12-volt working potential (see Figure 2). The batteries were all Willard low-discharge storage batteries. Switch (2-S) was wired so that dummy $\left(2-F^{\prime}\right)$ could be used for either the six-volt or the twelvevolt system. The A. C. source was used only to bring the calorimeter containers to $25^{\circ} \mathrm{C}$ and was then disconnerted.

The resistance of the heaters was measured with a Leeds and Northrup Mueller Temperature Bridge, Model G-2. It was also measured by measuring the potential drop across the heater and across the standard resistor while the same current was flowing through each. The two values for the resistance always agreed to within a few parts per one hundred thousand, and the average was taken as the correct resistance. The resistance of the heaters was measured at various times throughout the course of the research and found to be constant within 0.005 per cent.

The potentiometer (2-I) was a Leeds and Northrup Type K-2. The standard resistor and standard cell had been calibrated by the National Bureau of Standards. The electronic timer was calibrated against the National Bureau of Standards Station WWV, and found to be accurate to better than .01 second. 


\section{Thermopile and circuit}

The main thermopile consisted of two 30-junction thermopiles constructed from 24 B and S gauge constantan wire and $32 \mathrm{~B}$ and $\mathrm{S}$ gauge copper wire. Each thermopile had a resistance of ten ohms and was 11 centimeters long. Special solder supplied by the Ilston-Becker Instrument Company was used to solder the junctions, and to solder the $30 \mathrm{~B}$ and $\mathrm{S}$ gauge copper lead wires to the thermopiles. The thermopiles were housed in a thin copper case and were insulated from the case by thin sheets of mica. The four lead wires from the thermopile were connected to a fourconductor shielded cable at a junction block fastened to the underside of the submarine 11d. These four conductors were soldered, with Liston-Becker solder, to a Leeds and Northrup 31-3-0-3, 12-position silver contact rotary selector switch (3-V). The potential of either thermopile, separately, in series, or opposed, could be fed into a Model 14 ListonBecker breaker type D. C. amplifier with either direct or reversed polarities using switch $3-V$. This switch was helpful in determining whether the amplifier and thermopile were working correctly. The switch was mounted in a steel casing which was placed in a large Dewar and surrounded with blown mica.

The output of the amplifier was fed into a filter circuit which attenuated the signal slightly and greatly 


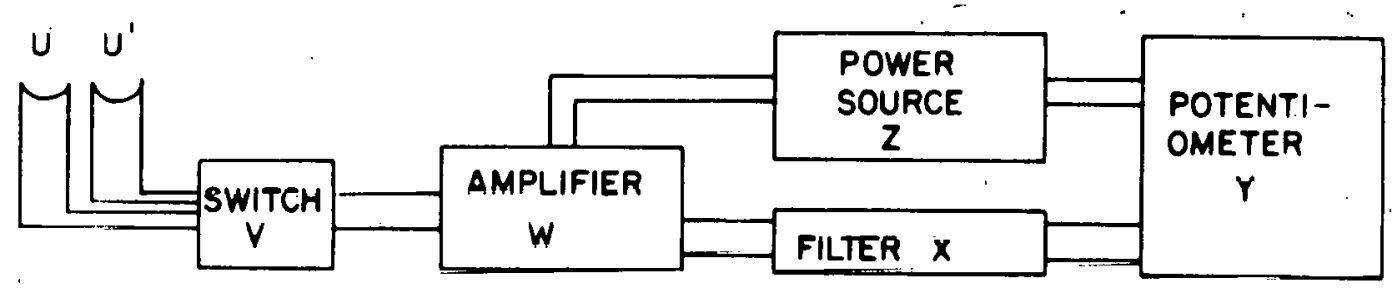

CIRCUIT FOR MAIN THERMEL

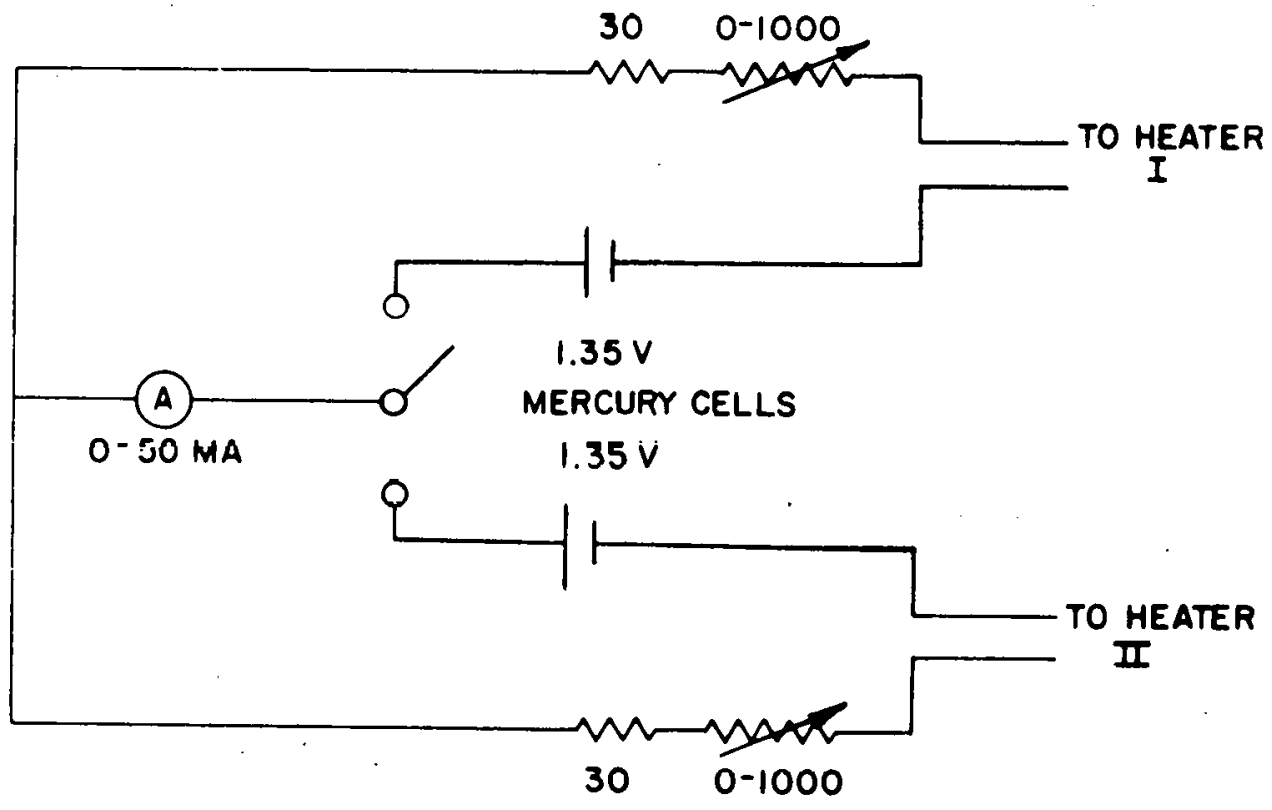

CURRENT SOURCE FOR TRICKLE HEATERS

Figure 3. Schematic diagrams of the thermopile and trickle heater circuits 
reduced the noise level. The signal was then recorded by a Brown recording potentiometer $(3-Y), 0$ to 60 millivolts full scale. A Stabiline Voltage regulator (3-Z), type IE-5101, provided a constant power supply for the amplifier and recorder.

\section{Adiabatic control}

The two five-junction control thermels were constructed from $36 \mathrm{~B}$ and $\mathrm{S}$ gauge copper wire and 30 . B and $\mathrm{S}$ gauge constantan wire. Each thermel was bound in a bundle, and one end was placed in a thin-walled glass tube (1-G) inside the calorimeter container. On the other end of the thermel, the junctions were spaced two centimeters apart and placed in a sealed copper tube $(1-L)$ in the outside bath. The empty space in both tubes was filled with melted parafin.

The lead wires of $36 \mathrm{~B}$ and $\mathrm{S}$ gauge copper wire were connected to a four-conductor shielded cable at the same junction strip used for the main thermopile. The other end of the shielded cable was connected to a Leeds and Northrup 31-3-0-3, 12-position selector switch $(2-K)$. With this switch the control thermels could be connected separately or in series to the automatic bath controller $(2-L)$. This switch was wired so that the potential developed by either thermel, or both in series, could be measured with the 
potentiometer $(2-I)$.

From this switch the signal was fed to an Aryton shunt $(2-M)$ and then to the automatic bath controller (2-L) which was built by the Ames Laboratory Electronics Shop. It amplified the signal from the thermels approximately $10^{6}$ times, and fed this output to a Thyratron relay switch which operated the bath heater. A Variac (2-P) was connected in series with the heater and controlled the heating rate. Cooling for the bath was provided by a constant flow of tap water through the cooling coil (1-A). Usually a heating period of 10 to 15 seconds, followed by an equal length cooling period, gave the best control. Using this system, the bath could be controlled to $0.0005^{\circ} \mathrm{C}$. The temperature of the bath was measured by a platinum resistance thermometer calibrated by the National Bureau of Standards in conjunction with a Leeds and Northrup Mueller Temperature Bridge., Model G-2.

\section{Experimental Procedure}

The experimental procedure given below was used for all dilution and solution measurements except for the specific steps involving the sample holders. The following procedure was employed when the stainless steel sample holders were used: 
1. Two stainless steel sample holders (i.e., four stainless steel tubes) were cleaned and allowed to stand in conductivity water for several hours. Each sample holder tube was then filled with 10 milliliters of the same rareearth chloride solution using a 10 milliliter pipette. The sample holders were weighed, allowed to stand for at least 10 hours, and then reweighed to check for leaks. If the weight had not changed by more than one milligram they were assumed to be leak proof.

Each calorimeter container was filled with enough conductivity water to give a total solution weight, water. plus sample welght, of 900 grams. The conductivity water was weighed to the nearest two milligrams. The containers were placed on a small laboratory jack and raised to their lids. A strip of Scotch electrical tape was wound around this junotion to form a vapor tight seal, and several drops of molten paraffin were applied to secure the tape.

2. The adiabatic temperature bath was raised to the bath lid with a hydraulic jack. The stirrers were started and the bath temperature was adjusted to the temperature of the calorimeter containers, which was usually less than $25^{\circ} \mathrm{C}$. The adiabatic control was started and the heating and cooling rates were adjusted to obtain the best control $\left( \pm 0.0005^{\circ} \mathrm{C}\right)$. If the temperature was below $25^{\circ} \mathrm{C}$ the temperature of the calorimeter system was raised by heating the 
containers simultaneously with the A. C. source. The maximum A. C. current used was 70 milliamperes. If the temperature of the calorimeter containers was above $25^{\circ} \mathrm{C}$, the bath was lowered, which caused the temperature of the adiabatic jacket to drop rapidly. The containers were cooled to $24.95^{\circ} \mathrm{C}$, the bath was again raised, and the adiabatic control adjusted.

3. After the temperature of the calorimeter system had attained $24.95^{\circ} \mathrm{C}$, the temperature of the two calorimeter containers was adjusted so that their temperature differed by less than $1 \times 10^{-40} \mathrm{C}$. This was accomplished by heating in the cooler container until the recorder pen was on the chart when the amplifier was set at gain 18. The calorimeter system was adjusted to $24.98^{\circ} \mathrm{C}$ by electrical heating with the heaters connected in series.

4. The recorder chart drive was switched on after about one hour, at which time the system had usually reached equilibrium. If the temperature difference between the two containers was not constant, the recorder pen would drift in one direction. This could be remedied by passing a current, usually 0 to 15 milliamperes, through the trickle heater of the container which was apparently cooling. Constant pen drifts could be attributed to a number of causes. The heat produced by stirring, or by the stirrer bearings may have been slightly different. In fact, it was 
found necessary to change the stirrer bearings at regular intervals to obtain a good thermal base line. A slight difference in the amount of evaporation from each container would also cause the recorder pen to drift.

5. The sensitivity of the calorimeter was determined when a non-drifting thermal base line was obtained. This line (fore slope) was recorded for 15 to 20 minutes and 0.05 to 0.08 calorie of electrical heat was added to one container. A period of four to five minutes was required to attain equilibrium. The after slope was again recorded for 15 to 20 minutes. For all heat of dilution measurements, the fore and after slopes were also recorded for a minimum of 15 minutes. The pen displacement was always obtalned by measuring the average distance between the fore and after slopes. The distance between the lines was measured perpendicular to the fore slope at the point when heat was first introduced, and perpendicular to the after slope at the point when equilibrium was first attained. 'Ihe average of the two measurements was taken as the correct displacement. Two calibrations were made for a given run, and the average of these two calibrations was taken as the correct censitivity for that rian. When the amplifier was set at gain 18 , the sensitivity was usually between 4.3 and $4.5 \times 10^{-4}$ calories per millimeter displacement.

The amount of electrical heat generated was calculated 
from the equation

$$
q_{e}=\frac{1}{4.1840} \frac{R_{H}}{R_{S}^{2}} E s^{2} t
$$

where $q_{e}$ is the heat liberated in defined calories (one calorle $=4.1840$ absolute joules); $\mathrm{B}_{\mathrm{H}}$ is the heater resistance; $R_{S}$ is the resistance of the standard resistor (10.0087 ohms); $E_{S}$ is the potential drop across the standard resistor; and $t$ is the time in seconds that current flows through the heater.

6. Dilutions were made by pushing the breaker cone through the top Saran disk, down through the stainless steel tube and out through the bottom Saran disk. A precalculated amount of electrical heat was immediately supplied to the opposite contalner to balance the heat of dilution. With experience, the amount of heat required to balance the dilution could usually be estimated to 0.03 of a calorie or two per cent of the total heat, whichever was larger. In this way, the after slope was brought to very nearly the same chart position as the fore slope, and consequently the heat contribution from the pen displacement to the total heat of dilution was small, usually 0.03 of a calorie or less. Sometimes a second electrical heating was required to achieve this. The heat of dilution was calculated from the 
equation

$$
q_{d i l}=q_{e} \pm q_{d}
$$

where $q_{d i l}$ is the heat of dilution of the sample; $q_{e}$ is the amount of electrical heat; and $q_{d}$ is the amount of heat calculated from the pen displacement.

For solutions below 0.1 molal, and for calibrations, a current of $15 \mathrm{milliamperes}$ was used, while for solutions between 0.1 molal and 0.25 molal a current of 25 milliamperes was used. The two-volt Wlllard, low discharge battery, was used as the current source. Current was always passed through the dummy heater at least. 30 minutes before any measurements were made. Using this procedure, the 15 milliamperes current was always stable to $10 \mathrm{microamperes}$ and the 25 milliamperes current was stable to 20 microamperes. Glass sample tubes were used for the heats of dilution of $\mathrm{HoCl}_{3}$ above 0.25 molal and some of the heats of dilution of $\mathrm{TbCl}_{3}$ above 0.25 molal. The heat of dilution of a sample above 0.25 molal increased very rapidly as the concentration increased. In order to limit the heat of dilution to less than 30 calories the number of grams of the sample was decreased. The heat evolved was between 10 and 20 calories, and only for the most concentrated solutions did it rise above this value. Since comparatively large 
amounts of heat were measured the amplifier was set at gain 17. which gave a sensitivity between 7.3 and $7.6 \times 10^{-4}$ calories per millimeter. Gain 17 was used for all solutions above 0.4 molal.

It was necessary during the dilution to keep the temperature of the two contalners very close together in order to minimize the heat leak. Thts was accomplished by a rapid heating rate, 57 milliamperes, and the method of opening the sample holders. Before the sample holder was opened, the electrical heater in the opposite container was switched on. The top seal of the sample holder was then slowly lifted and the dilution process was begun. By closely following the temperature difference on the recorder, the dilution rate could be controlled so that the rate of heat evolved was nearly the same as the electrical heating rate. The amount of electrical heat required to balance the dilution heat was estimated, and could usually be estimated to one or two per cent. Adiabatic control of the outside bath was maintained by increasing the current in the 500 watt Calrod heater.

The electrical current for the calorimeter heaters was supplied by the two six-volt Willard batteries connected in parallel. The 57-milliampere current was stable to 20 microamperes during the heating pertod.

Two glass sample holders were used in each container 
for the dilutions of $\mathrm{TbCl}_{3}$, while only one was used in each container for the dilutions of $\mathrm{HoCl}_{3}$.

The majority of the work on concentrated solutions was done using glass sample bulbs. When glass sample bulbs were used, calorimeter container I was used as the working calorimeter while container II was used as the tare calorimeter. A bulb containing solution in container I and one containing water in container II were always opened simultaneously to eliminate the heat of opening.

Two bulbs having the same wall thickness were carefully selected so that their heat of breakage would be the same. The selection was made by observing the "give" of each bulb when lightly pressed on a hard surface. These bulbs were very thin and required only a small amount of pressure to break them.

After the bulbs had been selected, one of them was filled with enough solution to give six to eight calories of heat upon dilution. It was necessary to limit the amount of heat evolved, because these bulbs could not be opened slowly. The tare bulb was filled with one milliliter of water, and the bulbs were sealed with a drop of melted Aplezon $W$ wax. Usually two of these selected sets were filled if the smaller bulbs were used.

Electrical heating was begun in the tare calorimeter before the sample was opened. A current of 57 milliamperes 
was used. When one-half of the estimated electrical heat had been added, the bulbs were broken and the dilution occurred. The bulbs were broken at the midpoint of the electrical heating to insure a negligible heat leak between the two containers. Since the heating period was short, 90 to 120 seconds, this was a good assumption. The accuracy of this method was checked by measuring the heat of fonization of water at $25^{\circ} \mathrm{C}$. These results will be given in the next section.

The same procedure as given above was used for the heat of solution measurements of $\mathrm{HoCl}_{3} \cdot 6 \mathrm{H}_{2} \mathrm{O}$ and $\mathrm{TbCl}_{3} \cdot 6 \mathrm{H}_{2} \mathrm{O}$. However, when these salts were run, the tare sample bulb was flushed with dry air and then sealed. Therefore, a heat of evaporation correction did not have to be applied to the heat of solution measurements.

It w111 be shown in the next section that the two calorimeter containers had the same heat capacity. However, when the glass bulbs were used, solution was present in container I while container II held only water. Hence, the total heat capacity of each was different. In order to determine the heat of dilution, the heat capacity ratio must be known. This quantity was determined by adding 30 calories of electrical heat in series to the two containers and measuring the pen deflection. A current of 63 milliamperes was used which was supplied by the 12-volt working source 
shown in Figure 2. The heat capactty ratio never differed more than 0.3 per cent from 1.0000 and was usually within 0.15 per cent of 1.0000 . It was found experimentally that the heat capactiy ratio before the samples were opened was, within experimental error ( 0.02 per cent), the same as that after the samples were opered, so only one ratlo was measured for each run.

The heat of dilution, $q_{d 1 l}$, evolved in container I was calculated from the equation

$$
q_{d I I}=\frac{c_{p I}}{c_{p I I}} q_{e}
$$

where $q_{e}$ is the electrical heat added to container II and $\mathrm{c}_{\mathrm{pI}} / \mathrm{C}_{\mathrm{pII}}$ is the heat capacity ratio.

When the calorimeter was running well, the fore and after slopes would be parallel, or very nearly so, and free from drifts. However, there were days when this 1deul behavior did not occur. Sometimes the fore slope was not the same as the after slope. This was generaliy attributed to a difference in evaporation; one of the vapor tight seals had broken, or a difference in evaporation around the breaker rods had occurred.

Another type of behavior which sometimes occurred was a shift in the pen displacement. The recorder would be 
tracing a straight line, a shift would occur, and the recorder would then trace another straight line which may or may not have been parallel to the previous line. These shifts were generally attributed to a break of a water-tight seal on the submarine jacket, uneven heating of the stirrer bearings, or changes in evaporation. If this behavior occurred before a run was started, the calorimeter was disassembled and the malfunction repaired. If it occurred during a run, all data after this behavior occurred was discarded.

\section{Calorimeter Tests}

\section{Electrical}

A third electrical heater was constructed and placen in container II. The resistance of this heater was within 0.1 per cent of the resistance of the regular 100 ohm calorimeter heaters. This heater was constructed by wrapping number 38 gauge manganin wire around a thin threaded copper tube, soldering one 32 gauge copper lead wire to each end of the heater, and then annealing it at $145^{\circ} \mathrm{C}$ for 48 hours. The heater was coated with two coats of glyptal and baked, and then completely covered with a thin layer of Aplezon $W$ wax. The resistance of this heater was measured with a Leeds and Northrup Mueller Temperature Bridge Model G-2, and one- 
half of the lead resistance was added to the heater resistance. The heater was suspended in container II by its lead wires only, in such a way that the copper tube would be completely submerged when the container was filled with water. Since this third heater was in excellent thermal contact with the solution; and since the only heat leak path avallable to the outside surroundings were the two nyclad insulated copper lead wires, it was assumed that all of the electrical heat generated in this heater would remain in the calorimeter container.

This heater was wired in the same manner as the regular calorimeter heaters, except that it did not have potential lead wires. However, a separate six-volt working potential, a separate standard resistor, and a separate potentlometer and standard cell were used to provide and determine the current flowing through this heater. This third heater was wired so that it was switched on when the regular heater in container I was switched on. A current of 57 milliamperes was used for each heater in order to obtain the same heating rate in each calorimeter container. Calorimeter container I was filled with 900 grams of water and calorimeter container II with 899 grams of water (one gram less in II due to the extra heater). After equilibrium was established, electrical heat was added to each calorimeter container simultaneously by passing a 
current of 61 milliamperes, supplied by the 12-volt working potential, through the regular heaters connected in series. The relative heat capacity of the two calorimeter containers, $\mathrm{C}_{I} / \mathrm{C}_{I I}$, could be determined from the quantity of heat added to each container, the recorder pen displacement, and the sensitivity of the calorimeter. After equilibrium was established, electrical heat was added to each container again, but by using the regular heater in container I which simultaneously turned on the third heater in container II. In this manner a completely independent value of $c_{I} / C_{I I}$ could be obtained.

The results of this calorimeter test are shown in Table 2. These values were all taken consecutively as listed in one run. The table is self-explanatory except that $\delta d$, the recorder pen displacement, is positive if heat must be added to container I to bring the recorder pen to the same chart position that it occupied before the heating began. These results show that

$$
\mathrm{C}_{I} / \mathrm{C}_{I I}=1.0000
$$

within experimental error, and that the two independent determinations of $C_{I} / C_{I I}$ agree within experimental error, which indicates that no measurable heat.is lost from the electrical heaters. 
Table 2. The ratio $C_{I} / C_{I I}$ for the calorimeter containers

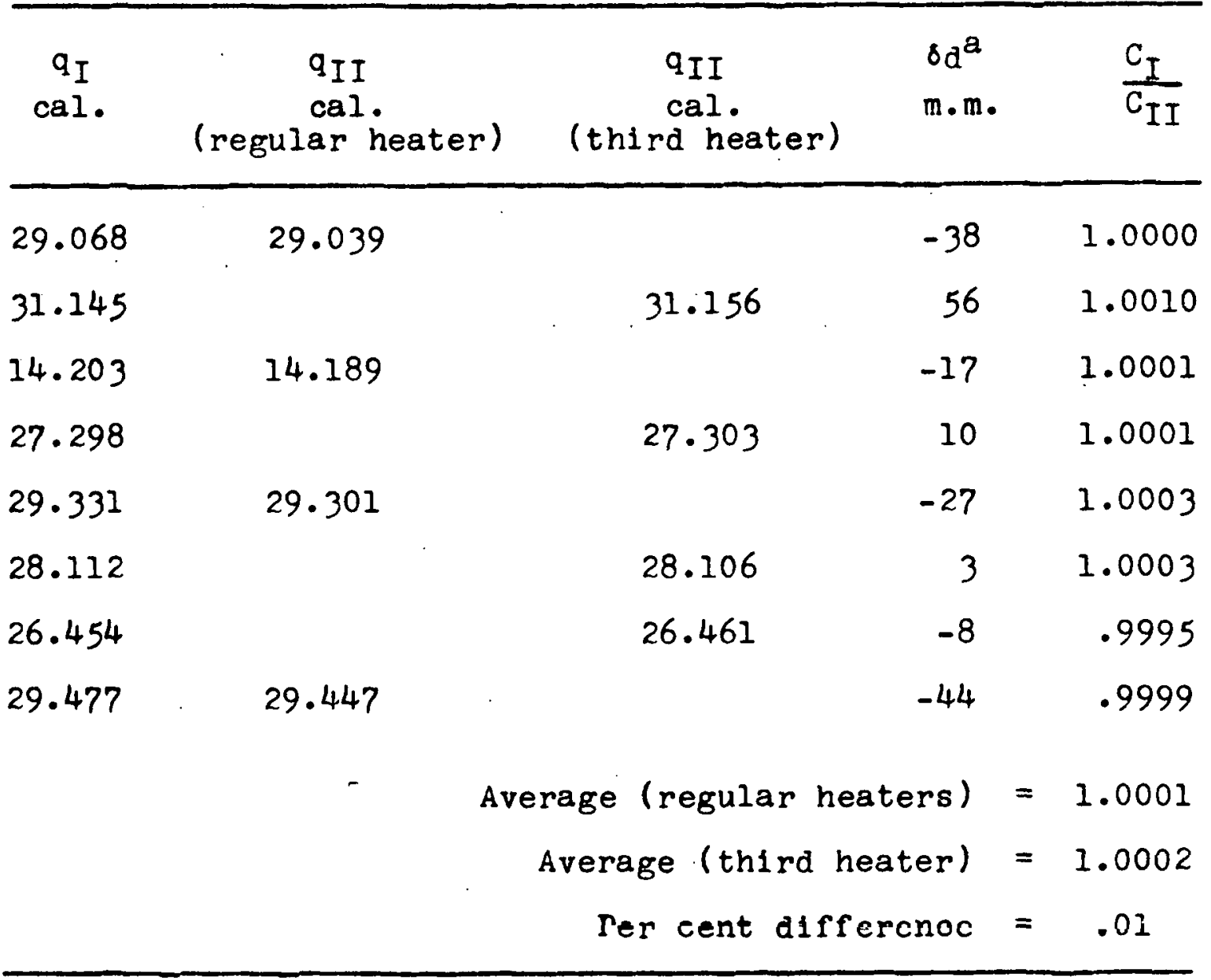
millimeter.

${ }^{a}$ Calorimeter sensitivity $=7.6$ calories per

\section{Chemical}

The accuracy of the calorlmeter was also checked by measuring the heat of neutralization of hydrochloric acid with sodium hydroxide. This reaction was chosen because two very recent calorimetric measurements of the heat of ionization of water at $25^{\circ} \mathrm{C}$ have been made $(28,77)$, and the 
matertals can be easily and accurately prepared.

The hydrochloric acid was prepared by weight dilution from constant bolling hydrochloric acid and conductivity water. The constant boiling hydrochloric acid was prepared by the method of Foulk and Hollingsworth (12). The concentration of the diluted hydrochloric acid was 0.29971 molal.

A dilute carbonate-free sodium hydroxide solution was prepared by the standard methods and stored in a large polyethylene-lined container. This solution was standardized by weight titration with constant bolling hydrochloric acid, and the equivalence point was taken as a pH of 6.6. The concentration of the sodium hydroxide was 0.003027 molal. All welghts were always corrected to vacuum.

The heat of neutralization measurements were made using the same procedure which was used for heat of dilution measurements with the glass sample bulbs. Approximately 1.5 grams of hydrochloric acid solution was broken into the $\mathrm{NaOH}$ solution. This gave a final concentration of approximately 0.0025 molal $\mathrm{NaOH}$ after the first sample was opened, and 0.0020 molal $\mathrm{NaOH}$ after the second sample was opened. Therefore, the change in $\mathrm{pH}$ between the initial and final solutions was negligible. Hence, there would be only a small shift in the equilibrium between the carbonate and bicarbonate ions, if any carbonate was present in the 
sodium hydroxide solution. When this procedure is used, the heats of neutralization should be free of any effects caused by the neutralization of sodium carbonate. Care was taken to prevent the absorption of carbon dioxide by the sodium hydroxide solution, but the solution was exposed to air while the calorimeter was being assembled.

The heat of ionization of water at infinite dilution, $\Delta H_{N}^{O}$, is related to the experimental heat of neutralization, $\Delta \mathrm{H}_{\mathrm{N}}$, by the relation

$$
\Delta \mathrm{H}_{\mathrm{N}}^{\mathrm{O}}:=\Delta \mathrm{H}_{\mathrm{N}}+\Delta \mathrm{H}_{\mathrm{C}}
$$

where $\Delta H_{C}$ is the heat effect resulting from the dilution of the products and reactants given by

$$
\Delta H_{c}=\sum-n_{f} \emptyset_{L} \text { (products) }+\sum n_{i} \emptyset_{L}(\text { reactants }) \cdot(4.6)
$$

Here, $n_{f}$ and $n_{j}$ refer to the number of moles of spectes in the final and initial states which would form one mole of water upon neutralization of hydrochloric acid with sodium hydroxide. $\emptyset_{L}$ is the relative apparent molal enthalpy which is the negative of the heat of dilution to infinite dilution. The method of calculating $\Delta \mathrm{H}_{\mathrm{c}}$ was that suggested by Vander Zee and Swanson (77). Essentially this method involves an "unmixing" of the electrolytes at constant ionic 
strength into two solutions of a single electrolyte assuming that no enthalpy change is associated with this process at 0.003027 molal total concentration. The results of Young, Wu, and Krawetz (86) for the enthalpy of mixing of various halides at constant ionic strength $(\mu=1.0$ molal) would appear to justify this assumption. The $\emptyset_{L}$ values obtained at the total ionic strength for each electrolyte were then substituted into equation 4.6 to calculate $\Delta \mathrm{H}_{\mathrm{c}} \cdot$ For all practical. purposes the final ionic strength (sodium hydroxide solution plus sodium chloride solution) was the same as the initial ionic strength (sodium hydroxide solution only). Therefore, the $\emptyset_{L}$ value for sodium hydroxide remained constant throughout the neutralization process.

The sodium hydroxide and hydrochloric acid $\emptyset_{L}$ data used were that of Sturtevent $(74 a, 74 b, 74 c, 74 d)$, as recalculated by Vander Zee and Swanson (77). The $\varnothing_{L}$ data of sodium chloride solutions were taken from the tabulated values of Rossini (61). The $\emptyset_{L}$ values at the concentrations studied were obtained from large scale plots of $\emptyset_{L}$ versus concentration. The $\emptyset_{\mathrm{L}}$ values used to correct the observed heats of neutralization to infinite dilution are given in Table 3.

It is obvious from Table 3 and equation 4.6 that the heat of dilution of the sodium hydroxide solution exactly cancels that of the sodium chloride solution, and 
Table 3. $\emptyset_{\mathrm{L}}$ values at $25^{\circ} \mathrm{C}$

\begin{tabular}{llll}
\hline Electrolyte & $\mathrm{HCl}$ & $\mathrm{NaOH}$ & $\mathrm{NaCl}$ \\
\hline molality & 0.29971 & 0.003027 & 0.003027 \\
$\emptyset_{\mathrm{L}}$ & 223 & 23 & 23 \\
\hline
\end{tabular}

only the heat of dilution of the hydrochloric acld remains. The heat of dilution correction, $\Delta H_{c}$, is then 223 calories per mole which was applied to all the observed heats of neutralization to obtain the heat of ionization of water at $25^{\circ} \mathrm{C}$.

The results of the heat of neutralization measurements are given in Table 4. All measurements were made at $25.00 \pm .02^{\circ} \mathrm{C}$, and all weights were corrected to vacuum. The average of the six determinations is $-13,326 \mathrm{cal} . / \mathrm{mole}$ with a standard deviation of $\pm 18 \mathrm{cal} . / \mathrm{mole}$. The accuracy of this measurement should be \pm 0.2 per cent which is \pm 26 cal./mole. This value agrees very well with that obtained by Vander Zee and Swanson (77) and Hale et al. (28). Vander Zee and Swanson (77) reported $-13,336 \pm 18 \mathrm{cal} . / \mathrm{mole}$. The good agreement indicates that the experimental procedure used was correct. 
Table 4. Heats of neutralization for hydrochloric acid $(\mathrm{aq})+$. sodium hydroxide $(\mathrm{aq}$.$) = final solution$

\begin{tabular}{|c|c|c|c|c|c|c|}
\hline Run & $\begin{array}{l}\text { Sodium } \\
\text { hydroxide } \\
\text { aqueous } \\
\text { grams }\end{array}$ & $\begin{array}{l}\text { Hydro- } \\
\text { chloric } \\
\text { acid } \\
\text { grams }\end{array}$ & $\begin{array}{l}\text { Moles } \\
\text { water } \\
\text { formed } \\
x 104\end{array}$ & $\begin{array}{c}-q \\
\text { cal. }\end{array}$ & $\begin{array}{l}-\Delta H_{N} \\
\text { cal./ } \\
\text { mole }\end{array}$ & $\begin{array}{l}-\Delta H R \\
\text { cal / } \\
\text { mole }\end{array}$ \\
\hline 1 & 899.645 & 1.3997 & 4.150 & 5.621 & 13,546 & 13,326 \\
\hline 2 & 897.912 & $\begin{array}{l}1.4807 \mathrm{c} \\
1.5178\end{array}$ & $\begin{array}{l}4.340 \\
4.500\end{array}$ & $\begin{array}{l}5.956 \\
6.106\end{array}$ & $\begin{array}{l}13,568 \\
13,569\end{array}$ & $\begin{array}{l}13,345 \\
13,346\end{array}$ \\
\hline 3 & 897.734 & 1.6364 & 4.852 & 6.575 & 13,552 & 13,329 \\
\hline 4 & 897.772 & $\begin{array}{l}1.5842 \\
1.5650^{c}\end{array}$ & $\begin{array}{l}4.697 \\
4.640\end{array}$ & $\begin{array}{l}6.353 \\
6.279\end{array}$ & $\begin{array}{l}13,527 \\
13,533\end{array}$ & $\begin{array}{l}13,304 \\
13,310\end{array}$ \\
\hline & & & & \multicolumn{2}{|c|}{ Average } & $27 \pm 13$ \\
\hline & & & Standard & \multicolumn{2}{|c|}{ Deviation } & \pm 18 \\
\hline
\end{tabular}

$$
\begin{aligned}
& \text { a Initial molality }=0.003027 . \\
& \text { bInitial molality }=0.29971 \text {. } \\
& \text { CThese saulules were diluted into the sodium }
\end{aligned}
$$
hydroxide + sodium chloride solution resulting from the opening of the first sample.

\section{E. Treatment of Data}

The heat of dilution data are divided into two concentration ranges; the first range is from zero molal to 0.25 molal, and the second from 0.25 molal to saturation. The data in the first range are used to obtain an extrapolation function for $\emptyset_{L}$ to infinite dilution. In order 
to obtain an accurate extrapolation function, it was necessary to make many heat of dilution measurements in the dilute range since only small amounts of heat were evolved when the sample was diluted. Usually only two heat of dilution measurements were made on a particular concentration in the second region, since these values were used only to determine the $\emptyset_{L}$ value for that sample concentration.

In the range from zero molal to 0.25 molal two samples of the same concentration were placed in each calorimeter container. When the first sample of molality $m_{1}$, containing $n_{2}$ moles of salt, was diluted into pure water to give a final molality of $m_{2}$, an amount of heat $q_{1}$ was evolved. When the second sample of molality $m_{1}$, containing $n_{2}^{*}$ moles of salt, was diluted into the solution of molality $m_{2}$, a final solution of molality $m_{3}$ was obtained. The heat associated with this dilution was $q_{2}$. The heat evolved for each dilution process can be related to the relative apparent molal heat contents by equations 3.33 and 3.34 giving

$$
q_{1}=n_{2}\left[\emptyset_{L}\left(m_{2}\right)-\emptyset_{L}\left(m_{1}\right)\right]
$$

and

$$
q_{2}=n\left[\emptyset_{L}\left(m_{3}\right)-\emptyset_{L}\left(m_{1}\right)\right]+n_{2}\left[\emptyset_{L}\left(m_{3}\right)-\emptyset_{L}\left(m_{2}\right)\right] \cdot \text { (4.8) }
$$


The heat $q$ is positive if heat is absorbed and negative if heat is evolved.

The heats of dilution per mole between two concentrations are given by equation 3.35 and are

$$
\begin{aligned}
& \Delta H_{1,2}=\emptyset_{L}\left(m_{2}\right)-\emptyset_{L}\left(m_{1}\right) \\
& \Delta H_{1,3}=\emptyset_{L}\left(m_{3}\right)-\emptyset_{L}\left(m_{1}\right) \\
& \Delta H_{3,2}=\emptyset_{L}\left(m_{2}\right)-\emptyset_{L}\left(m_{3}\right)
\end{aligned}
$$

where $\Delta \mathrm{H}_{1, f}$ is the heat absorbed when one mole of a solution of concentration $m_{i}$ is diluted to concentration $m_{f}$. The quantities $\Delta \mathrm{H}_{1,2}$ and $\Delta \mathrm{H}_{1,3}$ are referred to as "long chord dilutions" and the quantity $\Delta \mathrm{H}_{3,2}$ as a "short chord dilution".

The quantities $\Delta \mathrm{H}_{1,2}$ and $\Delta \mathrm{H}_{1,3}$ can be obtained from the heat of dilution measurements by substituting equations 4.9 and 4.10 into equations 4.7 and 4.8 to obtain

$$
\Delta H_{1,2}=\frac{q_{1}}{n_{2}}
$$

and 


$$
\Delta H_{1,3}=\frac{\left(q_{1}+q_{2}\right)}{n_{2}+n_{2}^{*}} .
$$

The short chord dilution. $\Delta \mathrm{H}_{3,2}$, is obtained by subtracting equation 4.10 from 4.9

$$
\Delta \mathrm{H}_{3,2}=\Delta \mathrm{H}_{1,2}-\Delta \mathrm{H}_{1,3} .
$$

By combining equations $4.12,4.13$, and $4.14, \Delta \mathrm{H}_{3,2}$ can also be calculated directly from the measured heats of dilution. However, enough figures were always retained in the calculations so that there was no loss of accuracy by calculating $\Delta \mathrm{H}_{3,2}$ from equation 4.14 .

It is obvious from equation 4.7 that only differences in $\emptyset_{\mathrm{L}}$ can be measured. However, since $\emptyset_{\mathrm{L}}$ approaches zero as the molality approaches zero, it is possible to obtain absolute values of $\emptyset_{L}$ by extrapolating the $\emptyset_{L}$ versus $\mathrm{m}^{1 / 2}$ curve to infinite dilution. The extrapolation method used in this research was developed by Young and co-workers $(83,85)$, and later modified by Wallace and Robinson (57). The average slope of $\emptyset_{\mathrm{L}}$ versus $\mathrm{m}^{1 / 2}$ between concentrations $m_{3}^{1 / 2}$ and $m_{2}{ }^{1 / 2}$ is given by the equation

$$
\bar{p}_{i}=\frac{-\Delta H_{3,2}}{m_{3}^{1 / 2}-m_{2}^{1 / 2}} .
$$


It is assumed that the true slope, $S$, can be represented by a power series in $\mathrm{m}^{1 / 2}$

$$
\mathrm{S}=\mathrm{S}^{0}+\mathrm{Bm}^{1 / 2}+\mathrm{Cm}
$$

and that a maximum of three terms is needed to represent the slope in the dilute concentration reginn. Tf the true slope $\mathrm{s}$, at the concentration $\mathrm{x}_{1}=1 / 2\left[\mathrm{~m}_{3}^{1 / 2}+\mathrm{m}_{2}{ }^{1 / 2}\right]$, is represented as $P_{i}$ then equation 4.16 can be written

$$
P_{i}=S^{0}+B x_{i}+\mathrm{Cx}_{1}^{2}
$$

The average slope $\bar{P}_{i}$ may be written

$$
\bar{p}_{i}=\frac{\int_{m_{2}^{1 / 2}}^{m_{3}^{1 / 2}} \mathrm{sdm}^{1 / 2}}{m_{3}^{1 / 2}-m_{2}^{1 / 2}}
$$

or

$$
\bar{P}_{i}=S^{0}+B x_{i}+\frac{C}{3}\left[4 x_{i}^{2}-m_{3}^{1 / 2} m_{2}^{1 / 2}\right] \text {. }
$$

The difference between the true slope and the 
average slope is

$$
P_{i}-\bar{P}_{i}=\frac{-C 8 i^{2}}{12}
$$

where

$$
8 i=\left[m_{3}^{1 / 2}-m_{2}^{1 / 2}\right] \text {. }
$$

Combining equations 4.20 and 4.17 leads to

$$
\bar{P}_{i}=S^{0}+B x_{i}+C\left(x_{i}^{2}+\frac{\delta 1^{2}}{12}\right) .
$$

If only a two parameter equation is needed to represent $S$, then $\bar{P}_{1}=P_{i}$ and

$$
\overline{\mathrm{P}}_{i}=S^{0}+\mathrm{Bx}_{1}
$$

The constants for equations 4.22 and 4.23 were determined by the method of least squares, using the inverse square of the probable error in the $\overline{\mathrm{P}}_{1}$ 's as the weighting factors. The constant $S^{\circ}$ was also determined from the Debye-Hückel (9) theory, which for aqueous solutions of 3-1 electrolytes has the value 6925. Equation 4.23 then becomes 


$$
\bar{P}_{i}=6925+\mathrm{Bx}_{i}
$$

where $B$ is again determined by the method of least squares using the same weighting factors. The constants were substituted into the appropriate equation, either 4.24, 4.23, or 4.17, which was integrated to yield $\emptyset_{L}$ in the dilute concentration range. The integration of equation 4.23 yields

$$
\emptyset_{L}=6925 \mathrm{~m}^{1 / 2}+\frac{B}{2} \mathrm{~m} .
$$

The absolute value of the relative apparent molal heat content, $\emptyset_{L}$, for the sample molality could then be determined from equations 4.9 and 4.10 . The average of these two values was used as the correct value for the $\varnothing_{L}$ of the sample molality. An unweighted least squares equation of the form

$$
\emptyset_{L}=\mathrm{am}^{1 / 2}+\mathrm{bm}+\mathrm{cm}^{3 / 2}+\mathrm{dm}^{2}
$$

was determined from the calculated values of $\emptyset_{I}\left(m_{1}\right), \emptyset_{L}\left(m_{2}\right)$, and $\phi_{L}\left(m_{3}\right)$. An IBM 7074 was used to make these calculations. The probable error $E$ of the arithmetic mean is. defined 


$$
E=\frac{0.67450}{n^{1 / 2}}
$$

where: $\sigma$ is: the standard deviation defined by

$$
\sigma=\left[\sum_{i=1}^{n} \frac{\left(\bar{x}-x_{i}\right)^{2}}{n-1}\right]^{1 / 2}
$$

where $\bar{x}$ is the average value, $x_{i}$ is the value of determination $i$, and $n$ is the number of determinations. $\bar{p}_{i}$ 's were not calculated from the data above 0.25 molal because the short chords. were: longer than desired and $\Delta \mathrm{H}_{3,2}$ could not be determined as precisely as in the lower concentration range. The quantity $\Delta \mathrm{H}_{1,3}$ was not calculated from equation 4.13 , but directly from equation 4.8 which may be. writton:

$$
\mathrm{q}_{2}=\mathrm{n}_{2}^{* \Delta \mathrm{H}_{1,3}}-\mathrm{n}_{2} \Delta \mathrm{H}_{3,2}
$$

where $\Delta \mathrm{H}_{3,2}$ was calculated from equation 4.25 . If the concentrations $m_{3}^{1 / 2}$ or $m_{2}^{1 / 2}$ were in the region where equation 4.25 applied, it. was used to calculate $\emptyset_{L}\left(m_{2}\right)$ and $\emptyset_{L}\left(m_{3}\right)$. If $m_{3} 1 / 2$ or $m_{2}^{1 / 2}$ was above the region where equation 4.25 applied, then equation 4.26 was used to calculate $\emptyset_{\mathrm{L}}\left(\mathrm{m}_{2}\right)$ and $\emptyset_{L}\left(m_{3}\right)$. 
Another change in the treatment of the data above 0.25 molal arose from the fact that a correction had to be applied to the observed heats of dilution. The vapor pressure above the solution in the sample bulb is $P^{O}-\Delta P$, where $\mathrm{pO}^{\mathrm{O}}$ is the vapor pressure of pure water at $25^{\circ} \mathrm{C}$. The vapor. pressure above the solution was calculated from activity coefficient data obtained in this laboratory. The water vapor pressure above the final solution is $\mathrm{P}^{\circ}$, since the final solution is very dilute. When the sarple bulb was opened, some water vapor was absorbed by the air which was above the sample solution. If the air space above the sample solution is $\mathrm{V}$ milliliters, and the vapor pressure difference between the sample solution and the final solution is $\Delta \mathrm{P}$ milimeters, the heat absorbed is

$$
8 \mathrm{q}=\frac{273}{298} \times \frac{\Delta \mathrm{P}}{760} \times \frac{\mathrm{V}}{22,400} \times 10,514
$$

or

$$
8 q=0.000566 \mathrm{~V} \Delta \mathrm{P} \text { calories }
$$

where the value 10,514 is the latent heat of vaporization of water and is taken from the tabulated data of Rossini (61). Equation 4.12 then becomes

$$
q_{1}+\delta q=\frac{\Delta H_{1,2}}{n_{2}}
$$


and a similar correction is applied to equation 4.29. The average correction for the heat of dilution of the saturated solution was 0.026 calories, which decreased rapidly to 0.002 calories for a one-molal solution.

An unweighted least squares treatment was applied to the values of $\emptyset_{L}\left(m_{1}\right)$ between 0.25 molal and saturation. An empirical equation of the form

$$
\emptyset_{L}=a+b m^{1 / 2}+c m+a m^{3 / 2}+e m^{2}
$$

was used to fit the experimental data.

The relative partial molal heat contents $\overline{\mathrm{L}}_{1}$ and $\overline{\mathrm{L}}_{2}$ were calculated from zero molal to saturation by applying equations 3.29 and 3.30 to equations 4.33 and 4.26. Values for the relative partial molal excess entropies $\bar{S}_{1}-\bar{S}_{1} 0$ and $\overline{\mathrm{s}}_{2}-\overline{\mathrm{s}}_{2} \mathrm{O}$ were calculatod from the equations

$$
\mathrm{T}\left(\bar{S}_{1}-\bar{S}_{1} 0\right)=\bar{L}_{1}-\operatorname{PT} \operatorname{PTn} \frac{a_{1}}{N_{1}}
$$

and

$$
T\left(\bar{S}_{2}-\bar{S}_{2}^{0}\right)=\bar{L}_{2}-\text { VI:TInY } \pm
$$

where $a_{1}$ and $Y \pm$ are the activities of the water and of the 
rare-earth chloride, respectively; $\mathrm{N}_{1}$ is the mole fraction of water and $\nu$ is the number of ions formed by the dissociation of one molecule of the electrolyte. Values for the activity coefficients above 0.1 molal were taken from the data of Saeger (62), Petheram (52), and Spedding and Weber ${ }^{1}$. The activity coefficients below 0.1 molal were taken from the data of Spedding et al. $(68,71)$ and Nelson (47).

\section{F. Heats of Dilution}

The heats of dilution of aqueous solutions of $\mathrm{LaCl}_{3}$ and $\mathrm{HoCl}_{3}$ were determined from 0.4 molal to saturation, and of $\mathrm{PrCl}_{3}, \mathrm{TbCl}_{3}$, and $\mathrm{YbCl}_{3}$ from zero molal to saturation. The experimental data and the thermodynamic quantities derived from this data are given in Tables 5 through 20 and in Figures 4 through 9. The only graphs of $\emptyset_{\mathrm{L}}$ versus $\mathrm{m}^{1 / 2}$ which will be presented are those for $\mathrm{PrCl}_{3}$ and for the dilute region of $\mathrm{YbCl}_{3}$, because while the differences between these solutions are real, on a small scale graph they would not be very evident.

Tables 7, 11, and 17 contain the experimental data for dilute aqueous solutions of $\mathrm{PrCl}_{3}, \mathrm{TbCl}_{3}$, and $\mathrm{YbCl}_{3}$.

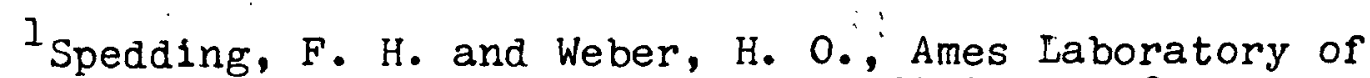
the A. E. C.,. Ames, Iowa. Activity coefficients of some aqueous rare-earth chloride solutions. Private communication. 1964. 
The run number and the molality of the sample, $m_{l}$, are given in the first column. The number of moles is denoted by $n$ and the final molality by $m_{f}$. The asterisk indicates the second sample in the calorimeter container was diluted into the final molality of the immediately preceding sample. The observed heats, $q$, are given in defined calories.

The number of grams of the sample and the number of grams of water are not given. However, these can be calculated from columns 1,2 , and 3 for the dilute data, and from columns 2,3 , and 4 for the concentrated data. The total liquid weight was usually 900 grams, but in some cases it was a few grams less.

Tables 8,12 , and 18 give the average values of $\bar{P}_{i}$, $\Delta \mathrm{H}_{1,2}$, and $\Delta \mathrm{H}_{1,3}$ with their standard deviations defined by equation 4.28. The last column in these tables gives the average relative apparent molal heat content, $\bar{\emptyset}_{L}\left(m_{1}\right)$. The experimental data for aqueous solutions of $\mathrm{LaCl}_{3}, \mathrm{PrCl}_{3}, \mathrm{TbCl}_{3}, \mathrm{HoCl}_{3}$, and $\mathrm{YbCl}_{3}$ from 0.4 molal to saturation are given in Tables $5,9,13,15$, and 19 respectively. The molality of the sample, $m_{1}$, is given directly adjacent to the number of moles in the sample. Only for $\mathrm{LaCl}_{3}$ solutions were two different molalities placed in the same calorimeter container.

The relative partial molal heat contents, $\bar{L}_{I}$ and $\bar{L}_{2}$, and the relative partial molal excess entropies, 
$\mathrm{T}\left(\overline{\mathrm{S}}_{1}-\overline{\mathrm{S}}_{1}{ }^{\circ}\right)$ and $\mathrm{T}\left(\overline{\mathrm{S}}_{2}-\overline{\mathrm{S}}_{2}{ }^{\circ}\right)$ for aqueous solutions of $\mathrm{LaCl}_{3}$, $\mathrm{PrCl}_{3}, \mathrm{TbCl}_{3}, \mathrm{HoCl}_{3}$, and $\mathrm{YbCl}_{3}$ solutions are given in Tables $6,10,14,16$, and 20 , respectively.

1. Lanthanum chloride

The data for aqueous lanthanum chloride solutions are presented in Tables 5 and 6 . The equation given by Eberts (10)

$$
\emptyset_{I}=6925-15.41 .3 \mathrm{~m}
$$

was used to calculate the values of $\phi_{L}\left(m_{f}\right)$ for $m_{f}<0.004$ molal. Values of $\phi_{L}\left(m_{f}\right)$ above 0.004 molal were calculated from the equation

$\emptyset_{I}=6901 \mathrm{~m}^{1 / 2}-14,709 \mathrm{~m}+15,264 \mathrm{~m}^{3 / 2}-1,438 \mathrm{~m}^{2} \cdot(4.37)$

This equation was obtained from a least squares analysis of Ebert's data covering his: entire concentration range from zero molal to $0.18 \mathrm{molal}$. It fit his data with a standard deviation of $4.0 \mathrm{cal} . / \mathrm{mole}$.

The equations for $\overline{\mathrm{L}}_{1}$ and $\overline{\mathrm{L}}_{2}$ derived from equation 4.37 are:

$\overline{\mathrm{L}}_{1}=-62.17 \mathrm{~m}^{3 / 2}+265.0 \mathrm{~m}^{2}-412.0 \mathrm{~m}^{5 / 2}+51.80 \mathrm{~m}^{3}$ 
and

$\bar{L}_{2}=10,352 \mathrm{~m}^{1 / 2}-29,418 \mathrm{~m}+38,116 \mathrm{~m}^{3 / 2}-4,312 \mathrm{~m}^{2} \cdot(4.39)$

A least squares analysis was applied to the $\emptyset_{L}\left(m_{1}\right)$ data, given in the last column of Table 5. Ebert's most concentrated value, $\emptyset_{L}(0.1809)$ equals $1398 \mathrm{cal} . / \mathrm{mole}$, was included in this analysis. The equation

$$
\phi_{L}=103.0+4,397.4 \mathrm{~m}^{1 / 2}-4,259 \cdot 5 \mathrm{~m}+2,677.9 \mathrm{~m}^{3 / 2}-\frac{342.30 \mathrm{~m}^{2}}{(4.40)}
$$

was obtained, which fit the data with a standard deviation of seven cal./mole from 0.1809 molal to saturation.

The data in Table 5 indicate that, within experimental error, there is no contribution to the heat of dilution of $\mathrm{LaCl}_{3}$ from hydrolysis.

The equations for $\bar{I}_{1}$ and $\bar{L}_{2}$ derived from equation 4.40 are:

$\bar{L}_{1}=-39.61 m^{3 / 2}+76.73 m^{2}-72.36 m^{2}+12.33 m^{3}$

and

$$
\begin{aligned}
\bar{L}_{2}= & 103.0+6,596.1 \mathrm{~m}^{1 / 2}-8,519.0 \mathrm{~m}+6,694.7 \mathrm{~m}^{3 / 2} \\
& -1,026.90 \mathrm{~m}^{2} .
\end{aligned}
$$


Table 5. Observed heats of dilution of aqueous lanthanum chloride solutions at $25^{\circ} \mathrm{C}$

\begin{tabular}{|c|c|c|c|c|c|c|}
\hline Run & $m_{1}$ & $\mathrm{n} \times 10^{4}$ & $m_{f}^{1 / 2} \times 10^{2}$ & $\begin{array}{c}-q \\
\text { cal. }\end{array}$ & $\begin{array}{c}\phi_{L}\left(m_{1}\right) \\
\mathrm{cal} . / \mathrm{mole}\end{array}$ & $\begin{array}{c}\bar{\phi}_{\mathrm{L}}\left(\mathrm{m}_{\mathrm{l}}\right) \\
\mathrm{cal} . / \mathrm{mole}\end{array}$ \\
\hline $\mathrm{I}_{1}$ & 0.4038 & 42.971 & 6.910 & $5 ., 082$ & 1804 & 1804 \\
\hline$I_{2}$ & 0.6469 & 34.841 & 6.222 & 6.131 & 2131 & 2131 \\
\hline$I_{3}$ & 0.8102 & 30.780 & 5.848 & 6.108 & 2336 & 2336 \\
\hline$I_{4}$ & 1.008 & 29.566 & 5.731 & 6.636 & 2591 & 2591 \\
\hline$I_{5}$ & 1.209 & 24.930 & 5.262 & 6.310 & 2853 & $2859 \pm 6$ \\
\hline$I_{6}$ & 1.411 & 25.116 & 5.282 & 7.043 & 3127 & $3130 \pm 3$ \\
\hline $\mathrm{I}_{16}$ & $\begin{array}{l}1.209 \\
1.693\end{array}$ & $\begin{array}{l}27.379 \\
26.017^{*}\end{array}$ & $\begin{array}{l}5.522 \\
7.704\end{array}$ & $\begin{array}{l}6.926 \\
7.718\end{array}$ & $\begin{array}{l}2866 \\
3529\end{array}$ & $3525 \pm 4$ \\
\hline$I_{8}$ & $\begin{array}{l}1.411 \\
1.693\end{array}$ & $\begin{array}{l}20.231 \\
23.711^{*}\end{array}$ & $\begin{array}{l}4.745 \\
6.988\end{array}$ & $\begin{array}{l}5.744 \\
7.130\end{array}$ & $\begin{array}{l}3133 \\
3520\end{array}$ & \\
\hline$I_{9}{ }^{a}$ & $\begin{array}{l}1.975 \\
2.252\end{array}$ & $\begin{array}{l}16.919 \\
16.277^{*}\end{array}$ & $\begin{array}{l}4.458 \\
6.203\end{array}$ & $\begin{array}{l}6.236 \\
6.430\end{array}$ & $\begin{array}{l}3965 \\
4409\end{array}$ & $\begin{array}{l}396.1 \pm 4 \\
4409\end{array}$ \\
\hline$I_{9 A}$ & $\begin{array}{l}1.975 \\
? .25 ?\end{array}$ & $\begin{array}{l}17.870 \\
16.758^{*}\end{array}$ & $\begin{array}{l}4.458 \\
6.203\end{array}$ & $\begin{array}{l}6.588 \\
6.60 / .\end{array}$ & $\begin{array}{l}3965 \\
1.4 .09\end{array}$ & \\
\hline $\mathrm{I}_{10^{\mathrm{a}}}$ & $\begin{array}{l}2.565 \\
2.832\end{array}$ & $\begin{array}{l}16.538 \\
16.133^{*}\end{array}$ & $\begin{array}{l}4.288 \\
6.025\end{array}$ & $\begin{array}{l}7.773 \\
8.802\end{array}$ & $\begin{array}{l}4969 \\
5465\end{array}$ & $\begin{array}{l}4971 \pm 2 \\
5465 \pm 1\end{array}$ \\
\hline$I_{11}$ & $\begin{array}{l}3.290 \\
3.896\end{array}$ & $\begin{array}{c}11.504 \\
8.498^{*}\end{array}$ & $\begin{array}{l}3.574 \\
4.713\end{array}$ & $\begin{array}{l}7.038 \\
6.121\end{array}$ & $\begin{array}{l}6346 \\
7570\end{array}$ & $\begin{array}{l}6345 \pm 1 \\
7576 \pm 6\end{array}$ \\
\hline$I_{13}^{a}$ & $\begin{array}{l}3.2 .90 \\
3.600\end{array}$ & $\begin{array}{l}9.440 \\
13.107\end{array}$ & $\begin{array}{l}3.239 \\
5.004\end{array}$ & $\begin{array}{l}5.792 \\
8.649\end{array}$ & $\begin{array}{l}6344 \\
6979\end{array}$ & $6975+4$ \\
\hline$I_{14}{ }^{a}$ & $\begin{array}{l}3.600 \\
3.896\end{array}$ & $\begin{array}{l}8.913 \\
7.740\end{array}$ & $\begin{array}{l}3.146 \\
4.300\end{array}$ & $\begin{array}{l}6.033 \\
5.601\end{array}$ & $\begin{array}{l}6971 \\
7582\end{array}$ & \\
\hline
\end{tabular}

${ }^{2}$ Dilutions made into very dilute $\mathrm{HCl}(\mathrm{pH}=4.4)$.

* In this table, and all succeeding tables, the single asterisk denotes this sample was diluted into the final molality of the immediately preceding sample. 
Table 6. Relative partial molal heat contents and relative partial molal excess entroples of aqueous lanthanum chloride solutions at $25^{\circ} \mathrm{C}$

\begin{tabular}{lcccc}
\hline Molality & $\begin{array}{c}-\bar{L}_{1} \\
c a l . / \mathrm{mole}\end{array}$ & $\begin{array}{c}\overline{\mathrm{L}}_{2} \\
\mathrm{cal.} / \mathrm{mole}\end{array}$ & $\begin{array}{l}-\mathrm{T}\left(\overline{\mathrm{S}}_{1}-\overline{\mathrm{S}}_{1} \mathrm{o}\right) \\
\mathrm{cal} . / \mathrm{mole}\end{array}$ & $\begin{array}{r}\mathrm{T}\left(\overline{\mathrm{S}}_{2}-\overline{\mathrm{S}}_{2} \mathrm{o}\right) \\
\mathrm{cal.} / \mathrm{mole}\end{array}$ \\
\hline 0.001 & 0.0017 & 299 & 0.0064 & 856 \\
0.005 & 0.016 & 598 & 0.052 & 1684 \\
0.01 & 0.040 & 779 & 0.111 & 2176 \\
0.05 & 0.256 & 1259 & 0.721 & 3513 \\
0.1 & 0.567 & 1494 & 1.520 & 4146 \\
0.2 & 1.92 & 1983 & 3.56 & 4939 \\
0.5 & 6.07 & 2618 & 7.71 & 5666 \\
1.0 & 22.9 & 3848 & 14.9 & 6293 \\
1.5 & 57.9 & 5391 & 26.1 & 6864 \\
2.0 & 116 & 7221 & 45.1 & 7537 \\
2.5 & 199 & 9280 & 78.6 & 8430 \\
3.0 & 310 & 11510 & 133 & 9370 \\
3.5 & 449 & 13880 & 207 & 10930 \\
3.896 & 579 & 15830 & 284 & 12130 \\
\hline
\end{tabular}

Values of $\bar{L}_{1}, \bar{L}_{2}, T\left(\bar{S}_{1}-\bar{S}_{1}{ }^{\circ}\right)$ and $T\left(\bar{S}_{2}-\bar{S}_{2}{ }^{\circ}\right)$ for $\mathrm{LaCl}_{3}$ solutions at rounded concentrations are given in Table 6 . 


\section{2.: Praseodymium chloride}

The data for aqueous praseodymium chloride solutions are given in Tables $7,8,9$, and 10 , and Figures 4, 5, and 6 .

Two weighted least squares analyses were applied to the $\bar{P}_{1}$ data given in Table 8 . The first, corresponding to equation 4.23 , gave

$$
\bar{p}_{i}=7276-37,514 x_{i}
$$

The second, using the theoretical intercept 6925, resulted in

$$
\bar{P}_{i}=6925-32,022 x_{i}
$$

Equation 4.44 is represented by the dotted line in Figure 4.

Integrating equation 4.44 gave

$$
\emptyset_{L}=6925 \mathrm{~m}^{1 / 2}-16,011 \mathrm{~m}
$$

which was used to calculate $\emptyset_{L}\left(m_{f}\right)$ for $m_{f}<0.0055$ molal. The equation for the $\varnothing_{L}$ data given in Table 8 from zero molal to 0.25 molal was found to be:

$$
\emptyset_{L}=6,945 \mathrm{~m}^{1 / 2}-18,118 \mathrm{~m}+31,512 \mathrm{~m}^{3 / 2}-21,862 \mathrm{~m}^{2} .
$$


Table 7. Observed heats of dilution of dilute aqueous praseodymium chloride solutions at $25^{\circ} \mathrm{C}$

\begin{tabular}{|c|c|c|c|c|c|c|}
\hline $\begin{array}{c}\text { Run } \\
m_{1}\end{array}$ & $\mathrm{n} \times 10^{4}$ & $\mathrm{~m}_{\mathrm{f}}^{1 / 2} \times 10^{2}$ & $\begin{array}{c}-q \\
\text { cal. }\end{array}$ & $\begin{array}{c}-\Delta_{\mathrm{H}_{1,2}} \\
\text { cal./mole }\end{array}$ & $\begin{array}{l}-\Delta \mathrm{H}_{1,3} \\
\mathrm{cal} . / \mathrm{mole}\end{array}$ & $\bar{P}_{i}$ \\
\hline $\begin{array}{l}\mathrm{B}_{1} \\
0.01900\end{array}$ & $\begin{array}{l}1.847 \\
1.850^{*} \\
1.852 \\
1.849^{*}\end{array}$ & $\begin{array}{l}1.440 \\
2.026 \\
1.442 \\
2.027\end{array}$ & $\begin{array}{l}0.104 \\
0.097 \\
0.114 \\
0.099\end{array}$ & $\begin{array}{l}550 \\
606\end{array}$ & $\begin{array}{l}531 \\
565\end{array}$ & 6950 \\
\hline $\begin{array}{l}\mathrm{B}_{2} \\
0.01900\end{array}$ & $\begin{array}{l}1.845 \\
1.844^{*} \\
1.850 \\
1.849^{*}\end{array}$ & $\begin{array}{l}1.439 \\
2.024 \\
1.441 \\
2.027\end{array}$ & $\begin{array}{l}0.109 \\
0.104 \\
0.113 \\
0.092\end{array}$ & $\begin{array}{l}579 \\
596\end{array}$ & $\begin{array}{l}565 \\
541\end{array}$ & $\begin{array}{l}2340 \\
9380\end{array}$ \\
\hline $\begin{array}{l}\text { B8 } \\
0.01900\end{array}$ & $\begin{array}{l}1.852 \\
1.852^{*} \\
1.853 \\
1.853^{*}\end{array}$ & $\begin{array}{l}1.442 \\
2.028 \\
1.442 \\
2.028\end{array}$ & $\begin{array}{l}0.111 \\
0.096 \\
0.114 \\
0.101\end{array}$ & $\begin{array}{l}584 \\
601\end{array}$ & $\begin{array}{l}547 \\
568\end{array}$ & $\begin{array}{l}6320 \\
5620\end{array}$ \\
\hline $\begin{array}{l}\mathrm{B}_{13} \\
0.01900\end{array}$ & $\begin{array}{l}1.854 \\
1.854^{*} \\
1.854 \\
1.853^{*}\end{array}$ & $\begin{array}{l}1.443 \\
2.029 \\
1.443 \\
2.028\end{array}$ & $\begin{array}{l}0.112 \\
0.096 \\
0.111 \\
0.103\end{array}$ & $\begin{array}{l}592 \\
586\end{array}$ & $\begin{array}{l}549 \\
564\end{array}$ & $\begin{array}{l}7090 \\
3720\end{array}$ \\
\hline $\begin{array}{l}\mathrm{B}_{3} \\
n . \cap 4738\end{array}$ & $\begin{array}{l}4.118 \\
4.121 \\
4.118 \\
4.117^{*}\end{array}$ & $\begin{array}{l}2.150 \\
3.02 \% \\
2.150 \\
3.024\end{array}$ & $\begin{array}{l}0.306 \\
0.263 \\
0.308 \\
0.268\end{array}$ & $\begin{array}{l}742 \\
747\end{array}$ & $\begin{array}{l}690 \\
699\end{array}$ & $\begin{array}{l}5990 \\
5460\end{array}$ \\
\hline $\mathrm{B}_{5} .04138$ & $\begin{array}{l}4.108 \\
4.113^{*} \\
4.124 \\
4.115^{*}\end{array}$ & $\begin{array}{l}2.147 \\
3.021 \\
2.152 \\
3.024\end{array}$ & $\begin{array}{l}0.308 \\
0.260 \\
0.305 \\
0.270\end{array}$ & $\begin{array}{l}749 \\
740\end{array}$ & $\begin{array}{l}690 \\
698\end{array}$ & $\begin{array}{l}6700 \\
4780\end{array}$ \\
\hline $\begin{array}{l}\mathrm{B}_{9} \\
0.04138\end{array}$ & $\begin{array}{l}4.123 \\
4.115^{*} \\
4.117 \\
4.120^{*}\end{array}$ & $\begin{array}{l}2.151 \\
3.024 \\
2.150 \\
3.024\end{array}$ & $\begin{array}{l}0.310 \\
0.266 \\
0.310 \\
0.260\end{array}$ & $\begin{array}{l}752 \\
753\end{array}$ & $\begin{array}{l}699 \\
695\end{array}$ & $\begin{array}{l}6030 \\
6640\end{array}$ \\
\hline $\begin{array}{l}\mathrm{B}_{4} \\
0.07835\end{array}$ & $\begin{array}{l}7.794 \\
7.791 \\
7.800 \\
7.798^{*}\end{array}$ & $\begin{array}{l}2.958 \\
4.160 \\
2.959 \\
4.162\end{array}$ & $\begin{array}{l}0.701 \\
0.584 \\
0.696 \\
0.582\end{array}$ & $\begin{array}{l}899 \\
893\end{array}$ & $\begin{array}{l}824 \\
820\end{array}$ & $\begin{array}{l}6230 \\
6060\end{array}$ \\
\hline
\end{tabular}


Table 7. (Continued)

\begin{tabular}{|c|c|c|c|c|c|c|}
\hline$\underset{m_{1}}{R}$ & $\mathrm{n} \times 10^{4}$ & $m_{f} 1 / 2 \times 10^{2}$ & $\begin{array}{c}-q \\
\text { cal. }\end{array}$ & $\begin{array}{c}-\Delta_{1,2} \\
\text { cal./mole }\end{array}$ & $\begin{array}{l}-\Delta H_{1,3} \\
\text { cal./mole }\end{array}$ & $\bar{P}_{i}$ \\
\hline $\begin{array}{l}{ }^{B} \\
0.07835\end{array}$ & $\begin{array}{l}7.759 \\
7.773^{*} \\
7.767 \\
7.788^{*}\end{array}$ & $\begin{array}{l}2.952 \\
4.153 \\
2.953 \\
4.156\end{array}$ & $\begin{array}{l}0.687 \\
0.575 \\
0.697 \\
0.593\end{array}$ & $\begin{array}{l}885 \\
897\end{array}$ & $\begin{array}{l}812 \\
829\end{array}$ & $\begin{array}{l}6050 \\
5610\end{array}$ \\
\hline $\begin{array}{l}\mathrm{B}_{11} \\
0.07835\end{array}$ & $\begin{array}{l}7.800 \\
7.798^{*} \\
7.800 \\
7.794^{*}\end{array}$ & $\begin{array}{l}2.959 \\
4.162 \\
2.959 \\
4.161\end{array}$ & $\begin{array}{l}0.696 \\
.0 .584 \\
0.701 \\
0.580\end{array}$ & $\begin{array}{l}892 \\
899\end{array}$ & $\begin{array}{l}820 \\
822\end{array}$ & $\begin{array}{r}5980 \\
.6410\end{array}$ \\
\hline $\begin{array}{l}\mathrm{B}_{7} \\
0.1216\end{array}$ & $\begin{array}{l}12.545 \\
12.537^{*} \\
12.548 \\
12.527^{*}\end{array}$ & $\begin{array}{l}3.751 \\
5.275 \\
3.754 \\
5.277\end{array}$ & $\begin{array}{l}1.266 \\
1.052 \\
1.258 \\
1.058\end{array}$ & $\begin{array}{l}1009 \\
1002\end{array}$ & 924 & $\begin{array}{l}5580 \\
5160\end{array}$ \\
\hline $\begin{array}{l}\mathrm{B}_{12} \\
0.1216\end{array}$ & $\begin{array}{l}12.529 \\
12.537^{*} \\
12.537 \\
12.538^{*}\end{array}$ & $\begin{array}{l}3.751 \\
5.276 \\
3.752 \\
5.277\end{array}$ & $\begin{array}{l}1.266 \\
1.041 \\
1.263 \\
1.058\end{array}$ & 1008 & $\begin{array}{l}921 \\
926\end{array}$ & $\begin{array}{l}5890 \\
5370\end{array}$ \\
\hline $\begin{array}{l}\mathrm{B}_{10} \\
0.2639\end{array}$ & $\begin{array}{l}26.136 \\
26.162^{*}\end{array}$ & $\begin{array}{l}5.420 \\
7.62 .5\end{array}$ & $\begin{array}{l}3.155 \\
2.599\end{array}$ & 1207 & 1100 & 4840 \\
\hline $\begin{array}{l}\mathrm{B}_{14} \\
0.2639\end{array}$ & $\begin{array}{l}26.136 \\
26.140^{*} \\
26.137 \\
26.145^{*}\end{array}$ & $\begin{array}{l}5.420 \\
7.623 \\
5.420 \\
7.623\end{array}$ & $\begin{array}{l}3.156 \\
2.605 \\
3.157 \\
2.597\end{array}$ & $\begin{array}{r}12.08 \\
\therefore \quad 1208\end{array}$ & 1101 & $\begin{array}{l}4790 \\
4870\end{array}$ \\
\hline
\end{tabular}


Table 8. Short chord data and relative apparent molal heat contents of dilute aqueous praseodymium ciloride solutions at $25^{\circ} \mathrm{C}$

\begin{tabular}{|c|c|c|c|c|c|c|c|c|}
\hline $\mathrm{m}_{1}$ & $\mathrm{~m}_{1}{ }^{1 / 2}$ & $m_{x 10^{2}}^{1 / 2}$ & $\bar{P}_{1}$ & $\begin{array}{l}\phi_{L}\left(m_{f}\right) \\
\text { cal./ } \\
\text { mole }\end{array}$ & $\begin{array}{l}-\Delta \mathrm{H}_{1, f} \\
\text { cal./ } \\
\text { mole }\end{array}$ & $\begin{array}{c}\text { Std. } \\
\text { dev } \\
\text { cal./mole }\end{array}$ & $\begin{array}{l}\phi_{\mathrm{L}}\left(\mathrm{m}_{1}\right) \\
\mathrm{cal} \cdot / \\
\text { mole }\end{array}$ & $\begin{array}{l}\bar{\phi}_{\mathrm{L}}\left(\mathrm{m}_{\mathrm{I}}\right) \\
\mathrm{cal} \cdot / \\
\text { mole }\end{array}$ \\
\hline 0.01900 & 0.1373 & $\begin{array}{l}1.456 \\
2.048\end{array}$ & $\begin{array}{l}6600 \\
2820^{a}\end{array}$ & $\begin{array}{r}98 \\
135\end{array}$ & $\begin{array}{l}587 \\
554\end{array}$ & $\begin{array}{l}17 \\
15\end{array}$ & $\begin{array}{l}685 \\
689\end{array}$ & 678 \\
\hline 0.04138 & 0.2034 & $\begin{array}{l}2.150 \\
3.024\end{array}$ & $\begin{array}{l}5930 \\
730^{\mathrm{a}}\end{array}$ & $\begin{array}{l}142 \\
195\end{array}$ & $\begin{array}{l}747 \\
695\end{array}$ & $\begin{array}{l}5 \\
4\end{array}$ & $\begin{array}{l}889 \\
890\end{array}$ & 889 \\
\hline 0.07835 & 0.2799 & $\begin{array}{l}2.960 \\
4.159\end{array}$ & $\begin{array}{c}6050 \\
270^{a}\end{array}$ & $\begin{array}{l}191 \\
260\end{array}$ & $\begin{array}{l}894 \\
821\end{array}$ & $\begin{array}{l}5 \\
6\end{array}$ & $\begin{array}{l}1085 \\
1081\end{array}$ & 1083 \\
\hline 0.1214 & 0.3552 & $\begin{array}{l}3 \cdot 752 \\
5.277\end{array}$ & $\begin{array}{l}5500 \\
310^{a}\end{array}$ & $\begin{array}{l}237 \\
321\end{array}$ & $\begin{array}{r}1007 \\
924\end{array}$ & $\begin{array}{l}4 \\
2\end{array}$ & $\begin{array}{l}1244 \\
1245\end{array}$ & 1245 \\
\hline 0.2639 & 0.5137 & $\begin{array}{l}5.420 \\
7.624\end{array}$ & $\begin{array}{l}4830 \\
40^{a}\end{array}$ & $\begin{array}{l}328 \\
435\end{array}$ & $\begin{array}{l}1208 \\
1101\end{array}$ & $\begin{array}{l}1 \\
1\end{array}$ & $\begin{array}{l}1536 \\
1536\end{array}$ & 1536 \\
\hline
\end{tabular}

a Standard deviation of $\overline{\mathrm{P}}_{1}$. 
Table 9. Observed heats of dilution of aqueous praseodymium chloride solutions at $25^{\circ} \mathrm{C}$

\begin{tabular}{|c|c|c|c|c|c|c|}
\hline Run & $m_{1}$ & $\mathrm{n} \times 10^{4}$ & $m_{f}^{1 / 2} \times 10^{2}$ & $\begin{array}{c}-q \\
\text { cal. }\end{array}$ & $\begin{array}{c}\phi_{\mathrm{L}}\left(\mathrm{m}_{1}\right) \\
\mathrm{cal} . / \mathrm{mole}\end{array}$ & $\begin{array}{c}\bar{\phi}_{L}\left(\dot{\mathrm{m}}_{1}\right) \\
\mathrm{cal} . / \mathrm{mole}\end{array}$ \\
\hline$P_{17}$ & 0.3671 & 36.270 & 6.348 & 4.843 & 1710 & 1710 \\
\hline$P_{16}$ & 0.5182 & 44.891 & 7.063 & 6.797 & 1923 & 1923 \\
\hline$P_{15}$ & 0.6240 & 41.698 & 6.807 & 6.909 & 2054 & 2054 \\
\hline$P_{13}$ & 0.8110 & 38.714 & 6.559 & 7.350 & 2284 & 2284 \\
\hline$P_{14}$ & 0.9880 & $\begin{array}{l}30.848 \\
33.915^{*}\end{array}$ & $\begin{array}{l}5.869 \\
8.487\end{array}$ & $\begin{array}{l}6.622 \\
6.470\end{array}$ & $\begin{array}{l}2498 \\
2499\end{array}$ & $2497 \pm 2$ \\
\hline$P_{10}$ & 0.9880 & $\begin{array}{l}29.277 \\
32.789\end{array}$ & $\begin{array}{l}5.716 \\
8.307\end{array}$ & $\begin{array}{l}6.293 \\
6.343\end{array}$ & $\begin{array}{l}2493 \\
2515^{a}\end{array}$ & \\
\hline$P_{9}$ & 1.198 & $\begin{array}{l}28.099 \\
29.219\end{array}$ & $\begin{array}{l}5.597 \\
7.981\end{array}$ & $\begin{array}{l}6.790 \\
6.390\end{array}$ & $\begin{array}{l}2754 \\
2753\end{array}$ & $2753 \pm 1$ \\
\hline$P_{8}$ & 1.433 & $\begin{array}{l}22.942 \\
23.300\end{array}$ & $\begin{array}{l}5.054 \\
7.169\end{array}$ & $\begin{array}{l}6.271 \\
5.881\end{array}$ & $\begin{array}{l}304+2 \\
3042\end{array}$ & 3042 \\
\hline$P_{6}$ & 1.718 & $\begin{array}{l}24.272 \\
21.6697\end{array}$ & $\begin{array}{l}5.198 \\
7.378\end{array}$ & $\begin{array}{l}7.558 \\
7.1 .45\end{array}$ & $\begin{array}{l}3431 \\
3422\end{array}$ & $3426 \pm 5$ \\
\hline $\mathrm{P}_{5}$ & 1.931 & $\begin{array}{l}18.209 \\
19.026^{*}\end{array}$ & $\begin{array}{l}4.501 \\
6.432\end{array}$ & $\begin{array}{l}6.287 \\
6.212\end{array}$ & $\begin{array}{l}3732 \\
3740\end{array}$ & $3736 \pm 4$ \\
\hline$P_{4}$ & 2.232 & $\begin{array}{l}17.527 \\
18.24+5^{*}\end{array}$ & $\begin{array}{l}4.415 \\
6.304\end{array}$ & $\begin{array}{l}6.890 \\
6.810\end{array}$ & $\begin{array}{l}4206 \\
4200\end{array}$ & $4203 \pm 3$ \\
\hline$P_{3}$ & 2.479 & $\begin{array}{l}15.642 \\
16.659^{*}\end{array}$ & $\begin{array}{l}4.170 \\
5.991\end{array}$ & $\begin{array}{l}6.758 \\
6.999\end{array}$ & $\begin{array}{l}4581 \\
4649\end{array}$ & $4613 \pm 21$ \\
\hline$P_{18}$ & 2.479 & $\begin{array}{l}16.909 \\
18.383^{*}\end{array}$ & $\begin{array}{l}4.336 \\
6.262\end{array}$ & $\begin{array}{l}7.321 \\
7.645\end{array}$ & $\begin{array}{l}4600 \\
4622\end{array}$ & \\
\hline$P_{2}$ & 2.871 & $\begin{array}{l}13.337 \\
1.4 .234^{*}\end{array}$ & $\begin{array}{l}3.850 \\
5.534_{t}\end{array}$ & $\begin{array}{l}6.776 \\
6.973\end{array}$ & $\begin{array}{l}5324 \\
5319\end{array}$ & $5321 \pm 3$ \\
\hline
\end{tabular}

$a_{\text {Rejected. }}$ 
Table 9. (Continued)

\begin{tabular}{|c|c|c|c|c|c|c|c|}
\hline Run & $m_{\perp}$ & & $\mathrm{nx} 10^{4}$ & $m_{f}^{1 / 2} \times 10^{2}$ & $\begin{array}{c}-q \\
\text { cal. }\end{array}$ & $\begin{array}{c}\phi_{\mathrm{L}}\left(\mathrm{m}_{1}\right) \\
\mathrm{cal} / \mathrm{mole}\end{array}$ & $\begin{array}{c}\bar{\Phi}_{1}\left(m_{1}\right) \\
\text { cal./mole }\end{array}$ \\
\hline$P_{1}$ & 3.095 & & $\begin{array}{l}12.726 \\
13.596^{*}\end{array}$ & $\begin{array}{l}3.761 \\
5.407\end{array}$ & $\begin{array}{l}7.030 \\
7.269\end{array}$ & $\begin{array}{l}5762 \\
5758 .\end{array}$ & $5760 \pm 2$ \\
\hline$P_{11}$ & 3.475 & & $\begin{array}{c}8.888 \\
10.685^{*}\end{array}$ & $\begin{array}{l}3.142 \\
4.662\end{array}$ & $\begin{array}{l}5.653 \\
6.637\end{array}$ & $\begin{array}{l}6562 \\
6572\end{array}$ & $6567 \pm 5$ \\
\hline $\mathrm{P}_{12}$ & 3.891 & . & $\begin{array}{l}10.128 \\
12.292^{*}\end{array}$ & $\begin{array}{l}3.355 \\
4.990\end{array}$ & $\begin{array}{l}7.365 \\
8.749\end{array}$ & $\begin{array}{l}7487 \\
7499\end{array}$ & $7493 \pm 4$ \\
\hline$P_{7}$ & 3.891 & & $\begin{array}{c}8.559 \\
10.520^{*}\end{array}$ & $\begin{array}{l}3.083 \\
4.603\end{array}$ & $\begin{array}{l}6.096 \\
7.510\end{array}$ & $\begin{array}{l}7321^{a} \\
7494\end{array}$ & \\
\hline
\end{tabular}


Table 10. Relative partial molal heat contents and relative partial molal excess entropies of aqueous praseodymium chloride solutions at $25^{\circ} \mathrm{C}$

\begin{tabular}{lcccc}
\hline Molality & $\begin{array}{c}-\overline{\mathrm{L}}_{1} \\
\text { cal./mole }\end{array}$ & $\begin{array}{c}\overline{\mathrm{L}}_{2} \\
\text { cal./mole }\end{array}$ & $\begin{array}{c}-\mathrm{T}\left(\overline{\mathrm{S}}_{1}-\overline{\mathrm{S}}_{1}{ }^{0}\right) \\
\mathrm{cal} . / \mathrm{mole}\end{array}$ & $\begin{array}{c}\mathrm{T}\left(\overline{\mathrm{S}}_{2}-\overline{\mathrm{S}}_{2}{ }^{0}\right) \\
\mathrm{cal} \cdot / \mathrm{mole}\end{array}$ \\
\hline 0.001 & 0.0016 & 299 & 0.0063 & 852 \\
0.005 & 0.015 & 582 & 0.051 & 1667 \\
0.01 & 0.038 & 752 & 0.109 & 2149 \\
0.05 & 0.261 & 1234 & 0.726 & 3472 \\
0.1 & 0.619 & 1506 & 1.54 & 4130 \\
0.2 & 1.47 & 1834 & 3.12 & 4766 \\
0.5 & 6.02 & 2568 & 7.55 & 5581 \\
1.0 & 21.4 & 3699 & 13.2 & 6098 \\
1.5 & 53.5 & 5112 & 21.1 & 6523 \\
2.0 & 109 & 6873 & 36.9 & 7095 \\
2.5 & 195 & 8988 & 70.1 & 7980 \\
3.0 & 317 & 11450 & 131 & 9267 \\
3.5 & 482 & 14250 & 226 & 10970 \\
3.891 & 643 & 16670 & 330 & 12570 \\
\hline & & & &
\end{tabular}

This equation fit the data in Table 8 with a standard deviation of one cal./mole. The equations for $\bar{L}_{1}$ and $\bar{L}_{2}$ derived from equation 4.46 are:

$$
\bar{L}_{1}=-62.56 \mathrm{~m}^{3 / 2}+326.4 \mathrm{~m}^{2}-851.5 \mathrm{~m}^{5 / 2}+787.7 \mathrm{~m}^{3} \quad(4.47)
$$




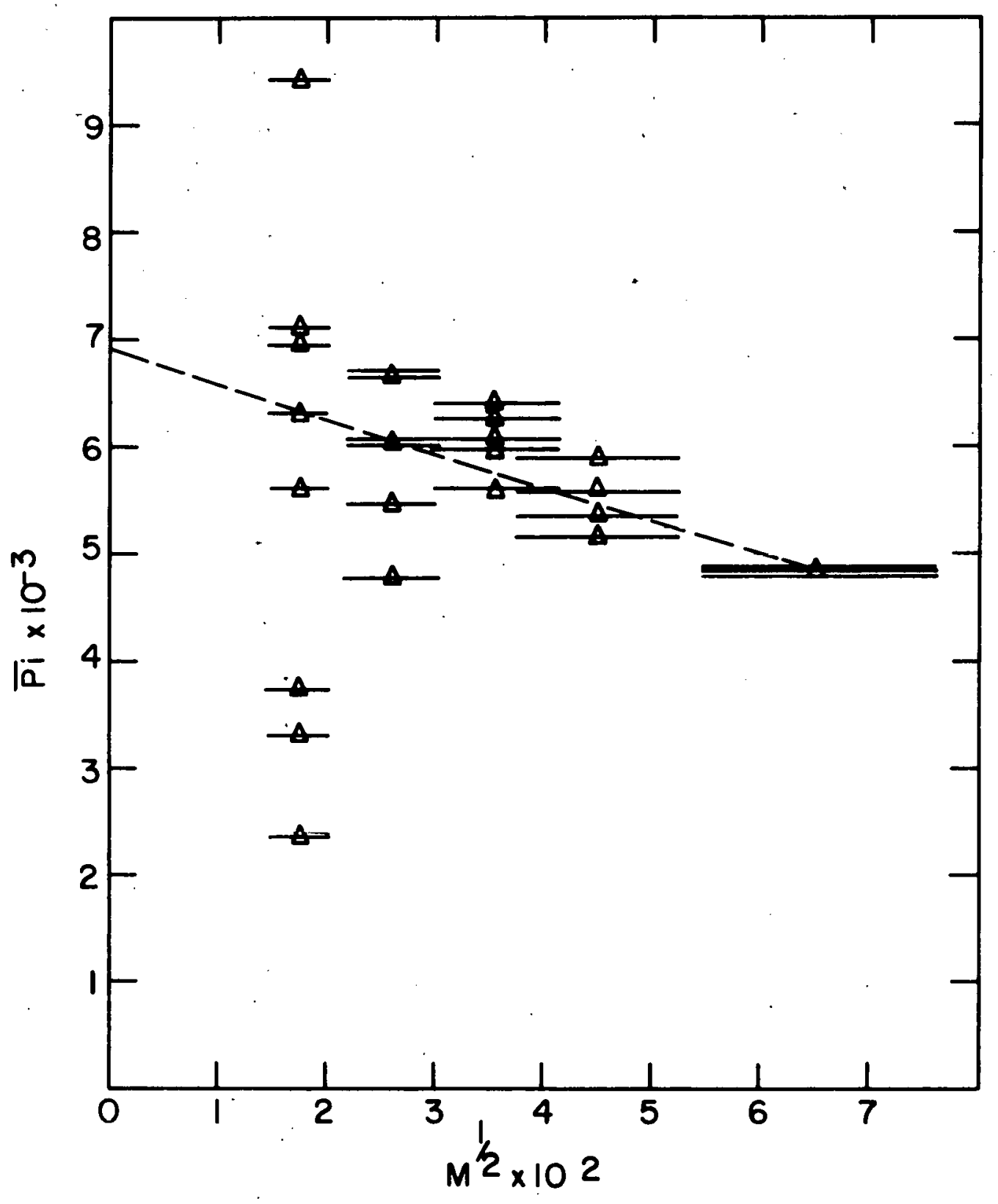

Figure 4. $\overline{\mathrm{P}}_{1}$ 's versus $\mathrm{m}^{1 / 2}$ for praseodymium chloride solutions at $25^{\circ} \mathrm{C}$ 


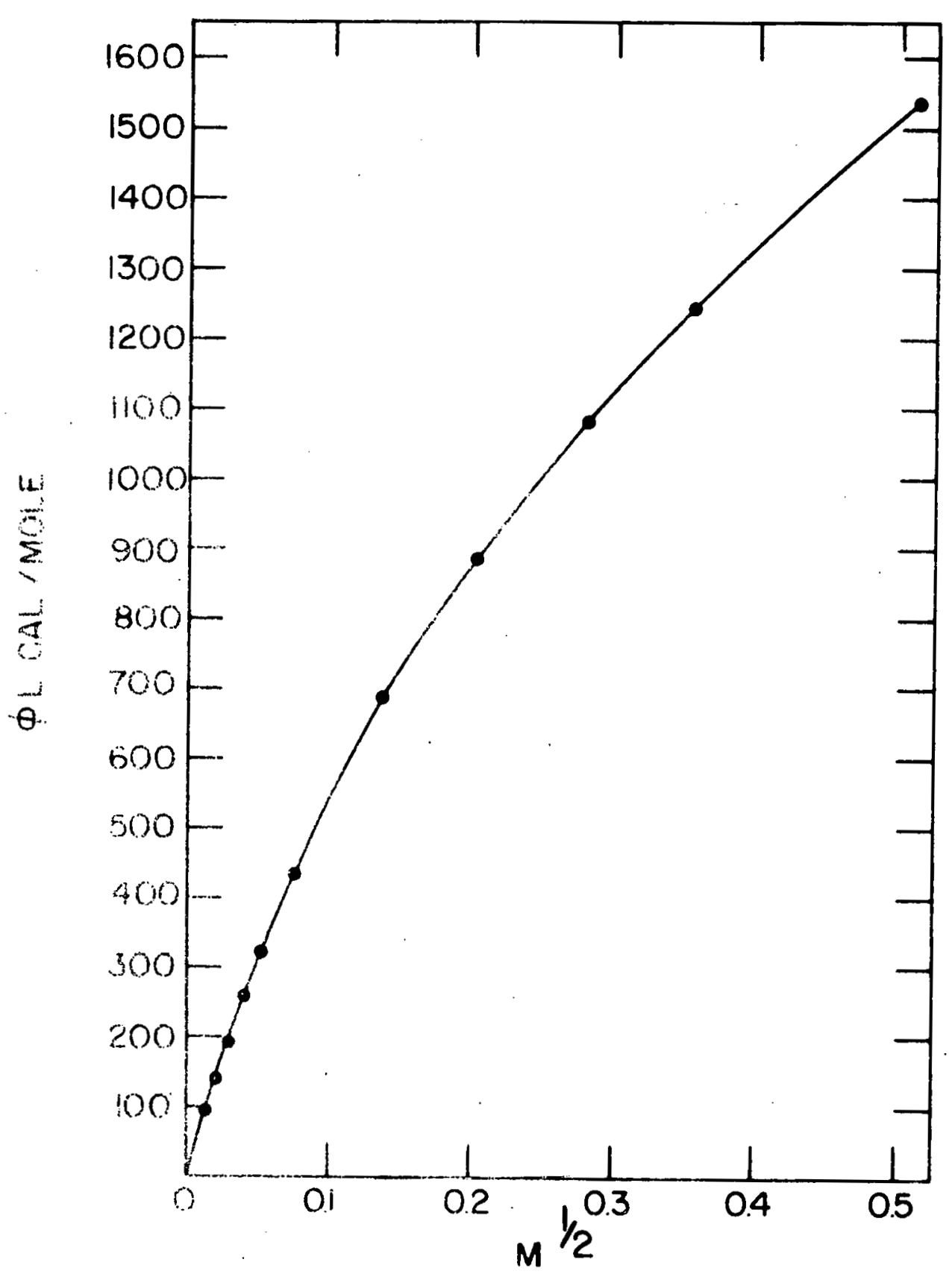

Figure 5. Relative apparent molal heat contents versus $\mathrm{m}^{1 / 2}$ for praseodymium chloride solutions at $25^{\circ} \mathrm{C}$ 


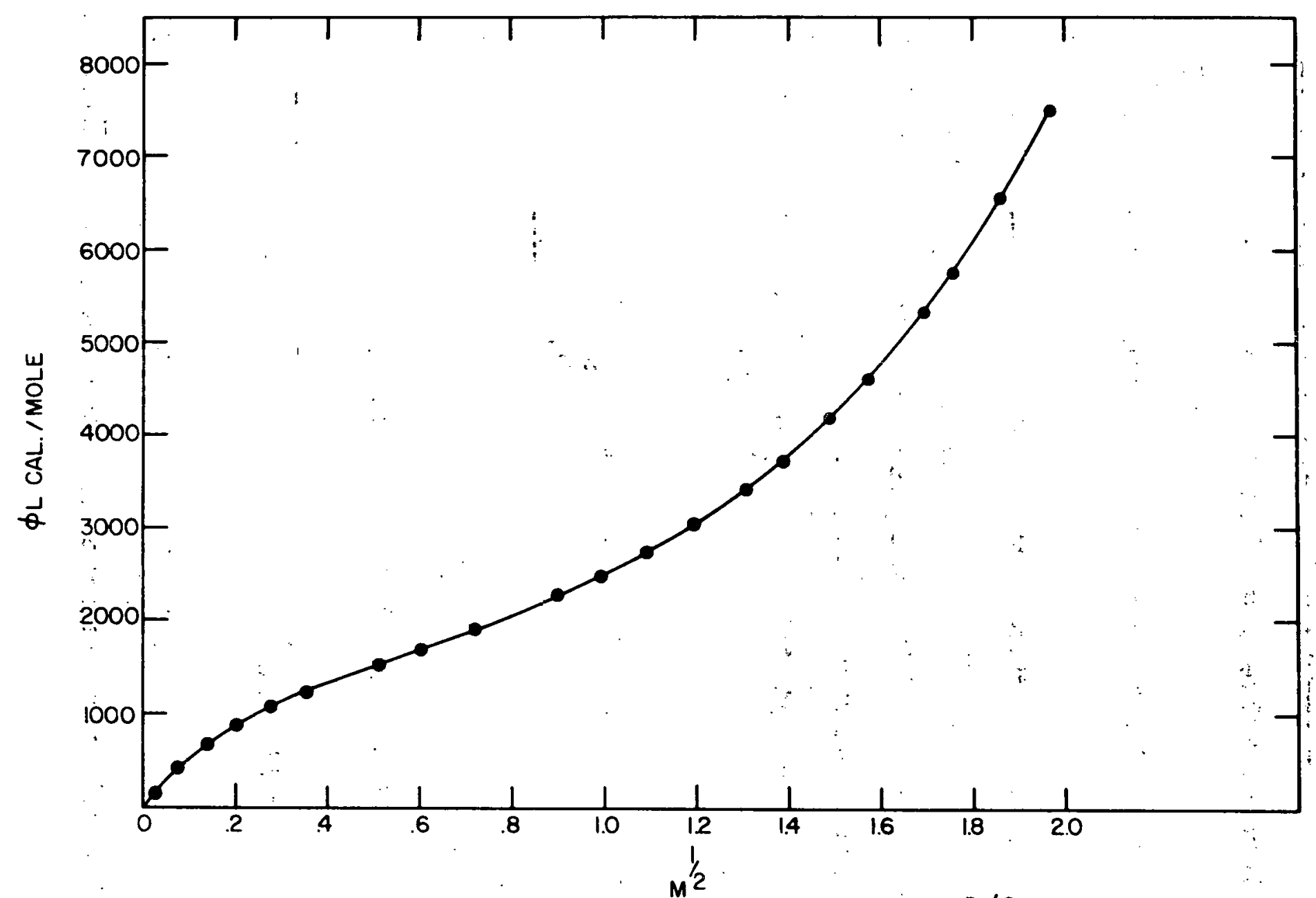

Figure 6. Relative apparent molal heat contents versus $\mathrm{m}^{1 / 2}$ for praseodymium chloride solutions at $25^{\circ} \mathrm{C}$ for the entire concentration range 
$\overline{\mathrm{L}}_{2}=10,417 \mathrm{~m}^{1 / 2}-36,237 \mathrm{~m}+78,780 \mathrm{~m}^{3 / 2}-65,586 \mathrm{~m}^{2} \cdot(4.48)$

The equation for the $\emptyset_{L}\left(m_{1}\right)$ data given in the last column of Table 9 was found to be:

$$
\emptyset_{\mathrm{L}}=247.6+3,387.5 \mathrm{~m}^{1 / 2}-2,307.8 \mathrm{~m}+1,117.0 \mathrm{~m}^{3 / 2}+64.40 \mathrm{~m}^{2}
$$

which fit the data with a standard deviation of four cal./ mole from 0.2639 molal to saturation. The value for $\emptyset_{L}(0.2639)$ in Table 8 was also included in this least squares analysis.

The equations for $\bar{L}_{1}$ and $\bar{L}_{2}$ derived from equation 4.49 are:

$\bar{L}_{1}=-30.513 \mathrm{~m}^{3 / 2}+41.578 \mathrm{~m}^{2}-30.186 \mathrm{~m}^{5 / 2}-2.320 \mathrm{~m}^{3}(4.50)$

and

$$
\begin{aligned}
\bar{I}_{2}= & 247.6+5081 \cdot \mathrm{m}^{1 / 2}-4,615.9 \mathrm{~m}+2,792.6 \mathrm{~m}^{3 / 2} \\
& +193.18 \mathrm{~m}^{2}
\end{aligned}
$$

Values of $\bar{L}_{1}, \bar{L}_{2}, T\left(\bar{S}_{1}-\bar{S}_{1}^{0}\right)$ and $T\left(\bar{S}_{2}-\bar{S}_{2}^{0}\right)$ for $\mathrm{PrCl}_{3}$ solutions at rounded concentrations are given in Table 10. 
3. Terbium chloride

The data for aqueous terbium chloride solutions are given in Tables $11,12,13$, and 14 , and values of $\bar{P}_{i}$ are plotted in Figure ?.

The equations found for $\overline{\mathrm{P}}_{\mathrm{i}}$ were

$$
\overline{\mathrm{P}}_{\mathbf{i}}=7021-30,928 \mathrm{x}_{i}
$$

and

$$
\bar{P}_{i}=6925-29,334 x_{i} .
$$

Equation 4.53 is represented by the dotted line in Figure 7 . Integration of equation 4.53 gave

$$
\emptyset_{L}=6925 \mathrm{~m}^{1 / 2}-14,667 \mathrm{~m}
$$

which was used to calculate $\emptyset_{L}\left(m_{f}\right)$ tor $m_{f}<0.0055$ molal.

The equation valid for the $\emptyset_{\mathrm{L}}$ data given in Table 8 was found to be:

$$
\phi_{L}=6872 \mathrm{~m}^{1 / 2}-15,042 \mathrm{~m}+20,995 \mathrm{~m}^{3 / 2}-10,611 \mathrm{~m}^{2} \quad(4.55)
$$

which fil the data from 0.0 molal to 0.2508 molal with a standard deviation of one cal./mole.

The equations for $L_{1}$ and $L_{2}$ are: 
Table 11. Observed heats of dilution of dilute aqueous terbium chloride solutions at $25^{\circ} \mathrm{C}$

\begin{tabular}{|c|c|c|c|c|c|c|}
\hline $\begin{array}{c}\text { Run } \\
m_{1}\end{array}$ & $n \times 10^{4}$ & $m_{f}^{1 / 2} \times 10^{2}$ & $\begin{array}{c}-q \\
\text { cal. }\end{array}$ & $\begin{array}{l}-\Delta \mathrm{H}_{1}, 2 \\
\mathrm{cal} .1 \mathrm{~mole}\end{array}$ & $\begin{array}{l}-\Delta H_{1} \\
\text { cal. } 7 h^{3} \text { le }\end{array}$ & $\bar{P}_{i}$ \\
\hline $\begin{array}{l}D_{10} \\
0.02046\end{array}$ & $\begin{array}{l}2.205 \\
2.207^{*}\end{array}$ & $\begin{array}{l}1.573 \\
2.213\end{array}$ & $\begin{array}{l}0.136 \\
0.115\end{array}$ & 615 & 569 & 7170 \\
\hline $\begin{array}{l}D_{11} \\
0.02046\end{array}$ & $\begin{array}{l}2.206 \\
2.206^{*}\end{array}$ & $\begin{array}{l}1.574 \\
2.213\end{array}$ & $\begin{array}{l}0.132 \\
0.114\end{array}$ & 598 & 558 & 6240 \\
\hline $\begin{array}{l}D_{13} \\
0.02046\end{array}$ & $\begin{array}{l}2.207 \\
2.208^{*} \\
2.208 \\
2.205^{*}\end{array}$ & $\begin{array}{l}1.574 \\
2.214 \\
1.574 \\
2.213\end{array}$ & $\begin{array}{l}0.133 \\
0.118 \\
0.130 \\
0.117\end{array}$ & $\begin{array}{l}604 \\
587\end{array}$ & $\begin{array}{l}569 \\
559\end{array}$ & $\begin{array}{l}5440 \\
4360\end{array}$ \\
\hline $\begin{array}{l}D_{15} \\
0.02046\end{array}$ & $\begin{array}{l}2.205 \\
2.206^{*} \\
2.206 \\
2.205^{*}\end{array}$ & $\begin{array}{l}1.573 \\
2.213 \\
1.574 \\
2.213\end{array}$ & $\begin{array}{l}0.132 \\
0.118 \\
0.130 \\
0.116\end{array}$ & $\begin{array}{l}599 \\
591\end{array}$ & $\begin{array}{l}567 \\
560\end{array}$ & $\begin{array}{l}5000 \\
4960\end{array}$ \\
\hline $\begin{array}{l}D_{18} \\
0.02046\end{array}$ & $\begin{array}{l}2.206 \\
2.204^{*} \\
2.206 \\
2.207^{*}\end{array}$ & $\begin{array}{l}2.476 \\
4.896 \\
2.476 \\
4.899\end{array}$ & $\begin{array}{l}0.129 \\
0.120 \\
0.132 \\
0.119\end{array}$ & $\begin{array}{l}585 \\
600\end{array}$ & $\begin{array}{l}564 \\
569\end{array}$ & $\begin{array}{l}3240 \\
4860\end{array}$ \\
\hline $\begin{array}{l}D_{5} \\
0.03878\end{array}$ & $\begin{array}{l}3.859 \\
3.859 \\
3.859 \\
3.861\end{array}$ & $\begin{array}{l}2.081 \\
2.927 \\
2.081 \\
2.927\end{array}$ & $\begin{array}{l}0.303 \\
0.261 \\
0.301 \\
0.256\end{array}$ & $\begin{array}{l}785 \\
781\end{array}$ & $\begin{array}{l}731 \\
722\end{array}$ & $\begin{array}{l}6450 \\
6940\end{array}$ \\
\hline $\begin{array}{l}D_{7} \\
0.03878\end{array}$ & $\begin{array}{l}3.861 \\
3.862^{*}\end{array}$ & $\begin{array}{l}2.082 \\
2.928\end{array}$ & $\begin{array}{l}0.304 \\
0.263\end{array}$ & 788 & 734 & 6400 \\
\hline $\begin{array}{l}D_{12} \\
0.03878\end{array}$ & $\begin{array}{l}3.861 \\
3.859^{*} \\
3.861 \\
3.857^{*}\end{array}$ & $\begin{array}{l}2.082 \\
2.928 \\
2.082 \\
2.927\end{array}$ & $\begin{array}{l}0.292 \\
0.259 \\
0.306 \\
0.260\end{array}$ & $\begin{array}{l}756 \\
793\end{array}$ & $\begin{array}{l}714 \\
733\end{array}$ & 7010 \\
\hline $\begin{array}{l}D_{17} \\
0.03878\end{array}$ & $\begin{array}{l}3.859 \\
3.862^{*} \\
3.862 \\
3.857\end{array}$ & $\begin{array}{l}2.081 \\
2.928 \\
2.082 \\
2.927\end{array}$ & $\begin{array}{l}0.296 \\
0.263 \\
0.305 \\
0.260\end{array}$ & $\begin{array}{l}767 \\
790\end{array}$ & $\begin{array}{l}724 \\
732\end{array}$ & $\begin{array}{l}5030 \\
6910\end{array}$ \\
\hline
\end{tabular}


Table 11. (Continued)

\begin{tabular}{|c|c|c|c|c|c|c|}
\hline $\begin{array}{c}\text { Run } \\
\mathrm{m}_{\mathrm{J}} .\end{array}$ & $\mathrm{n} \times 10^{4}$ & $m_{f}{ }^{1 / 2} \times 10^{2}$ & $\begin{array}{c}-q \\
\text { cal. }\end{array}$ & $\begin{array}{l}-\Delta \mathrm{H}_{1,2} \\
\text { cal./mole }\end{array}$ & $\begin{array}{l}-\Delta H_{1,3} \\
\mathrm{cal} . / \mathrm{mole}\end{array}$ & $\vec{P}_{i}$ \\
\hline $\begin{array}{l}D_{1} \\
0.06339\end{array}$ & $\begin{array}{l}6.306 \\
6.308^{*} \\
6.306 \\
6.295^{*}\end{array}$ & $\begin{array}{l}2.661 \\
3.743 \\
2.661 \\
3.741\end{array}$ & $\begin{array}{l}0.563 \\
0.482 \\
0.559 \\
0.477\end{array}$ & $\begin{array}{l}892 \\
887\end{array}$ & $\begin{array}{l}828 \\
823\end{array}$ & $\begin{array}{l}5920 \\
5980\end{array}$ \\
\hline $\begin{array}{l}D_{2} \\
0.06339\end{array}$ & $\begin{array}{l}6.306 \\
6.305^{*} \\
6.304 \\
6.304^{*}\end{array}$ & $\begin{array}{l}2.661 \\
3.742 \\
2.66 .1 \\
3.742 .\end{array}$ & $\begin{array}{l}0.568 \\
0.483 \\
0.560 \\
0.490\end{array}$ & $\begin{array}{l}901 \\
889\end{array}$ & $\begin{array}{l}833 \\
833\end{array}$ & $\begin{array}{l}6220 \\
5160\end{array}$ \\
\hline $\begin{array}{l}D_{3} \\
0.11+1\end{array}$ & $\begin{array}{l}11.351 \\
11.348^{*}\end{array}$ & $\begin{array}{l}3.571 \\
5.021\end{array}$ & $\begin{array}{l}1.193 \\
1.005\end{array}$ & 1051 & 968 & 5690 \\
\hline$D_{4}$ & $\begin{array}{l}11.356 \\
11.360^{*} \\
1.3 .349 \\
11.356^{*}\end{array}$ & $\begin{array}{l}3.57 .1 \\
5.023 \\
3.570 \\
5.022\end{array}$ & $\begin{array}{l}1.192 \\
1.000 \\
1.194 \\
0.998\end{array}$ & 1052 & 966 & $59 ? 0$ \\
\hline $\begin{array}{l}\left.D_{1}\right]_{4} \\
0.2508\end{array}$ & $\begin{array}{l}24.837 \\
24.868^{*} \\
24.84 ? \\
24.855^{*}\end{array}$ & $\begin{array}{l}5.284 \\
7.433 \\
5.285 \\
7.433\end{array}$ & $\begin{array}{l}3.247 \\
2.719 \\
3.270 \\
2.725\end{array}$ & 1316 & 12.06 & 5110 \\
\hline $\begin{array}{l}\text { D.1.6 } \\
0.2508\end{array}$ & $\begin{array}{l}24.858 \\
24.855^{\circ}\end{array}$ & $\begin{array}{l}3.286 \\
7.434\end{array}$ & $\begin{array}{l}3.274 \\
2.737\end{array}$ & $1,31 . \%$ & 1209 & 5020 \\
\hline
\end{tabular}


Table 12. Short chord data and relative apparent molal heat contents of dilute aqueous terbium chloride solutions at $25^{\circ} \mathrm{C}$

\begin{tabular}{|c|c|c|c|c|c|c|c|c|}
\hline $\mathrm{m}_{1}$ & $m_{1}^{1 / 2}$ & $\begin{array}{l}m_{\mathrm{f}} 1 / 2 \\
\mathrm{x} 10^{2}\end{array}$ & $\overline{\mathbf{P}}_{i}$ & $\begin{array}{l}\emptyset_{L}\left(m_{f}\right) \\
\text { cal. } / \\
\text { mole }\end{array}$ & $\begin{array}{l}-\Delta \mathrm{H}_{\mathrm{I}, \mathrm{f}} \\
\mathrm{cal} \cdot / \\
\text { mole }\end{array}$ & $\begin{array}{c}\text { Std. } \\
\text { dev. } \\
\text { cal./mole }\end{array}$ & $\begin{array}{l}\emptyset_{L}\left(m_{1}\right) \\
\text { cal./ } \\
\text { mole }\end{array}$ & $\begin{array}{l}\bar{\emptyset}_{L}\left(m_{1}\right) \\
\text { cal./ } \\
\text { mole }\end{array}$ \\
\hline 0.02046 & 0.1430 & $\begin{array}{l}1.574 \\
2.213\end{array}$ & $\begin{array}{l}5160 \\
1180^{a}\end{array}$ & $\begin{array}{l}105 \\
146\end{array}$ & $\begin{array}{l}597 \\
564\end{array}$ & $\begin{array}{r}10 \\
5\end{array}$ & $\begin{array}{l}702 \\
710\end{array}$ & $706^{b}$ \\
\hline 0.03878 & 0.1969 & $\begin{array}{l}2.082 \\
2.928\end{array}$ & $\begin{array}{c}6240 \\
890^{\mathrm{a}}\end{array}$ & $\begin{array}{l}138 \\
190\end{array}$ & $\begin{array}{l}780 \\
727\end{array}$ & $\begin{array}{r}13 \\
7\end{array}$ & $\begin{array}{l}918 \\
917\end{array}$ & 917 \\
\hline 0.06339 & 0.2518 & $\begin{array}{l}2.661 \\
3.742\end{array}$ & $\begin{array}{l}5820 \\
460^{\mathrm{a}}\end{array}$ & $\begin{array}{l}174 \\
239\end{array}$ & $\begin{array}{l}892 \\
829\end{array}$ & $\begin{array}{l}6 \\
5\end{array}$ & $\begin{array}{l}1066 \\
1068\end{array}$ & 1067 \\
\hline 0.1143 & 0.3381 & $\begin{array}{l}3.571 \\
5.022\end{array}$ & $\begin{array}{l}5840 \\
140^{a}\end{array}$ & $\begin{array}{l}229 \\
311\end{array}$ & $\begin{array}{r}1051 \\
966\end{array}$ & $\begin{array}{l}1 \\
2\end{array}$ & $\begin{array}{l}1280 \\
1277\end{array}$ & 1279 \\
\hline 0.2508 & 0.5008 & $\begin{array}{l}5.285 \\
7.433\end{array}$ & $\begin{array}{c}5040 \\
70^{\mathrm{a}}\end{array}$ & $\begin{array}{l}325 \\
434\end{array}$ & $\begin{array}{l}1313 \\
1205\end{array}$ & $\begin{array}{l}4 \\
4\end{array}$ & $\begin{array}{l}1638 \\
1639\end{array}$ & 1639 \\
\hline
\end{tabular}

astandard deviation of $\overline{\mathrm{P}}_{1}$.

$b_{\text {This }}$ value was not used in the least square analysis. 


\section{1}

Table 13. Observed heats of dilution of aqueous terbium chloride solutions at $25^{\circ} \mathrm{C}$

\begin{tabular}{|c|c|c|c|c|c|c|}
\hline Run & $m_{1}$ & $\mathrm{n} \times 10^{4}$ & $m_{f}^{1 / 2} \times 10^{2}$ & $\begin{array}{c}-q \\
c a l\end{array}$ & $\begin{array}{c}\phi_{\mathrm{L}}\left(\mathrm{m}_{\mathrm{I}}\right) \\
\mathrm{cal} . / \mathrm{mole}\end{array}$ & $\begin{array}{c}\bar{\phi}_{\mathrm{L}}\left(\mathrm{m}_{\mathrm{l}}\right) \\
\mathrm{cal} . / \mathrm{mole} e\end{array}$ \\
\hline $\mathrm{D}_{19}$ & 0.1492 & $\begin{array}{l}22.062 \\
22.046^{*} \\
22.080 \\
22.103^{*}\end{array}$ & $\begin{array}{l}4.966 \\
7.002 \\
4.967 \\
7.008\end{array}$ & $\begin{array}{l}3.746 \\
3.291 \\
3.745 \\
3.291\end{array}$ & $\begin{array}{l}2006 \\
2.011 \\
2005 \\
2008\end{array}$ & $2007 \pm 2$ \\
\hline $\mathrm{D}_{22}$ & $\begin{array}{l}0.7544 \\
0.9855\end{array}$ & $\begin{array}{l}29.393 \\
29.31]^{*} \\
38.062 \\
37.744^{*}\end{array}$ & $\begin{array}{l}5.729 \\
8.079 \\
6.521 \\
9.183\end{array}$ & $\begin{array}{l}6.366 \\
5.671 \\
9.543 \\
8.465\end{array}$ & $\begin{array}{l}2515 \\
2522 \\
2896 \\
2894\end{array}$ & $\begin{array}{l}2518 \pm 4 \\
2895 \pm 1\end{array}$ \\
\hline$D_{31}$ & 1.139 & $\begin{array}{l}19.554 \\
18.309^{*}\end{array}$ & $\begin{array}{l}4.666 \\
6.486\end{array}$ & $\begin{array}{l}5.533 \\
4.832\end{array}$ & $\begin{array}{l}3121 \\
3129\end{array}$ & $3125+4$ \\
\hline$D_{30}$ & 1.588 & $\begin{array}{l}31.656 \\
31.728^{*}\end{array}$ & $\begin{array}{l}5.930 \\
5.937\end{array}$ & $\begin{array}{l}11.134 \\
11.118\end{array}$ & $\begin{array}{l}3876 \\
3863\end{array}$ & $3870 \pm 6$ \\
\hline$D_{23}$ & 1.694 & $\begin{array}{l}44.506 \\
43.481^{*}\end{array}$ & $\begin{array}{l}7.049 \\
9.895\end{array}$ & $\begin{array}{l}16.152 \\
14.569\end{array}$ & $\begin{array}{l}4044 \\
401+3\end{array}$ & $4045 \pm 1$ \\
\hline $\mathrm{D}_{24}$ & 1.694 & 16.066 & 4.227 & 6.073 & 4046 & \\
\hline$D_{S A}$ & 2.049 & $\begin{array}{l}19.609 \\
20.973^{*}\end{array}$ & $\begin{array}{l}4.671 \\
6.716\end{array}$ & $\begin{array}{l}8.594 \\
8.755\end{array}$ & $\begin{array}{l}4674 \\
167 \%\end{array}$ & 4674 \\
\hline $\mathrm{D}_{2 \mathrm{~A}}$ & 2.509 & $\begin{array}{l}15.006 \\
17.002^{*}\end{array}$ & $\begin{array}{l}4.085 \\
5.963\end{array}$ & $\begin{array}{l}7.961 \\
8.690\end{array}$ & $\begin{array}{l}5.563 \\
5563\end{array}$ & 5563 \\
\hline $\mathrm{D}_{3 \mathrm{~A}}$ & 2.932 & $\begin{array}{l}15.639 \\
17.174^{*}\end{array}$ & $\begin{array}{l}4.170 \\
6.038\end{array}$ & $\begin{array}{r}9.640 \\
10.273\end{array}$ & $\begin{array}{l}6427 \\
6439\end{array}$ & $6433+6$ \\
\hline $\mathrm{D}_{l_{+} \mathrm{A}}$ & 3.380 & $\begin{array}{l}12.156 \\
13.341^{*}\end{array}$ & $\begin{array}{l}3.676 \\
5.322\end{array}$ & $\begin{array}{l}8.72 .3 \\
9.393\end{array}$ & $\begin{array}{l}7411 \\
7452\end{array}$ & $7429 \pm 13$ \\
\hline$D_{6 \mathrm{~A}}$ & 3.380 & $\begin{array}{l}11.389 \\
11.981\end{array}$ & $\begin{array}{l}3.557 \\
5.095\end{array}$ & $\begin{array}{l}8.205 \\
8.4 .16\end{array}$ & $\begin{array}{l}7432 \\
7422\end{array}$ & \\
\hline$D_{r} / A$ & 3.571 & $\begin{array}{l}9.236 \\
9.179^{*}\end{array}$ & $\begin{array}{l}3.203 \\
4.522\end{array}$ & $\begin{array}{l}7.079 \\
6.872\end{array}$ & $\begin{array}{l}7871 \\
7847\end{array}$ & $7859 \pm 12$ \\
\hline
\end{tabular}


Table 14. Relative partial molal heat contents and relative partial molal excess entropies of aqueous terbium chloride solutions at $25^{\circ} \mathrm{C}$

\begin{tabular}{lcccc}
\hline Molality & $\begin{array}{c}-\overline{\mathrm{L}}_{1} \\
\text { cal./mole }\end{array}$ & $\begin{array}{c}\overline{\mathrm{L}}_{2} \\
\mathrm{cal} . / \mathrm{mole}\end{array}$ & $\begin{array}{c}-\mathrm{T}\left(\mathrm{S}_{1}-\mathrm{S}_{1}{ }^{\mathrm{O}}\right) \\
\mathrm{cal} . / \mathrm{mole}\end{array}$ & $\begin{array}{c}\mathrm{T}\left(\mathrm{S}_{2}-\mathrm{S}_{2}{ }^{\mathrm{O}}\right) \\
\mathrm{cal} . / \mathrm{mole}\end{array}$ \\
\hline 0.001 & 0.0017 & 297 & 0.034 & 854 \\
0.005 & 0.016 & 596 & 0.052 & 1677 \\
0.01 & 0.040 & 779 & 0.139 & 2165 \\
0.05 & 0.284 & 1308 & 0.749 & 3540 \\
0.1 & 0.659 & 1593 & 1.56 & 4189 \\
0.2 & 1.79 & 2014 & 3.34 & 4888 \\
0.5 & 7.66 & 2954 & 8.72 & 5846 \\
1.0 & 28.5 & 4491 & 18.1 & 6644 \\
1.5 & 67.9 & 6233 & 30.1 & 7256 \\
2.0 & 131 & 8234 & 48.5 & 7911 \\
2.5 & 223 & 10500 & 82.2 & 8811 \\
3.0 & 349 & 13040 & 140 & 10040 \\
3.5 & 514 & 15840 & 228 & 11610 \\
3.571 & 540 & 16260 & 244 & 11870 \\
\hline
\end{tabular}




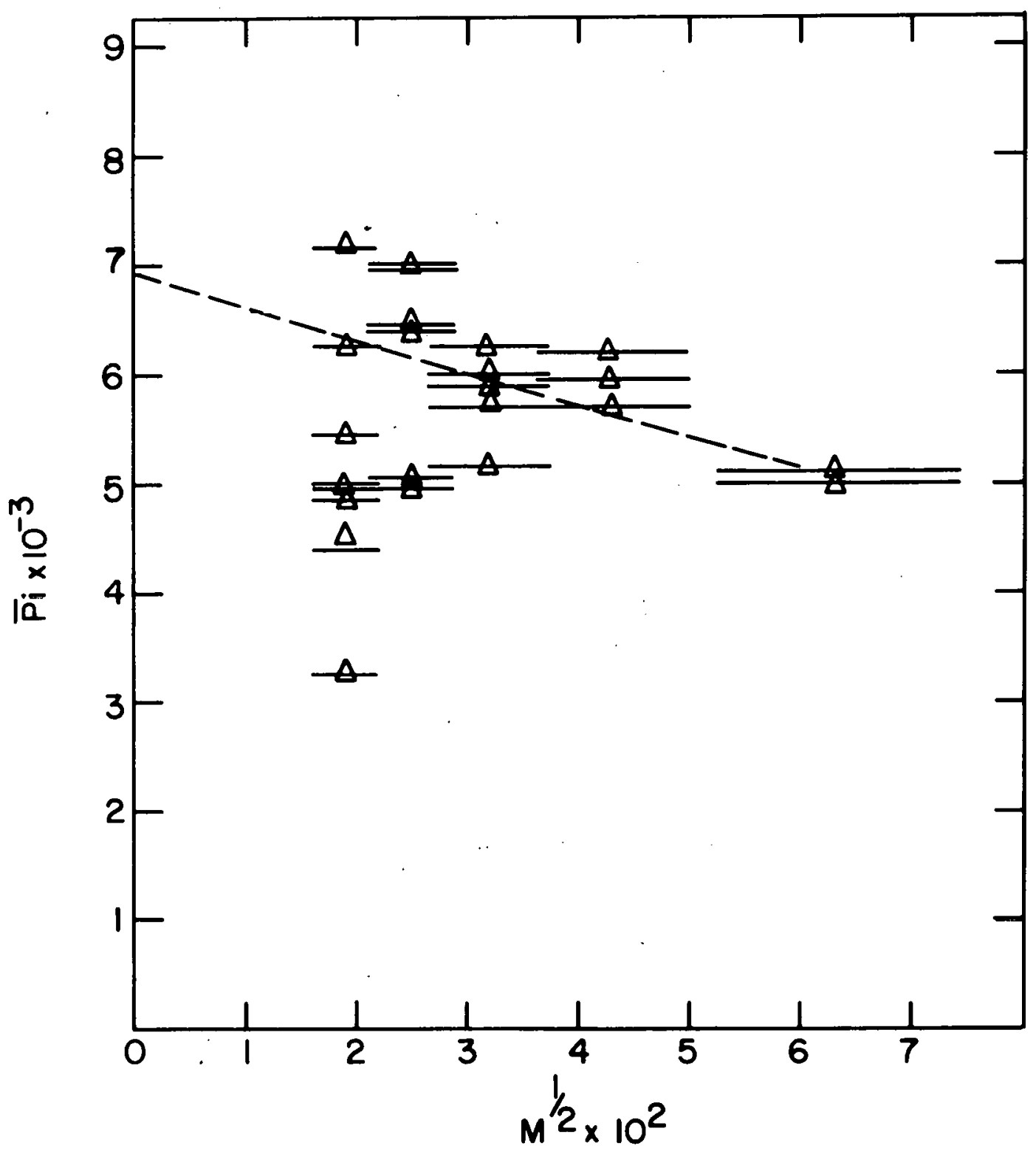

Figure 7. $F_{1}$ 's versus $m^{1 / 2}$ for terblum chloride solutions at $25^{\circ} \mathrm{C}$ 
$\overline{\mathrm{L}}_{1}=-61.90 \mathrm{~m}^{3 / 2}+271.00 \mathrm{~m}^{2}-567.34 \mathrm{~m}^{5 / 2}+382.31 \mathrm{~m}^{3} \quad(4.56)$

and

$\bar{L}_{2}=10,308 \mathrm{~m}^{1 / 2}-30,085 \mathrm{~m}+52,487 \mathrm{~m}^{3 / 2}-31,832 \mathrm{~m}^{2} \cdot(4.57)$

The equation for the $\emptyset_{L}$ data in the concentrated region given in Table 13 1s:

$\phi_{L}=532.3+2,444.0 \mathrm{~m}^{1 / 2}-855.6 \mathrm{~m}+709.2 \mathrm{~m}^{3 / 2}+77.11 \mathrm{~m}^{2}$.

The value of $\emptyset_{L}(0.2508)$ from Table 12 was also included with the $\bar{\emptyset}_{L}\left(m_{1}\right)$ values of Table 13 in the least squares analysis. Equation $4.58 \mathrm{fit}$ the data in the last column of Table 13 with a standard deviation of five cal./ mole from 0.2508 molal to saturation.

The equations for $\bar{L}_{1}$ and $\bar{L}_{2}$ derived from equation 4.29 are:

$\bar{L}_{1}=-22.015 \mathrm{~m}^{3 / 2}+15.414 \mathrm{~m}^{2}-19.163 \mathrm{~m}^{5 / 2}-2.778 \mathrm{~m}^{3}$

and

$$
\begin{aligned}
\bar{I}_{2}= & 532.3+3,666.1 \mathrm{~m}^{1 / 2}-1,711.2 \mathrm{~m}+1,772.9 \mathrm{~m}^{3 / 2} \\
+ & 231.32 \mathrm{~m}^{2} .
\end{aligned}
$$




$$
\text { Values of } \bar{L}_{1}, \bar{I}_{2}, T\left(\bar{S}_{1}-\bar{S}_{1}^{0}\right) \text { and } T\left(\bar{S}_{2}-\bar{S}_{2}^{\circ}\right) \text { for }
$$

$\mathrm{TbCl}_{3}$ solutions at rounded concentrations are given in. Table 14.

4. Holmium chloride

The data for aqueous holmium chloride solutions are presented in Tables 15 and 16.

The $\emptyset_{L}\left(m_{1}\right)$ values in the dilute concentration range were determined by Csejka ( 8 ). He gave the following equation for $\overline{\mathrm{P}}_{i}$ :

$$
\bar{P}_{1}=6806-22,629 x_{1}
$$

His data was reanalyzed using the theoretical value for the intercept to give

$$
\bar{P}_{i}=6925-25,870 x_{i}
$$

Integrating this equation gave

$$
\emptyset_{L}=6925 \mathrm{~m}^{1 / 2}-12,935 \mathrm{~m}
$$

which is valid for $m<0.0055$ molal.

Using his reanalyzed data the following equation was obtained for $\emptyset_{L}$ : 
Table 15. Observed heats of dilution of aqueous holmium chloride solutions at $25^{\circ} \mathrm{C}$

\begin{tabular}{|c|c|c|c|c|c|c|}
\hline Run & $m_{1}$ & $n \times 10^{4}$ & $\mathrm{~m}_{\mathrm{f}} \mathrm{J} \cdot \mathrm{2}_{\mathrm{x} 10^{2}}$ & $\begin{array}{c}-q \\
\text { cal. }\end{array}$ & $\begin{array}{c}\phi_{\mathrm{L}}\left(\mathrm{m}_{\mathrm{l}}\right) \\
\mathrm{cal} . ! \mathrm{mole}\end{array}$ & $\begin{array}{c}\bar{\phi}_{L}\left(m_{1}\right) \\
\text { cal./mole }\end{array}$ \\
\hline $\mathrm{C}_{2 \mathrm{~A}}$ & 0.5183 & 42.433 & 6.867 & 7.231 & 2119 & 2119 \\
\hline $\mathrm{C}_{1 \mathrm{~A}}$ & 0.8195 & $\begin{array}{l}31.199 \\
34.530^{*}\end{array}$ & $\begin{array}{l}5.904 \\
8.550\end{array}$ & $\begin{array}{l}6.999 \\
6.896\end{array}$ & $\begin{array}{l}2607 \\
2605\end{array}$ & $2606 \pm 1$ \\
\hline $\mathrm{C}_{2}$ & 1.013 & $\begin{array}{l}30.088 \\
29.952\end{array}$ & $\begin{array}{l}5.782 \\
5.768\end{array}$ & $\begin{array}{l}7.665 \\
7.648\end{array}$ & $\begin{array}{l}2905 \\
2909\end{array}$ & $2907 \pm 2$ \\
\hline $\mathrm{C}_{3}$ & 1.349 & $\begin{array}{l}40.065 \\
40.088\end{array}$ & $\begin{array}{l}6.673 \\
6.675\end{array}$ & $\begin{array}{l}12.10 \\
12.20\end{array}$ & $\begin{array}{l}3 / 26 \\
3448\end{array}$ & $3437 \pm 11$ \\
\hline$C_{4}$ & 1.685 & $\begin{array}{l}32.905 \\
32.860\end{array}$ & $\begin{array}{l}6.047 \\
6.042\end{array}$ & $\begin{array}{l}11.92 \\
11.88\end{array}$ & $\begin{array}{l}3994 \\
3986\end{array}$ & $3990+4$ \\
\hline $\mathrm{C}_{5}$ & 2.007 & $\begin{array}{l}38.241 \\
38.530\end{array}$ & $\begin{array}{l}6.519 \\
6.543\end{array}$ & $\begin{array}{l}15.87 \\
16.05\end{array}$ & $\begin{array}{l}4548 \\
4563\end{array}$ & $4556 \pm 8$ \\
\hline $\mathrm{C}_{6}$ & 2.365 & $\begin{array}{l}42.222 \\
41.799\end{array}$ & $\begin{array}{l}6.850 \\
6.816\end{array}$ & $\begin{array}{l}20.34 \\
20.09\end{array}$ & $\begin{array}{l}5232 \\
5219\end{array}$ & $5225 \pm 7$ \\
\hline$C_{7}$ & 2.669 & $\begin{array}{l}38.138 \\
39.733\end{array}$ & $\begin{array}{l}6.510 \\
6.594\end{array}$ & $\begin{array}{l}20.71 \\
21.29\end{array}$ & $\begin{array}{l}5827 \\
5840\end{array}$ & $5834 \pm 7$ \\
\hline $\mathrm{C}_{8}$ & 2.913 & $\begin{array}{l}39.871 \\
40.538\end{array}$ & $\begin{array}{l}6.656 \\
6.712\end{array}$ & $\begin{array}{l}23.72 \\
24.08\end{array}$ & $\begin{array}{l}6352 \\
6347\end{array}$ & $6349 \pm 3$ \\
\hline $\mathrm{C}_{9}$ & 3.323 & $\begin{array}{l}38.557 \\
36.314\end{array}$ & $\begin{array}{l}6.546 \\
6.352\end{array}$ & $\begin{array}{l}26.37 \\
24.95\end{array}$ & $\begin{array}{l}7238 \\
7258\end{array}$ & $7248 \pm 10$ \\
\hline $\mathrm{C}_{10}$ & 3.694 & $\begin{array}{l}43.306 \\
46.973\end{array}$ & $\begin{array}{l}6.938 \\
7.226\end{array}$ & $\begin{array}{l}32.91 \\
35.91\end{array}$ & $\begin{array}{l}8018^{a} \\
8078\end{array}$ & 8073 \\
\hline$c_{11}$ & 3.6914 & $\begin{array}{l}40.897 \\
40.914\end{array}$ & $\begin{array}{l}6.742 \\
6.743\end{array}$ & $\begin{array}{l}31.28 \\
31.41\end{array}$ & $\begin{array}{l}8056 \\
8086\end{array}$ & \\
\hline
\end{tabular}

${ }^{a}$ Rejected. 
Table 16. Relative partial molal heat contents and relative partial molal excess entropies of aqueous holmium chloride solutions at $25^{\circ} \mathrm{C}$

\begin{tabular}{lcccc}
\hline Molality & $\begin{array}{c}-\overline{\mathrm{I}}_{1} \\
\text { cal./mole }\end{array}$ & $\begin{array}{c}\overline{\mathrm{I}}_{2} \\
\text { cal./mole }\end{array}$ & $\begin{array}{c}-\mathrm{T}\left(\overline{\mathrm{S}}_{1}-\overline{\mathrm{S}}_{1}{ }^{0}\right) \\
\mathrm{cal} . / \mathrm{mole} e\end{array}$ & $\begin{array}{c}\mathrm{T}\left(\overline{\mathrm{S}}_{2}-\overline{\mathrm{S}}_{2}{ }^{0}\right) \\
\mathrm{cal} . / \mathrm{mole}\end{array}$ \\
\hline 0.001 & 0.0017 & 303 & 0.034 & 860 \\
0.005 & 0.016 & 597 & 0.052 & 1671 \\
0.01 & 0.039 & 772 & 0.138 & 2147 \\
0.05 & 0.281 & 1289 & 0.746 & 3483 \\
0.1 & 0.700 & 1606 & 1.60 & 4167 \\
0.2 & 1.73 & 2003 & 3.26 & 4833 \\
0.5 & 7.54 & 2935 & 8.40 & 5758 \\
1.0 & 27.8 & 4425 & 16.9 & 6488 \\
1.5 & 67.3 & 6169 & 28.1 & 7065 \\
2.0 & 131 & 8186 & 45.9 & 7701 \\
2.5 & 223 & 10450 & 76.8 & 8531 \\
3.0 & 347 & 12940 & 128 & 9630 \\
3.5 & 504 & 15630 & 204 & 11000 \\
3.694 & 575 & 16720 & 241 & 1590 \\
\hline & & & &
\end{tabular}


$\emptyset_{L}=7128 \mathrm{~m}^{1 / 2}-18,831 \mathrm{~m}+34,662 \mathrm{~m}^{3 / 2}-24,974 \mathrm{~m}^{2} \cdot(4.64)$

This equation fit his data with a standard deviation of one cal./mole from 0.0 molal to 0.2524 molal.

The equations for $\bar{L}_{1}$ and $\bar{L}_{2}$ derived from equation 4. 35 are:

$\bar{L}_{1}=-64.21 \mathrm{~m}^{3 / 2}+339.25 \mathrm{~m}^{2}-936.66 \mathrm{~m}^{5 / 2}+899.82 \mathrm{~m}^{3} \quad(4.65)$

and

$\bar{L}_{2}=10,693 m^{1 / 2}-37,663 m+86,654 m^{3 / 2}-74,922 m^{2} \cdot(4.66)$

The equation for the $\emptyset_{L}$ data given in Table 15 is

$$
\begin{aligned}
\emptyset_{L}= & 221.2+3,744.0 \mathrm{~m}^{1 / 2}-2,748.6 \mathrm{~m}+1,816.7 \mathrm{~m}^{3 / 2} \\
& -212.53 \mathrm{~m}^{2} .
\end{aligned}
$$

The value of $\emptyset_{L}(0.2524)$ equals $1632 \mathrm{cal} . / \mathrm{mole}$ was also included with the data from the last column of Table 15 in the least squares analysis. This equation fit the $\emptyset_{\mathrm{L}}$ data for $\mathrm{HoCl}_{3}$ solutions from 0.2524 molal to saturation with a standard deviation of seven cal./mole. The equations for $\bar{L}_{1}$ and $\overline{\mathrm{L}}_{2}$ derived from equation 
4.67 are:

$\bar{L}_{1}=-33.72 \mathrm{~m}^{3 / 2}+49.52 \mathrm{~m}^{2}-49.09 \mathrm{~m}^{5 / 2}+5.49 \mathrm{~m}^{3}$

and

$$
\begin{aligned}
\overline{\mathrm{L}}_{2}= & 221.2+5,616.0 \mathrm{~m}^{1 / 2}-5,497.1 \mathrm{~m}+4,541.7 \mathrm{~m}^{3 / 2} \\
& -457.24 \mathrm{~m}^{2} .
\end{aligned}
$$

Values of $\bar{L}_{1}, \bar{L}_{2}, T\left(\bar{S}_{1}-\bar{S}_{1}{ }^{0}\right)$ and $T\left(\bar{S}_{2}-\bar{S}_{2}^{\circ}\right)$ for $\mathrm{HoCl}_{3}$ solutions are given at rounded concentrations in Table 16.

\section{Ytterbium chloride}

The dala for aqueous ytterbium chloride solutions are presented in Tables 17, 18, 19, and 20, and a plot of $\overline{\mathrm{P}}_{i}$ versus $\mathrm{m}^{1 / 2}$ is given in Figure 8 .

Several weighted least square analyses of the $\bar{P}_{i}$ data presented in Table 18 were made. The following equations were obtained:

$$
\bar{P}_{i}=6925-30,350 x_{i}
$$

and

$$
\bar{P}_{i}=6470-22,550 x_{i}
$$


Table 17. Observed heats of dilution of dilute aqueous ytterbium chloride solutions at $25^{\circ} \mathrm{C}$

\begin{tabular}{|c|c|c|c|c|c|c|}
\hline Run & $\mathrm{n} \times 10^{4}$ & $\mathrm{~m}_{\mathrm{f}}^{1 ! 2} \times 10^{2}$ & $\begin{array}{c}-q \\
\text { cal. }\end{array}$ & $\begin{array}{l}-\Delta \mathrm{H}_{1}, 2 \\
\mathrm{cal} . / \mathrm{mole}\end{array}$ & $\begin{array}{l}-\Delta \mathrm{H}_{1}, 3 \\
\mathrm{cal} . / \mathrm{mole}\end{array}$ & $\overrightarrow{\mathrm{P}}_{i}$ \\
\hline $\begin{array}{l}A_{1} \\
0.02254\end{array}$ & $\begin{array}{l}2.243 \\
2.244^{*} \\
2.242 \\
2.242^{*}\end{array}$ & $\begin{array}{l}1.587 \\
2.233 \\
1.587 \\
2.232\end{array}$ & $\begin{array}{l}0.139 \\
0.126 \\
0.142 \\
0.134\end{array}$ & $\begin{array}{l}619 \\
634\end{array}$ & $\begin{array}{l}590 \\
617\end{array}$ & $\begin{array}{l}4600 \\
2710\end{array}$ \\
\hline $\begin{array}{l}\mathrm{A}_{10} \\
0.02254\end{array}$ & $\begin{array}{l}2.239 \\
2.233^{*} \\
2.239 \\
2.232^{*}\end{array}$ & $\begin{array}{l}1.585 \\
2.228 \\
1.585 \\
2.228\end{array}$ & $\begin{array}{l}0.142 \\
0.131 \\
0.152 \\
0.127\end{array}$ & $\begin{array}{r}633 \\
679\end{array}$ & $\begin{array}{l}609 \\
624\end{array}$ & $\begin{array}{l}3670 \\
8450\end{array}$ \\
\hline $\begin{array}{l}A_{19} \\
0.02235\end{array}$ & $\begin{array}{l}2.222 \\
2.223^{*} \\
2.224 \\
2.221\end{array}$ & $\begin{array}{l}1.579 \\
2.221 \\
1.580 \\
2.221\end{array}$ & $\begin{array}{l}0.137 \\
0.132 \\
0.135 \\
0.115\end{array}$ & $\begin{array}{l}618 \\
608\end{array}$ & $\begin{array}{l}607 \\
563\end{array}$ & $\begin{array}{l}1700 \\
7180\end{array}$ \\
\hline $\begin{array}{l}\mathrm{A}_{20} \\
0.02235\end{array}$ & $\begin{array}{l}2.216 \\
2.218^{*} \\
2.219 \\
2.217^{*}\end{array}$ & $\begin{array}{l}1.577 \\
2.219 \\
1.578 \\
2.219\end{array}$ & $\begin{array}{l}0.130 \\
0.123 \\
0.145 \\
0.123\end{array}$ & $\begin{array}{l}588 \\
652\end{array}$ & $\begin{array}{l}571 \\
603\end{array}$ & $\begin{array}{l}2500 \\
7600\end{array}$ \\
\hline $\begin{array}{l}A_{22} \\
0.022 .34\end{array}$ & $\begin{array}{l}2.227 \\
2.223^{*} \\
2.227 \\
2.223^{*}\end{array}$ & $\begin{array}{l}1.581 \\
2.223 \\
1.581 \\
2.223\end{array}$ & $\begin{array}{l}0.138 \\
0.131 \\
0.136 \\
0.128\end{array}$ & $\begin{array}{l}620 \\
616\end{array}$ & .595 & $\begin{array}{l}2110 \\
3200\end{array}$ \\
\hline $\begin{array}{l}\mathrm{A}_{23} \\
0.022 .34\end{array}$ & $\begin{array}{l}2.219 \\
2.214^{*} \\
2.214 \\
2.220^{*}\end{array}$ & $\begin{array}{l}1.578 \\
2.218 \\
1.577 \\
2.219\end{array}$ & $\begin{array}{l}0.145 \\
0.125 \\
0.136 \\
0.128\end{array}$ & $\begin{array}{l}652 \\
612\end{array}$ & $\begin{array}{l}607 \\
594\end{array}$ & $\begin{array}{l}7090 \\
2.930\end{array}$ \\
\hline $\begin{array}{l}\mathrm{A}_{2} \\
0.04334\end{array}$ & $\begin{array}{l}4.312 \\
4.092 \\
4.311 \\
4.308^{*}\end{array}$ & $\begin{array}{l}2.199 \\
3.054 \\
2.198 \\
3.093\end{array}$ & $\begin{array}{l}0.341 \\
0.295 \\
0.337 \\
0.307\end{array}$ & $\begin{array}{l}79.1 \\
783\end{array}$ & $\begin{array}{l}756 \\
749\end{array}$ & $\begin{array}{l}4000 \\
3710\end{array}$ \\
\hline${ }_{0}^{A_{8}} 84334$ & $\begin{array}{l}4.306 \\
4.303^{*} \\
4.304 \\
4.305^{*}\end{array}$ & $\begin{array}{l}2.199 \\
3.092 \\
2.198 \\
3.092\end{array}$ & $\begin{array}{l}0.343 \\
0.297 \\
0.340 \\
0.295\end{array}$ & $\begin{array}{l}797 \\
789\end{array}$ & $\begin{array}{l}744 \\
738\end{array}$ & 5770 \\
\hline
\end{tabular}


Table 1.7. (Continued)

\begin{tabular}{|c|c|c|c|c|c|c|}
\hline Run & $\mathrm{n} \times 10^{4}$ & $m_{f}^{1 / 2} \times 10^{2}$ & $\begin{array}{c}-q \\
\text { cal. }\end{array}$ & $\begin{array}{l}-\Delta \mathrm{H}_{1}, 2 \\
\text { cal. } 7 \text { mole }\end{array}$ & $\begin{array}{l}-\Delta \mathrm{H}_{1}, 3 \\
\text { cal. } / \text { mole }\end{array}$ & $\bar{P}_{i}$ \\
\hline $\begin{array}{l}A_{15} \\
0.04334\end{array}$ & $\begin{array}{l}4.301 \\
4.291^{*}\end{array}$ & $\begin{array}{l}2.197 \\
3.089\end{array}$ & $\begin{array}{l}0.349 \\
0.291\end{array}$ & 81.1 & 744 & 7480 \\
\hline $\begin{array}{l}A_{16} \\
0.04334 k\end{array}$ & $\begin{array}{l}4.299 \\
4.305^{*} \\
4.307 \\
4.289\end{array}$ & $\begin{array}{l}2.197 \\
3.091 \\
2.199 \\
3.089\end{array}$ & $\begin{array}{l}0.327 \\
0.292 \\
0.333 \\
0.293\end{array}$ & $\begin{array}{l}760 \\
774\end{array}$ & $\begin{array}{l}719 \\
730\end{array}$ & $\begin{array}{l}4550 . \\
5010\end{array}$ \\
\hline $\begin{array}{l}A_{3} \\
0.06346\end{array}$ & $\begin{array}{l}6.312 \\
6.305^{*} \\
6.312 \\
6.312^{*}\end{array}$ & $\begin{array}{l}2.662 \\
3.743 \\
2.661 \\
3.742\end{array}$ & $\begin{array}{l}0.549 \\
0.474 \\
0.555 \\
0.474\end{array}$ & $\begin{array}{l}870 \\
879\end{array}$ & $\begin{array}{l}811 \\
815\end{array}$ & $\begin{array}{l}5500 \\
5920\end{array}$ \\
\hline $\begin{array}{l}A 7 \\
0.06346\end{array}$ & $\begin{array}{l}6.310 \\
6.297^{*} \\
6.290 \\
6.291\end{array}$ & $\begin{array}{l}2.662 \\
3.7142 \\
2.658 \\
3.738\end{array}$ & $\begin{array}{l}0.552 \\
0.741 \\
0.550 \\
0.475\end{array}$ & $\begin{array}{l}875 \\
873\end{array}$ & 814 & $\begin{array}{l}5850 \\
5510\end{array}$ \\
\hline $\begin{array}{l}A_{17} \\
0.06,346\end{array}$ & $\begin{array}{l}6.293 \\
6.304^{*} \\
6.283 \\
6.287^{*}\end{array}$ & $\begin{array}{l}2.658 \\
3.740 \\
2.656 \\
3.736\end{array}$ & $\begin{array}{l}0.552 \\
0.472 \\
0.549 \\
0.468\end{array}$ & $\begin{array}{l}877 \\
874\end{array}$ & $\begin{array}{l}813 \\
809\end{array}$ & $\begin{array}{l}5980 \\
6010\end{array}$ \\
\hline${ }_{0}^{A_{6}}{ }_{0.1353}$ & $\begin{array}{l}13.438 \\
13.425^{*} \\
13.421 \\
13.42 .1\end{array}$ & $\begin{array}{l}3.885 \\
5.463 \\
3.883 \\
5.461\end{array}$ & $\begin{array}{l}1.471 \\
1.209 \\
1.435 \\
1.185\end{array}$ & $\begin{array}{l}1095 \\
1069\end{array}$ & $\begin{array}{l}998 \\
976\end{array}$ & $\begin{array}{l}6160 \\
5910\end{array}$ \\
\hline $\begin{array}{l}A_{12} \\
0.1353\end{array}$ & $\begin{array}{l}13.430 \\
13.412^{*} \\
13.434 \\
13.430^{*}\end{array}$ & $\begin{array}{l}3.884 \\
5.461 \\
3.885 \\
5.463\end{array}$ & $\begin{array}{l}1.451 \\
1.210 \\
1.439 \\
1.216\end{array}$ & $\begin{array}{l}1080 \\
1071\end{array}$ & $\begin{array}{l}991 \\
988\end{array}$ & $\begin{array}{l}5640 \\
5240\end{array}$ \\
\hline $\begin{array}{l}{ }^{A} 9 \\
0.2535\end{array}$ & $\begin{array}{l}25.095 \\
25.078^{*}\end{array}$ & $\begin{array}{l}5.311 \\
7.468\end{array}$ & $\begin{array}{l}3.239 \\
2.6911\end{array}$ & 1291 & 1182 & .5050 \\
\hline $\begin{array}{l}{ }^{A} 13 \\
0.2535\end{array}$ & $\begin{array}{l}25.039 \\
25.090 \\
25.127 \\
25.074\end{array}$ & $\begin{array}{l}5.305 \\
7.465 \\
5.314 \\
7.470\end{array}$ & $\begin{array}{l}3.212 \\
2.689 \\
3.235 \\
2.680\end{array}$ & $\begin{array}{l}12.83 \\
1288\end{array}$ & $\begin{array}{l}1177 \\
1178\end{array}$ & $\begin{array}{l}4900 \\
5070\end{array}$ \\
\hline
\end{tabular}


Table 18. Short chord data and relative apparent molal heat contents of dilute aqueous ytterbium chloride solutions at $25^{\circ} \mathrm{C}$

\begin{tabular}{|c|c|c|c|c|c|c|c|c|}
\hline$m_{1}$ & $m_{1}^{1 / 2}$ & $\begin{array}{l}m_{f}^{1 / 2} \\
\times 10^{2}\end{array}$ & $\bar{P}_{1}$ & $\begin{array}{l}\emptyset_{\mathrm{L}}\left(\mathrm{m}_{\mathrm{f}}\right) \\
\text { cal./ } \\
\text { mole }\end{array}$ & $\begin{array}{l}-\Delta \mathrm{H}_{1}, \mathrm{f} \\
\mathrm{cal} . j \\
\text { mole }\end{array}$ & $\begin{array}{c}\text { Std. } \\
\text { dev. } \\
\text { cal./mole }\end{array}$ & $\begin{array}{l}\emptyset_{\mathrm{L}}\left(\mathrm{m}_{1}\right) \\
\mathrm{cal} \cdot / \\
\text { mole }\end{array}$ & $\begin{array}{l}\bar{\phi}_{L}\left(m_{1}\right) \\
\text { cal.l } \\
\text { mole }\end{array}$ \\
\hline 0.02241 & 0.1497 & $\begin{array}{l}1.581 \\
2.224\end{array}$ & $\begin{array}{l}4780 \\
2450^{\circ}\end{array}$ & $\begin{array}{l}106 \\
147\end{array}$ & $\begin{array}{l}628 \\
599\end{array}$ & $\begin{array}{l}24 \\
18\end{array}$ & $\begin{array}{l}734 \\
746\end{array}$ & 740 \\
\hline 0.04334 & 0.2082 & $\begin{array}{l}2.198 \\
3.087\end{array}$ & $\begin{array}{l}5210 \\
1300^{\mathrm{a}}\end{array}$ & $\begin{array}{l}145 \\
199\end{array}$ & $\begin{array}{l}786 \\
740\end{array}$ & $\begin{array}{l}16 \\
12\end{array}$ & $\begin{array}{l}931 \\
939\end{array}$ & 935 \\
\hline 0.06346 & 0.2519 & $\begin{array}{l}2.659 \\
3.740\end{array}$ & $\begin{array}{c}5890 \\
230^{\mathrm{a}}\end{array}$ & $\begin{array}{l}173 \\
238\end{array}$ & $\begin{array}{l}875 \\
812\end{array}$ & $\begin{array}{l}3 \\
2\end{array}$ & $\begin{array}{l}1048 \\
1050\end{array}$ & 1049 \\
\hline 0.1353 & 0.3679 & $\begin{array}{l}3.884 \\
5.462\end{array}$ & $\begin{array}{c}5740 \\
390^{\mathrm{a}}\end{array}$ & $\begin{array}{l}246 \\
333\end{array}$ & $\begin{array}{r}1079 \\
988\end{array}$ & $\begin{array}{r}12 \\
9\end{array}$ & $\begin{array}{l}1325 \\
1321\end{array}$ & 1323 \\
\hline 0.2535 & 0.5035 & $\begin{array}{l}5.310 \\
7.467\end{array}$ & $\begin{array}{c}5010 \\
90^{a}\end{array}$ & $\begin{array}{l}323 \\
432\end{array}$ & $\begin{array}{l}1287 \\
1179\end{array}$ & $\begin{array}{l}4 \\
3\end{array}$ & $\begin{array}{l}1610 \\
1611\end{array}$ & 1611 \\
\hline
\end{tabular}

${ }^{a}$ Standard deviation of $\overline{\mathrm{P}}_{1}$. 
Table 19. Observed heats of dilution of aqueous ytterbium chloride solutions at $25^{\circ} \mathrm{C}$

\begin{tabular}{|c|c|c|c|c|c|c|}
\hline Run & $m_{1}$ & $\mathrm{n} \times 10^{4}$ & $m_{f}{ }^{1 / 2} \times 10^{2}$ & $\begin{array}{c}-q \\
\text { cal。 }\end{array}$ & $\begin{array}{c}\emptyset_{\mathrm{L}}\left(\mathrm{m}_{1}\right) \\
\text { cal.! mole }\end{array}$ & $\begin{array}{c}\bar{D}_{L}\left(m_{1}\right) \\
\text { cal./mole }\end{array}$ \\
\hline $\mathrm{K}_{1}$ & 0.3875 & 25.276 & 6.261 & 5.289 & 1873 & 1873 \\
\hline $\mathrm{K}_{2}$ & 0.4975 & 35.421 & 6.274 & 5.948 & 2054 & 2054 \\
\hline $\mathrm{K}_{16}$ & 0.6567 & 35.774 & 6.305 & 6.896 & 2.304 & 2304 \\
\hline$K_{4}$ & 0.7944 & $\begin{array}{l}29.386 \\
29.559^{*}\end{array}$ & $\begin{array}{l}5.728 \\
8.096\end{array}$ & $\begin{array}{l}6.362 \\
5.705\end{array}$ & $\begin{array}{l}2512 \\
2509\end{array}$ & $2511 \pm 2$ \\
\hline$k_{5}$ & 1.005 & $\begin{array}{l}28.077 \\
28.615^{*}\end{array}$ & $\begin{array}{l}5.596 \\
7.939\end{array}$ & $\begin{array}{l}6.969 \\
6.431\end{array}$ & $\begin{array}{l}2822 \\
2818\end{array}$ & 2820 \\
\hline$k_{6}$ & 1.206 & $\begin{array}{l}23.117 \\
24.354^{*}\end{array}$ & $\begin{array}{l}5.075 \\
7.264\end{array}$ & $\begin{array}{l}6.489 \\
6.294\end{array}$ & $\begin{array}{l}3119 \\
3118\end{array}$ & $311.9 \pm 1$ \\
\hline $\mathrm{K}_{7}$ & 1.445 & $\begin{array}{l}23.882 \\
23.323^{*}\end{array}$ & $\begin{array}{l}5.257 \\
7.244\end{array}$ & $\begin{array}{l}7.567 \\
6.878\end{array}$ & $\begin{array}{l}3485 \\
3484\end{array}$ & $3485 \pm 1$ \\
\hline$k_{8}$ & 1.667 & $\begin{array}{l}21.155 \\
23.779\end{array}$ & $\begin{array}{l}4.850 \\
7.063\end{array}$ & $\begin{array}{l}7.474 \\
7.884\end{array}$ & $\begin{array}{l}3833 \\
3835\end{array}$ & $3834 \pm 1$ \\
\hline $\mathrm{k}_{9}$ & 1.920 & 15.986 & 4.217 & 6.348 & 4236 & $42.43 \pm 7$ \\
\hline$K_{18}$ & 1,9200 & 16.186 & 4.241 & 6.448 & 4250 & \\
\hline$k_{10}$ & 2.176 & $\begin{array}{l}15.287 \\
14.441\end{array}$ & $\begin{array}{l}4.123 \\
5.747\end{array}$ & $\begin{array}{l}6.766 \\
6.124\end{array}$ & $\begin{array}{l}4686 \\
4690\end{array}$ & $4688 \pm 2$ \\
\hline $\mathrm{K}_{11 \mathrm{~A}}$ & 2.558 & $\begin{array}{l}16.304 \\
17.309^{\star}\end{array}$ & $\begin{array}{l}4.258 \\
6.112\end{array}$ & $\begin{array}{l}8.331 \\
8.541\end{array}$ & $\begin{array}{l}5377 \\
5388\end{array}$ & $5383+6$ \\
\hline $\mathrm{K}_{12}$ & 2.881 & $\begin{array}{l}15.802 \\
16.297^{*}\end{array}$ & $\begin{array}{l}4.192 \\
5.972\end{array}$ & $\begin{array}{l}9.076 \\
9.063\end{array}$ & $\begin{array}{l}6007 \\
6021\end{array}$ & $6014 \pm 7$ \\
\hline$K_{14}$ & 3.204 & $\begin{array}{l}11.815 \\
11.065^{*}\end{array}$ & $\begin{array}{l}3.623 \\
5.041\end{array}$ & $\begin{array}{l}7.61 .5 \\
6.936\end{array}$ & $\begin{array}{l}6676 \\
6671\end{array}$ & $6673 \pm 3$ \\
\hline$K_{13}$ & 3.515 & 10.318 & 3.386 & 7.341 & 7332 & $7320 \pm 12$ \\
\hline $\mathrm{K}_{15}$ & 3.515 & 9.924 & 3.302 & 7.042 & 7308 & \\
\hline$K_{19}$ & 4.003 & $\begin{array}{c}9.170 \\
10.006\end{array}$ & $\begin{array}{l}3.192 \\
4.615\end{array}$ & $\begin{array}{l}7.49 / 4 \\
8.023\end{array}$ & $\begin{array}{l}8378 \\
8383\end{array}$ & $8381 \pm 3$ \\
\hline
\end{tabular}


Table 20. Relative partial molal heat contents and relative partial molal excess entropies of aqueous ytterbium chloride solutions at $25^{\circ} \mathrm{C}$

\begin{tabular}{|c|c|c|c|c|}
\hline Molality & $\begin{array}{c}-\overline{\mathrm{L}}_{1} \\
\mathrm{cal} \cdot / \mathrm{mole}\end{array}$ & $\begin{array}{c}\overline{\mathrm{L}}_{2} \\
\mathrm{cal} . / \mathrm{mole}\end{array}$ & $\begin{array}{l}-\mathrm{T}\left(\bar{S}_{1}-\bar{S}_{1}{ }^{\circ}\right) \\
\text { cal./mole }\end{array}$ & $\begin{array}{l}\mathrm{T}\left(\bar{S}_{2}-\bar{S}_{2}{ }^{o}\right)^{a} \\
\mathrm{cal} \cdot / \mathrm{mole}\end{array}$ \\
\hline 0.001 & 0.0017 & 295 & 0.034 & 852 \\
\hline 0.005 & 0.0157 & 588 & 0.052 & 1668 \\
\hline 0.01 & 0.0391 & 766 & 0.138 & 2152 \\
\hline 0.05 & 0.279 & 1283 & 0.744 & 3542 \\
\hline 0.1 & 0.661 & 1573 & 1.59 & 4183 \\
\hline 0.2 & 1.70 & 1966 & 3.25 & 4842 \\
\hline 0.5 & 7.26 & 2870 & 8.14 & 5738 \\
\hline 1.0 & 26.4 & 4276 & 15.2 & 6362 \\
\hline 1.5 & 63.7 & 5922 & $24 \cdot 3$ & 6844 \\
\hline 2.0 & 124 & 7821 & 36.2 & 7329 \\
\hline 2.5 & 210 & $99 / 1.1 .1$. & 59.5 & 7968 \\
\hline 3.0 & 325 & 12260 & 99.6 & 8863 \\
\hline 3.5 & 470 & 14730 & 157 & 9984 \\
\hline 4.003 & 648 & 17360 & 236 & \\
\hline
\end{tabular}

Equations 4.71 and 4.70 are shown in Figure 8 by the solid Ine and dotted line respectively. 


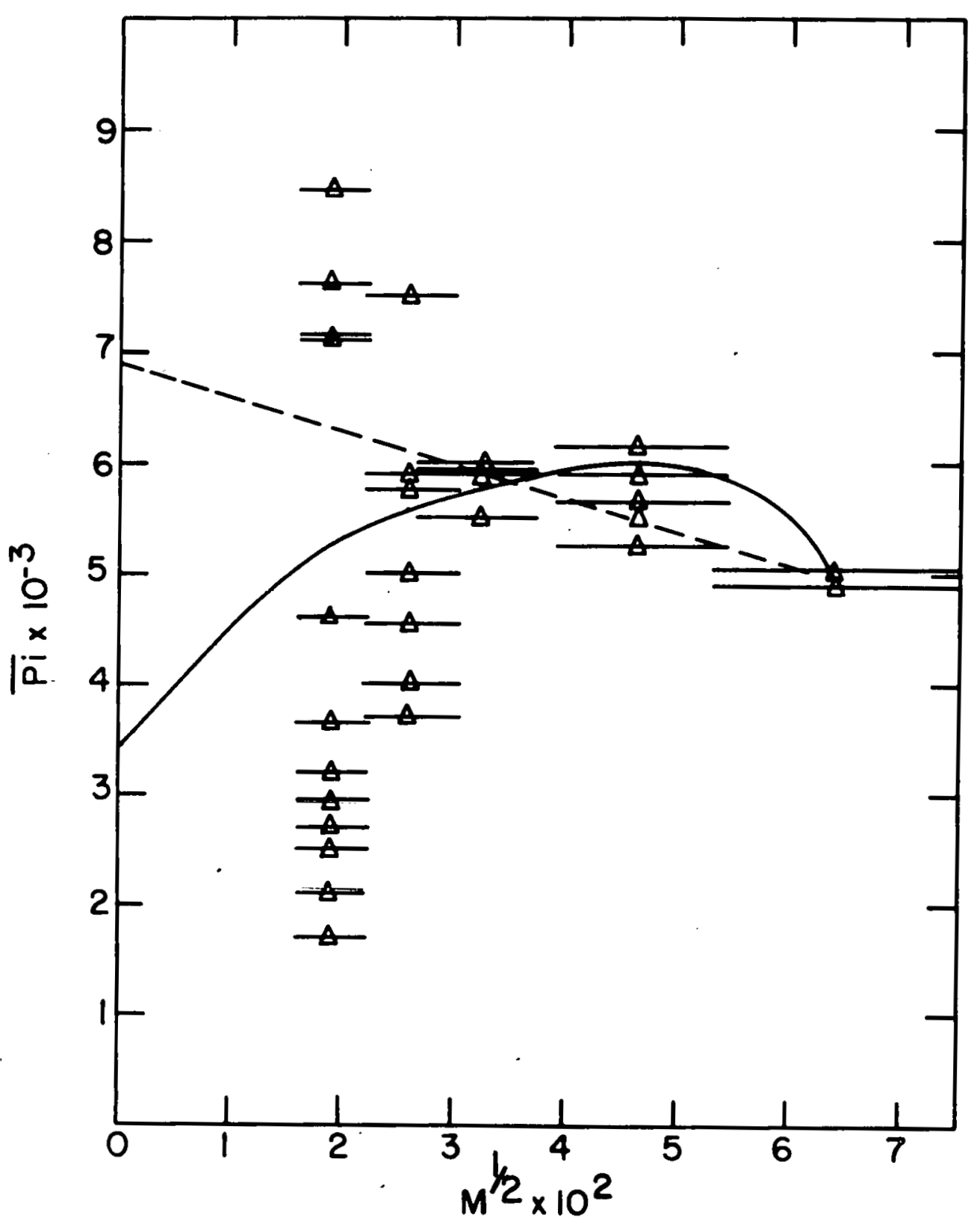

Figure 8. $\bar{P}_{1}^{\prime}$ 's versus $\mathrm{m}^{1 / 2}$ for ytterbium chloride solutions at $25^{\circ} \mathrm{C}$ 
Equations 4.70 and 4.71 were integrated to give

$\emptyset_{L}=6925 \mathrm{~m}^{1 / 2}-15.175 \mathrm{~m}$

$$
\phi_{L}=3409 \mathrm{~m}^{1 / 2}+.6251 \times 10^{5} \mathrm{~m}-.5219 \times 10^{6} \mathrm{~m}^{3 / 2}
$$

However, a better fit of $\emptyset_{L}\left(m_{1}\right)$ over the entire concentration range was obtained when equation 4.72 was used to calculate $\emptyset_{L}\left(m_{f}\right)$.

The equation obtalned for the concentration range from zero molal to 0.25 molal was

$$
\emptyset_{L}=6859 m^{1 / 2}-16,098 m+25,379 m^{3 / 2}-15,585 m^{2} \cdot(4.74)
$$

This equation fit the data given in Table 18 with a standard deviation of two cal./mole from 0.0 molal to 0.2535 molal. Eberts (10) has also determined the heats of dilution of aqueous $\mathrm{YbCl}_{3}$ solutions. He obtalned the following equation from his $P_{i}$ data:

$\bar{p}_{i}=246.5+2.0287 \times 10^{5} x_{i}-2.2143 \times 10^{6}\left(x_{i}^{2}+\frac{8_{j}^{2}}{12}\right) \quad(4.75)$

which was integrated to give

$$
\emptyset_{L}=246.5 \mathrm{~m}^{1 / 2}+1.045 \times 10^{5} \mathrm{~m}-0.7381 \times 10^{6} \mathrm{~m}^{3 / 2}
$$


If his data are analyzed using equation 4.72 to calculate $\emptyset_{L}\left(m_{f}\right)$, his values for $\emptyset_{L}\left(m_{l}\right)$ are in good agreement with those obtained in this research. A comparison of the two sets of data is given in Figure 9.

The equations for $\bar{L}_{1}$ and $\bar{L}_{2}$ derived from equation 4.74 are:

$$
\bar{I}_{1}=-61.78 \mathrm{~m}^{3 / 2}+290.01 \mathrm{~m}^{2}-685.81 \mathrm{~m}^{5 / 2}+561.53 \mathrm{~m}^{3}(4.77)
$$

and

$$
\overline{\mathrm{L}}_{2}=10,288 \mathrm{~m}^{1 / 2}-32,196 \mathrm{~m}+63,447 \mathrm{~m}^{3 / 2}-46,755 \mathrm{~m}^{2} \cdot(4 \cdot 78)
$$

The equation for the $\emptyset_{L}$ data given in Table 19 is:

$$
\begin{aligned}
\emptyset_{L}= & 159.9+3,957.9 \mathrm{~m}^{1 / 2}-3100.0 \mathrm{~m}+7, .997 .4 \mathrm{~m}^{3 / 2} \\
& -204.87 \mathrm{~m}^{2} .
\end{aligned}
$$

The equations for $\bar{L}_{1}$ and $\bar{L}_{2}$ derived from equation 4.79 are:

$$
\bar{L}_{1}=-35.65 \mathrm{~m}^{3 / 2}+55.84 \mathrm{~m}^{2}-53.97 \mathrm{~m}^{5 / 2}+7.38 \mathrm{~m}^{3}
$$

and 


$$
\begin{aligned}
\bar{I}_{2}= & 159.9+5,936.9 \mathrm{~m}^{1 / 2}-6200.0 \mathrm{~m}+4,993.4 \mathrm{~m}^{3 / 2} \\
& -614.6 \mathrm{~m}^{2} .
\end{aligned}
$$

The value of $\emptyset_{L}(0.2535)$ from Table 18 was included with the $\emptyset_{L}\left(m_{1}\right)$ values in Table 19 for the least squares analysis. This equation fit the data in the last column of Table 19 with a standard deviation of five cal./mole from 0.2535 molal to saturation.

$$
\text { Values of } \bar{L}_{1}, \bar{L}_{2}, T\left(\bar{S}_{1}-\bar{S}_{1}{ }^{\circ}\right) \text { and } T\left(\bar{S}_{2}-\bar{S}_{2}{ }^{\circ}\right) \text { for }
$$

$\mathrm{YbCl}_{3}$ solutions are given at rounded concentrations in Table 20. The activity coefficients for $\mathrm{YbCl}_{3}$ were not available at the time of writing. However, enough osmotic coefficients were avallable ${ }^{l}$ to calculate the activity of water at some concentrations. The values at rounded concentrations were obtained by extrapolation. The avallable osmotic coefficients indicated that the activity of aqueous $\mathrm{YbCl}_{3}$ solutions would be nearly that of aqueous $\mathrm{YCl}_{3}$ solutions as determined by Petheram $(52)$. Hence, the values of $\mathrm{YCl}_{3}$, were used in calculating the $\mathrm{T}\left(\overline{\mathrm{S}}_{2}-\overline{\mathrm{S}}_{2}{ }^{\circ}\right)$ values for aqueous $\mathrm{YbCl}_{3}$ solutions.

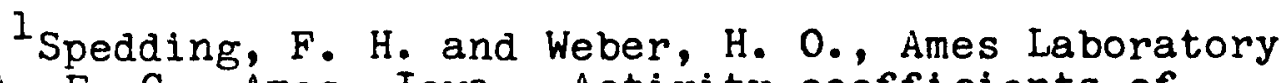
of the A. E. C., Ames, Iowa. Activity coefficients of some aqueous rare-earth chloride solutions. Private communication. 1964. 


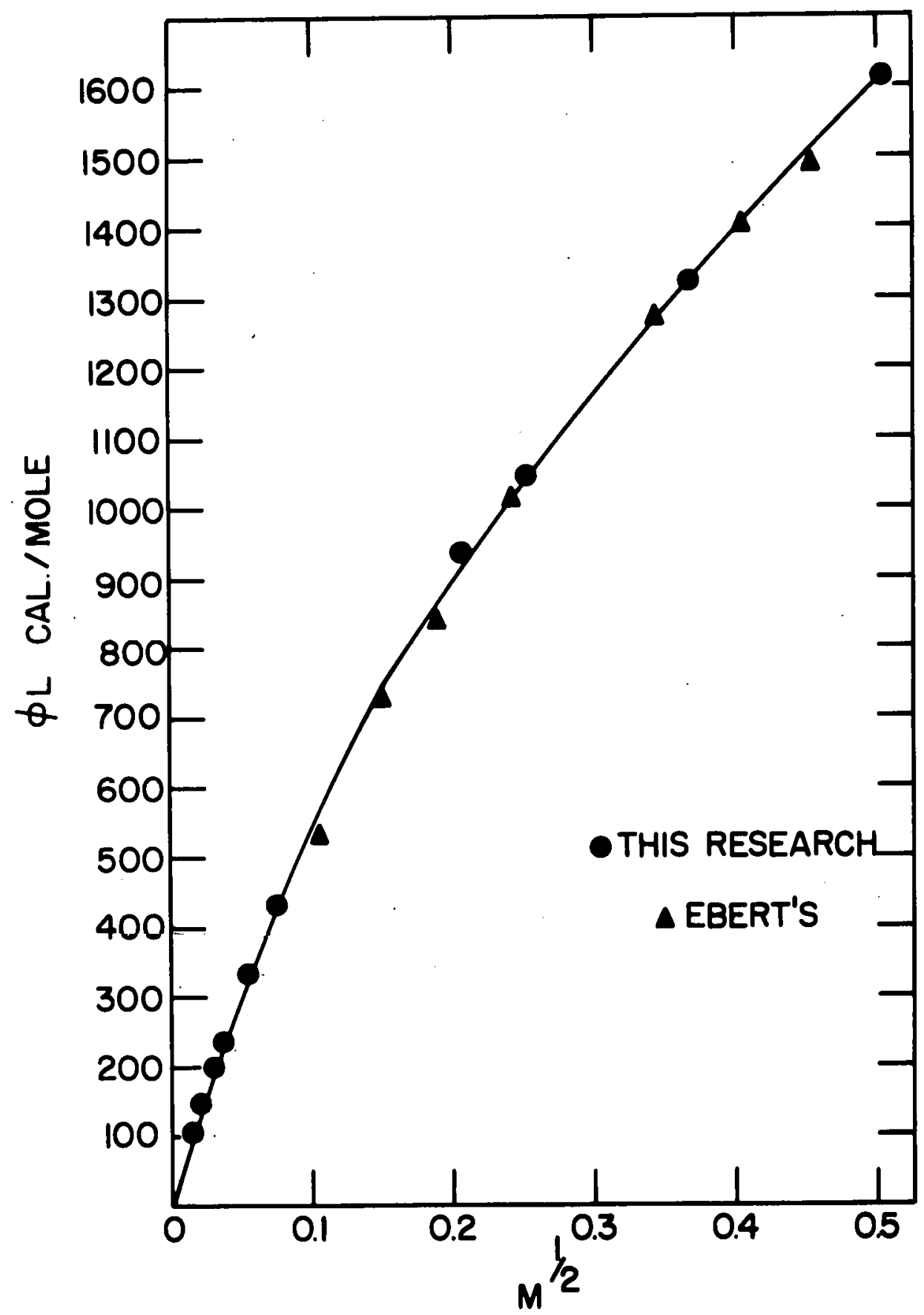

Figure 9. Relative apparent molal heat contents of ytterbium chloride solutions at $25^{\circ} \mathrm{C}$ 
G. Heats of Solution of Terbium Chloride Hexahydrate and Holmium Chloride Hexahydrate

The heats of solution of $\mathrm{TbCl}_{3} \cdot 6 \mathrm{H}_{2} \mathrm{O}$ and $\mathrm{HoCl}_{3} \cdot 6 \mathrm{H}_{2} \mathrm{O}$ are presented in Tables 21 and 22. Equations 4.54 and 4.63 were used to calculate $\emptyset_{\mathrm{L}}\left(\mathrm{m}_{\mathrm{f}}\right)$ for $\mathrm{TbCl}_{3}$ and $\mathrm{HoCl}_{3}$ respectively $\cdot \overline{\mathrm{I}}_{2} \cdot$ is the relative partial molal heat content of the rare-earth chloride hexahydrate which is equal in magnitude and opposite in sign to the heat of solution at infinite dilution. The number of moles present in the sample is denoted by $n$, and $m_{f}$ is the final molality. The amount of heat, $q$, is given in defined calories.

Table 21. Observed heats of solution of terbium chloride hexahydrate in water at $25^{\circ} \mathrm{C}$.

\begin{tabular}{|c|c|c|c|c|}
\hline Run & $n \times 10^{4}$ & $m_{f}^{1 / 2} \times 10^{2}$ & $\begin{array}{l}-q \\
\text { cal. }\end{array}$ & $\begin{array}{c}\overline{\mathrm{L}}_{2} \\
\text { cal./mole }\end{array}$ \\
\hline $\mathrm{T}_{1}$ & $\begin{array}{l}9.21 \\
9.16_{9}^{2}\end{array}$ & $\begin{array}{l}3.199 \\
4.518\end{array}$ & $\begin{array}{l}8.654 \\
8.405\end{array}$ & $\begin{array}{l}960_{1} \\
9526\end{array}$ \\
\hline $\mathrm{T}_{2}$ & $\begin{array}{l}8.292 \\
7.770^{*}\end{array}$ & $\begin{array}{l}3.035 \\
4.223\end{array}$ & $\begin{array}{l}7.752 \\
7.118\end{array}$ & $\begin{array}{l}9545 \\
950_{1}\end{array}$ \\
\hline $\mathrm{T}_{4}$ & $\begin{array}{l}8.908 \\
9.143^{*}\end{array}$ & $\begin{array}{l}3.145 \\
4.477\end{array}$ & $\begin{array}{l}8.305 \\
8.415\end{array}$ & $\begin{array}{l}9526 \\
9560\end{array}$ \\
\hline $\mathrm{T}_{5}$ & $\begin{array}{l}12.25 \\
14.26\end{array}$ & $\begin{array}{l}3.670 \\
5.398\end{array}$ & $\begin{array}{l}11.44 \\
13.13\end{array}$ & $\begin{array}{l}9568 \\
9616\end{array}$ \\
\hline \multirow[t]{2}{*}{$\mathrm{T}_{6}$} & $\begin{array}{l}10.19 \\
14.14^{*}\end{array}$ & $\begin{array}{l}3.365 \\
5.199\end{array}$ & $\begin{array}{l}9.486 \\
13.00\end{array}$ & $\begin{array}{l}9525 \\
9589\end{array}$ \\
\hline & \multicolumn{3}{|c|}{$\begin{array}{r}\text { Average } \\
\text { Standard deviation }\end{array}$} & $\begin{array}{r}=9556 \\
=32\end{array}$ \\
\hline
\end{tabular}


Table 22. Observed heats of solution of holmium chloride hexahydrate in water at $25^{\circ} \mathrm{C}$

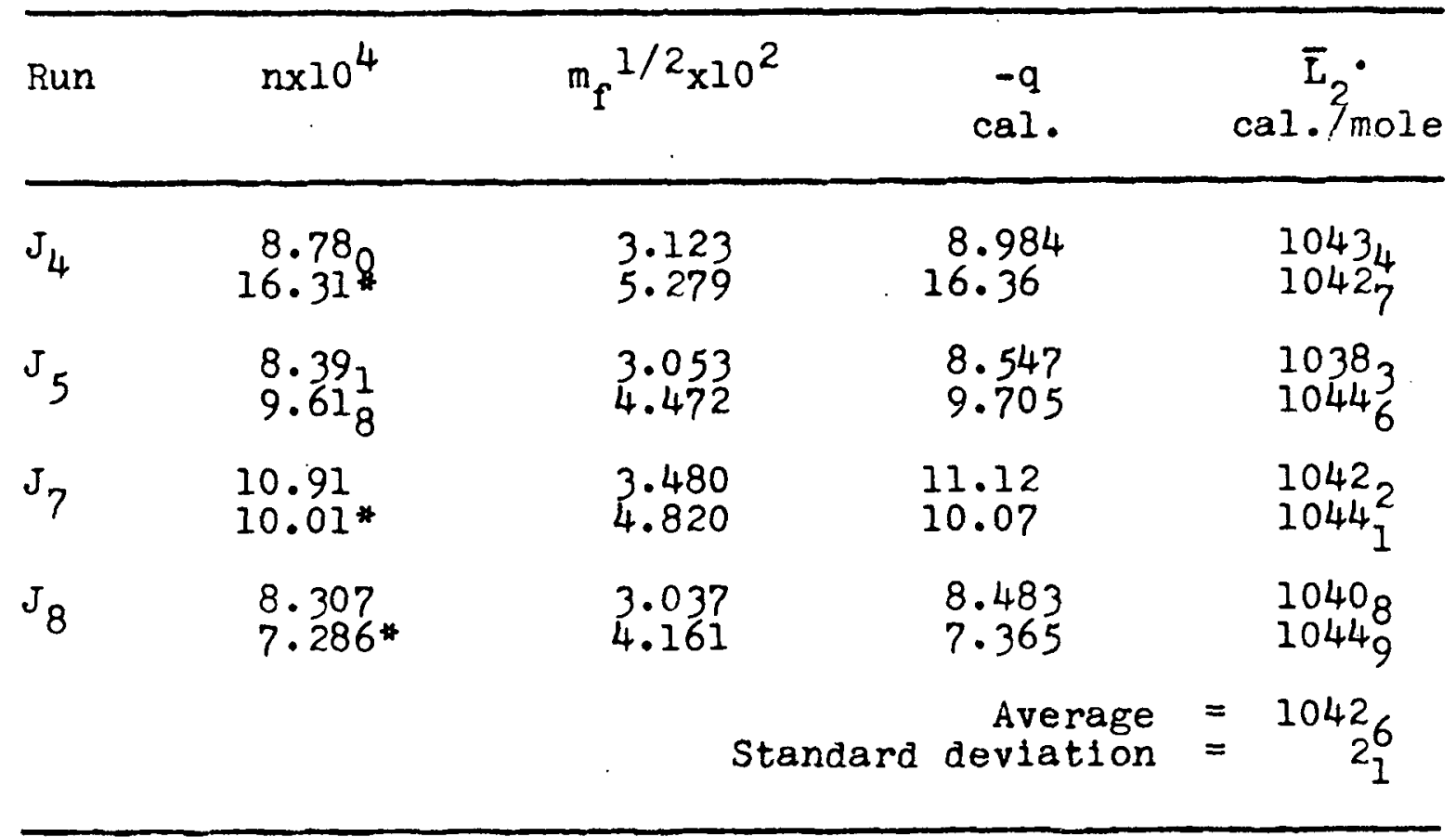

H. Error Analysis

The error in the heat evolved for all allution experiments is estimated to be \pm 0.2 per cent of the total heat or \pm 0.01 calorie whichever is larger. This estimate is based on the precision of the data and the accuracy of the value for the heat of ionization of water. The accuracy of the solution analyses is estimated to be 0.1 per cent which gives a total accuracy of 0.3 per cent for the $\Delta \mathrm{H}_{1, \mathrm{f}}$ values. In general the error in the electrical heat contributed less than 0.05 per cent to the total error 
in $\Delta \mathrm{H}_{1, f^{\circ}}$ The remaining errors were random errors arising from slope changes and heats of opening.

In order to estimate the accuracy of the relative apparent molal heat contents it is necessary to know the accuracy of the $\overline{\mathrm{P}}_{\mathfrak{i}}$ equation. This was calculated from the method of propagation of errors and from the accuracy of the least squares coefficients as described by Worthing and Geffner $(80)$. The method of propagation of errors states that if $u$ is a function of $n$ independent measurable quantities $x_{1}, x_{2}, \ldots x_{n}$, then the probable error in the average value of $u$ is estimated by

$$
\left(P_{\bar{u}}\right)^{2}=\sum_{i=1}^{n}\left(\frac{\partial u}{\partial x_{i}}\right)^{2}\left(P_{\bar{x}_{i}}\right)^{2}
$$

where $P_{\bar{u}}$ is the probable error in $\bar{u}$, the average value of $u$; and $\mathrm{P}_{\bar{x}_{i}}$ is the probable error in $\bar{x}_{i}$, the average value of $x_{1}$. The probable errors were calculated for the first and second coefficients of the $\bar{P}_{i}$ equations and were found to be approximately 400 for $S^{\circ}$ and 5000 for B. Since the theoretical slope was used for $S^{\circ}$, only the error in $B$ is significant. This would give an error of about 10 to 15 cal./mole in the extrapolation of $\phi_{L}$ to infinite dilution. The errors in the partial molal quantities, $\overline{\mathrm{L}}_{1}, \overline{\mathrm{L}}_{2}$, $\mathrm{T}\left(\bar{S}_{1}-\bar{S}_{1}^{\circ}\right)$ and $\mathrm{T}\left(\bar{S}_{2}-\bar{S}_{2}{ }^{\circ}\right)$ are much more difficult to 


\section{3}

estimate since these quantities involve the derivatives of empirical equations. However, it is estimated that these values are probably accurate to \pm 1.0 per cent. This estimate does not include the 10 to $15 \mathrm{cal} / \mathrm{mole}$ error which may be present in the extrapolation of $\emptyset_{L}$ to infinite dilution. 


\section{DISCUSSION}

The heats of dilution of eleven rare-earth chlorides have been measured in the dilute concentration range by Naumann (46), Eberts (10), Csejka (8), and the author. These data are an excellent test of the DebyeHückel (9) theory for 3-1 electrolytes. The experimental limiting slopes, $\mathrm{S}^{\circ}$, for the various rare-earth chlorides are given in Table 3. These $S^{\circ}$ values were taken from the linear equations for $\bar{P}_{i}$ given by Naumann, Eberts, Csejka, and this research.

Table 23. Observed values of $\mathrm{S}^{\circ}$ for aqueous rare-earth chlorides at $25^{\circ} \mathrm{C}$

\begin{tabular}{lllllll}
\hline $\mathrm{LaCl}_{3}$ & $\mathrm{PrCl}_{3}$ & $\mathrm{NaCl}_{3}$ & $\mathrm{SmCl}_{3}$ & $\mathrm{GCCl}$ & $\mathrm{TbCl}_{3}$ \\
\hline 6630 & 7280 & 6630 & 6780 & 7180 & 7020 \\
$\frac{\mathrm{DyCl}_{3}}{6200}$ & $\frac{\mathrm{HoCl}_{3}}{6810}$ & $\frac{\mathrm{ErCl}_{3}}{4930}$ & $\frac{\mathrm{TmCl}_{3}}{6670}$ & $\frac{\mathrm{YbCl}_{3}}{6470}$ \\
\hline
\end{tabular}

The average of these values is 6600 , which is only 4.7 per cent below the theoretical value of 6925 . If the value for $\mathrm{ErCl}_{3}$ is omitted, the average is 6770 which is only 2.3 per cent below 6925. From Figures 4 and 8 it can be seen 
that the scatter in the $\overline{\mathrm{P}}_{i}$ 's becomes large as the concentration is decreased so that this agreement is excellent confirmation of the Debye-Hückel theory. At finite concentrations, wood et al. I report that the theoretical equation, equation 3.47, with dina \% d equal to zero, fits the data of $\mathrm{LaCl}_{3}$ and $\mathrm{NaCl}_{3}$ to about 0.002 molal. The theory will fit the data to higher concentrations if the dlna\% d term is retained, but then an arbitrary parameter has been introduced.

The $\overline{\mathrm{P}}_{\mathrm{I}}$ data of two rare earths, $\mathrm{Er}$ and $\mathrm{Yb}$, do not appear to obey the limiting law at the lowest concentrations for their chloride or nitrate salts. This could be caused by scatter in the data or hydrolysis. Naumann (46) attempted to determine whether this anomoly was due to hydrolysis, by adjusting two of his initial $\mathrm{ErCl}_{3}$ solutions to a $\mathrm{pH}$ of 4.0 with $\mathrm{HCl}$ solution. He observed the same scatter in $\overline{\mathrm{P}}_{1}$ and $\Delta H_{1, f}$ for these solulions ao for these same solutions at their equivalence $\mathrm{pH}$. However, because of the scatter it is not possible to determine whether the apparent trend is due to hydrolysis. For all dilutions, hydrolysis should be at a minimum since the initial and final molalities are at their equivalence $\mathrm{pH}^{\prime} \mathrm{s}$. Hydrolysis would account for the

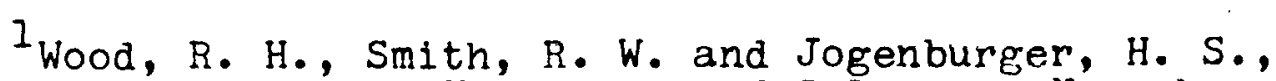
Department of Chemistry, University of Delaware, Newark, Delaware. The extrapolation of the heats of dilution of strong electrolytes to zero concentration. Private communication. 1963. 
observed deviations, since the hydrolysis effect increases as the concentration is decreased.

It does not seem possible to explain the apparent trend of the $\overline{\mathrm{P}}_{1}$ 's of the Er and $\mathrm{Yb}$ salts on the basis of the dissociation of some complex species. If the apparent trend is due to the dissociation of a complex ion, the $\bar{P}_{1}$ values would approach the theoretical value as the concentration is decreased. However, exactly the opposite behavior is observed. The only complexes which would be present in the rare-earth chloride or nitrate solutions, disregarding hydrolysis, are chloride or nitrate complexes, or possibly some carbonate complexes $\left(\mathrm{CO}_{3}=\right.$ present from the absorption of $\mathrm{CO}_{2}$ in the air). It can be shown, at the concentrations of interest, $10^{-3}$ to $10^{-4}$ molal, that the amount of complex present would be negligible. There is an anomalnus heat effect which could arise from the presence of $\mathrm{CO}_{2}$ in the water. Vander Zee and Swanson (77) have observed anomalous heat effects for the heat of dilution of perchloric acid into water which was $1 \times 10^{-5}$ molal in $\mathrm{CO}_{2}$. This anomaly is due to a shift in the equilibrium between the various carbonate species present in the solution. However, in this research the $\mathrm{pH}$ of the final solution was very nearly equal to the $\mathrm{pH}$ of the initial water for solutions in the concentration range $10^{-3}$ to $10^{-4}$ molal. This would result in only a small shift between the various carbonate species 
in solution, and therefore very little, if any, heat effect. If this effect were present for solutions of $\mathrm{Er}$ and $\mathrm{Yb}$, it should also be present for the rest of the lanthanides which do obey the Debye-Hückel limiting law. It is difficult to decide whether the discrepancy in the $\bar{P}_{i}$ values for these rare-earths is due to some extraneous reaction, or whether Er and Yb salts deviate from the Debye-Hückel limiting law at the lowest concentrations. However, since Csejka (8) found that both $\mathrm{HoCl}_{3}$ and $\mathrm{TmCl}_{3}$ solutions obey the DebyeHückel limiting law, it is very difficult to see why $\mathrm{ErCl}_{3}$ would be different.

The $\bar{P}_{i}$ values obtained in this research for $\mathrm{YbCl}_{3}$ solutions do not show nearly as pronounced a trend as Eberts (10) reports. The $\mathrm{S}^{\mathrm{O}}$ value obtained for $\mathrm{YbCl}_{3}$ from the data in this research was 6470 . This value is within experimental orror of the theoretical limiting slope. Since it was felt that the deviations from the limiting slope were due to some extraneous reaction, possibly hydrolysis, and not to an intrinsic property of the $\mathrm{Yb}^{+3}$ ion itself, the $\mathrm{YbCl}_{3}$ data were analyzed using the theoretical limiting slope. If the discrepancy was caused by some extraneous reaction, the use of the limiting slope would merely subtract out the effect of that reaction.

The regular decrease of the ionic radil across the lanthanide series provides an excellent opportunity to study 
the effect of ion size on the apparent molal heat content. The apparent molal heat contents decrease regularly as the ion size increases for dilute solutions of the alkali and alkaline-earth chlorides. If the same behavior occurred for dilute rare-earth chloride solutions, the apparent molal heat contents should decrease regularly from Lu to La. A plot of $\emptyset_{\mathrm{L}}$ and $\emptyset_{\mathrm{V}}$ at constant molality $\left(\mathrm{m}^{1 / 2}=0.3\right)$ is given in Figure 10. The $\emptyset_{\mathrm{V}}$ data are taken from Saeger (62), Spedding, Brown and Gray ${ }^{1}$, and the $\phi_{L}$ data from Naumann (46), Eberts (10), Csejka (8) and this research. It is obvious from Figure 10 that $\emptyset_{L}$ does not decrease regularly from Lu to La, but on the contrary both $\emptyset_{L}$ and $\emptyset_{V}$ decrease from $\mathrm{La}$ to $\mathrm{Nd}$, then increase from $\mathrm{Nd}$ to around $\mathrm{Tb}$, and again decrease from $\mathrm{Tb}$ to $\mathrm{Yb}$. The point for $\mathrm{ErCl}_{3}$, taken from Naumann (46), has been reanalyzed using the theoretical limiting slope. The close correlation between $\emptyset_{V}$ and $\emptyset_{L}$ in the dilute concentration range was first noted by Csejka ( 8 ). Ayers (4) was the first to observe this trend in the apparent molal volumes of some rare-earth chlorides and nitrates at infinite dilution. This work has been extended ${ }^{2}$

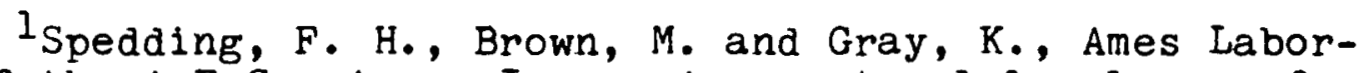
atory of the A.E.C., Ames, Iowa. Apparent molal volumes of some aqueous rare-earth chloride solutions at $25^{\circ} \mathrm{C}$. Private communication. 1964.

${ }^{2}$ Spedding, F. H. and Pikal, M. J., Ames Laboratory of the A.E.C., Ames, Iowa. Apparent molal volumes of some aqueous rare-earth chloride solutions at $25^{\circ} \mathrm{C}$. Private communication. 1964. 


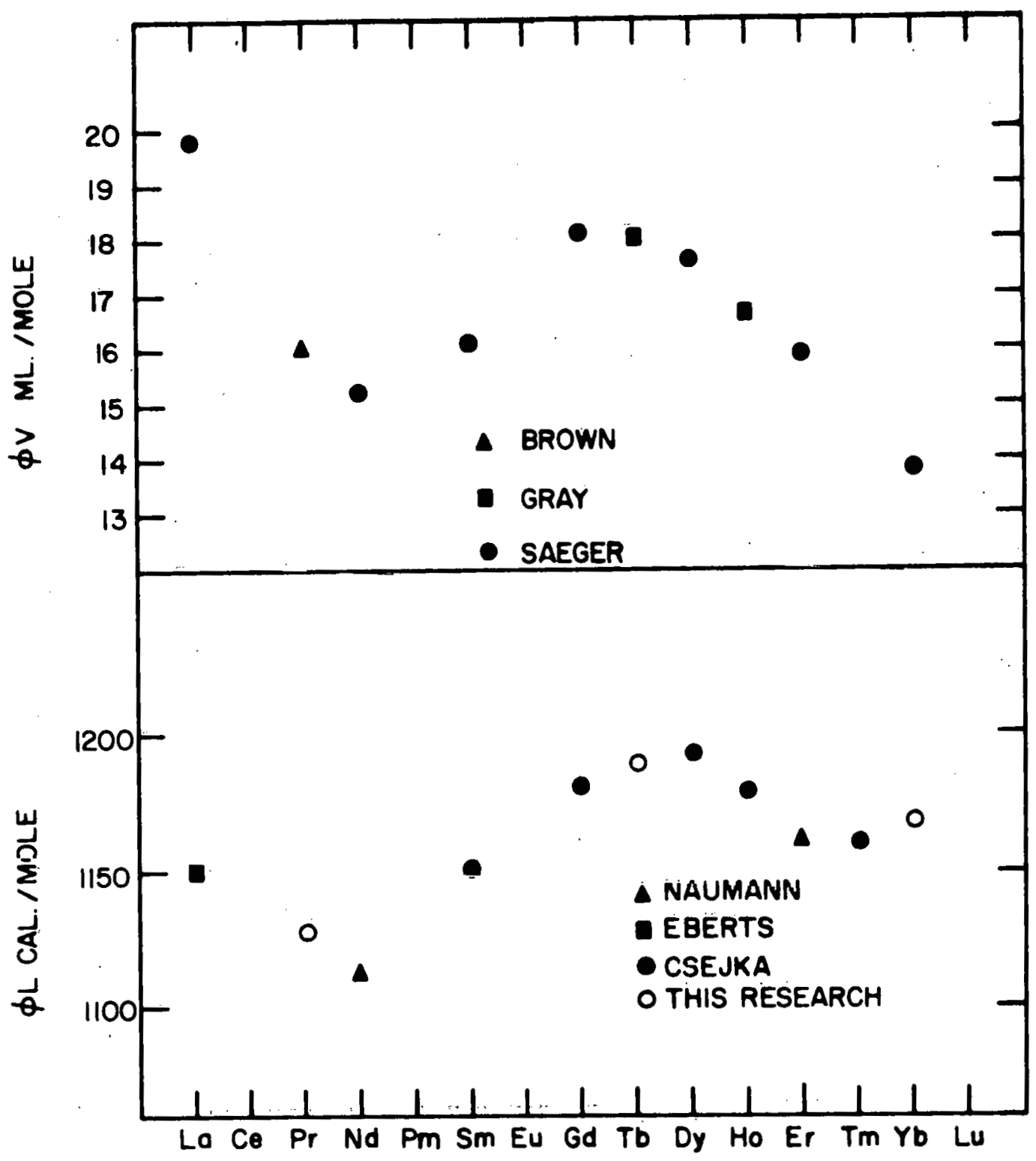

Figure 10. Comparison of $\phi_{\mathrm{L}}$ and $\phi_{\mathrm{V}}$ for aqueous rare-earth chloride solutions at $\mathrm{m}^{1 / 2}=0.3$ and $25^{\circ} \mathrm{C}$ 
to include measurements of the apparent molal volumes of most of the rare-earth chlorides to infinite dilution. Spedding, Pikal and Ayers qualitatively explain their data by assuming that an equilibrium between two hydration numbers exists for the rare-earth lons from $\mathrm{Nd}$ to $\mathrm{Tb}$. The increase in $\phi_{\mathrm{V}}{ }^{\circ}$ from beyond $N d$ to around $T b$ indicates that the equilibrium is increasingly shifted toward the lower hydration number as the lonic radii decrease from $\mathrm{Nd}$ to $\mathrm{Tb}$. The smooth decrease in $\emptyset_{\mathrm{V}}{ }^{\circ}$ from La to $\mathrm{Nd}$ and from around $\mathrm{Tb}$ to $\mathrm{Yb}$ indicates that the higher hydration number is favored by the former series and the lower hydration number by the latter series. It seems reasonable to assume that this same explanation for $\phi_{\mathrm{V}}$ is valid at $\mathrm{m}^{1 / 2}=0.3$, since effects from complexing and hydrolysis should be small and nearly the same for all the rare earths at this concentration.

Figure 10 shows that the apparent molal heat content changes $80 \mathrm{cal} . / \mathrm{mole}$ between $\mathrm{NaCl}_{3}$ and $\mathrm{TbCl}_{3}$ at $\mathrm{m}^{1 / 2}=0.3$. It is doubtful whether this difference could be accounted for by hydrolysis, since no contribution from hydrolysis to the heats of dilution of $\mathrm{LaCl}_{3}$ or $\mathrm{ErCl}_{3}$ was detected. It is also unlikely that this difference is due only to a difference in the heat of complexation of these two rare earths. At this concentration, it is estimated that a difference of $3.5 \mathrm{kcal} . / \mathrm{mole}$ between the chloride complexes 
of $\mathrm{Nd}$ and $\mathrm{Tb}$ would be required to account for a difference of $80 \mathrm{cal} . / \mathrm{mole}$ in their heats of dilution. Although no data are avallable for the heats of complexing of the rareearth chlorides, a preliminary study made during the course of this research indicates that this difference would be unlikely. The heats of complexing of chloride ion with $\mathrm{La}^{+3}, \mathrm{~Tb}^{+3}$, and $\mathrm{Yb}^{+3}$ were studied by simultaneously diluting the respective rare-earth chloride solution into a one-molal $\mathrm{HCl}$ solution and one-molal $\mathrm{HClO}_{4}$ solution and measuring the heat difference. The heat of dilution of the rare-earth chloride solution into the two mediums was assumed to be equal. The heats of dilution of the $\mathrm{KCl}$ and $\mathrm{HClO}_{4}$ solutions were calculated from their intial and final ionic strengths in the same manner as the heats of dilution of $\mathrm{NaOH}$ and $\mathrm{NaCl}$ in the heat of neutralization experiments. The results showed that the heat of chloride complexing of $\mathrm{La}^{+3}, \mathrm{~Tb}^{+3}$, and $\mathrm{Yb}^{+3}$ at one-molal chloride ion concentration 10.002 to 0.004 molal rare-earth ion concentration) was ncarly the same for all three rare earths and equal to approximately $-1.5 \mathrm{kcal} . /$ mole rare earth.

The data can be qualitatively explained if $a^{\circ}$, the mean distance of closest approach, increases from La to $\mathrm{Nd}$, decreases after Nd to around $\mathrm{Tb}$, and then increases from around $\mathrm{Tb}$ to $\mathrm{Yb}$. The rise of $80 \mathrm{cal} . / \mathrm{mole}$ from $\mathrm{Nd}$ to $\mathrm{Tb}$ would require a change of only 0.6 angstroms between $\mathrm{Nd}^{+3}$ 
and $\mathrm{Tb}^{+3}$. This behavior of the $a^{\circ}$ 's would be expected if the interpretation projected by Spedding, Pikal, and Ayers for their $\emptyset_{\mathrm{V}}{ }^{\circ}$ data is correct. According to their postulate, La and Nd have the same hydration number. This will lead to a tighter binding of the first hydration sphere around the $\mathrm{Nd}^{+3}$ ion than around the $\mathrm{La}^{+3}$ ion, since the $\mathrm{Nd}^{+3}$ ion has a smaller ionic radius than the $\mathrm{La}^{+3}$ ton. Hence, the $\mathrm{Nd}^{+3}$ ion is able to influence the water outside the first hydration sphere more strongly than the $\mathrm{La}^{+3}$ ion. This will give a larger hydrated radius for the $\mathrm{Nd}^{+} 3$ ion with a consequent increase in the $a^{\circ}$ value. After $\mathrm{Nd}, a^{\circ}$ would decrease to around $\mathrm{Tb}$ if a shift toward a lower hydration number occurred in this interval, since $a^{\circ}$ reflects primarily the number of waters in the first hydration sphere. The increase in $a^{\circ}$ from around $\mathrm{Tb}$ to $\mathrm{Yb}$ again arises from a decrease in the ionic radii with a consequent increase in the radil of the hydrated ions. The behavior of the heats of dilution of the rare-earth chloride solutions, from $\mathrm{La}$ to $\mathrm{Nd}$, and from $\mathrm{Tb}$ or $\mathrm{Dy}$ to $\mathrm{Yb}$; is opposite that of the alkall and alkaline earth chloride solutions. However, from the above explanation it can be seen that this behavior arises from the tripositive charge of the rare-earth ion and its ability to influence water molecules outside the first hydration sphere, thus giving the smaller ion a larger hydrated radius. This is undoubtedly too simple a picture, since the dina $/$ dt term 
has been omitted, and this quantity may be very sensitive to a shift in the hydration number.

This same trend has been observed for the heat of formation of several chelates with the rare-earth ions. Mackey et al. (40) have observed this trend for EDTA complexes, Grenthe (23) for the diglycollate and dipicolinate complexes, and Edelin De La Praudiere and Staveley (11) for the 1:I nitrilotriacetate complexes. These authors all agree that the trend shown by the heat of formation of the I:I complexes of these chelates cannot be explained by ligand field effects on the $4 f$ electrons, but is probably due to a change in the hydration number of the rare-earth ions in the midale of the series.

The structural study of various rare-earth hydrate crystals also suggests a change in the coordination number of the rare-earth ions in solution across the lanthanide series. The structural studies of Helmholtz (31) on $\mathrm{Na}\left(\mathrm{BrO}_{3}\right)_{3} \cdot 9 \mathrm{H}_{2} \mathrm{O}$ give a coordination number of nino for water about the $\mathrm{Nd}^{+3}$ ion, while those of Marezio et al. (42) on $\mathrm{GdCl}_{3} \cdot 6 \mathrm{H}_{2} \mathrm{O}$ give a coordination number of eight, six waters and two chloride ions, around the $\mathrm{Gd}^{+} 3$ ion. Although a change in the coordination number around the ions in the crystal does not prove that such a change occurs around the ione in solution, it does lend support to the argument that such a change may indeed occur. 
The relative apparent molal heat contents of aqueous solutions of $\mathrm{LaCl}_{3}, \mathrm{PrCl}_{3}, \mathrm{TbCl}_{3}, \mathrm{HoCl}_{3}$, and $\mathrm{YbCl}_{3}$ from zero molal to saturation are shown in Figure 11. It is interesting to note that the relative order of the $\emptyset_{\mathrm{L}}$ values of these five rare-earth chlorides is maintained over the entire concentration range. The rapid rise of $\phi_{L}$ from zero molal to about 0.1 molal is predicted by the Debye-Hückel (9) theory. The $\emptyset_{L}$ curve then levels off and becomes straight, as a function of $\mathrm{m}^{1 / 2}$, from $\mathrm{m}^{1 / 2}=0.3$ to $\mathrm{m}^{l / 2}=0.8$. The $\emptyset_{\mathrm{L}}$ curve then rises rapidly from 1.0 molal to saturation. A curious feature of these $\emptyset_{L}$ values is observed when $\emptyset_{L}$ is plotted versus $\mathrm{m}^{3 / 2}$. From 1.25 molal to saturation the $\emptyset_{L}$ values then lie on a straight line.

The rapid rise of $\emptyset_{L}$ above one molal is generally attributed to hydration effects. Energy is released when the rare-earth ion fulfills its hydration requirements. The dissociation of various rare-earth chloride complexes will also contribute to the heat of dilution. However, the dissociation is an endothermic reaction at fonic strength of one molal, and so at this concentration complexing does not contribute to the increase in the heat of dilution. It is recognized that at higher concentrations the type of complex may change, that is from outer sphere complexes (at least one water molecule between the chloride and rareearth ion) to inner sphere complexes (the chloride fon 


\section{5}

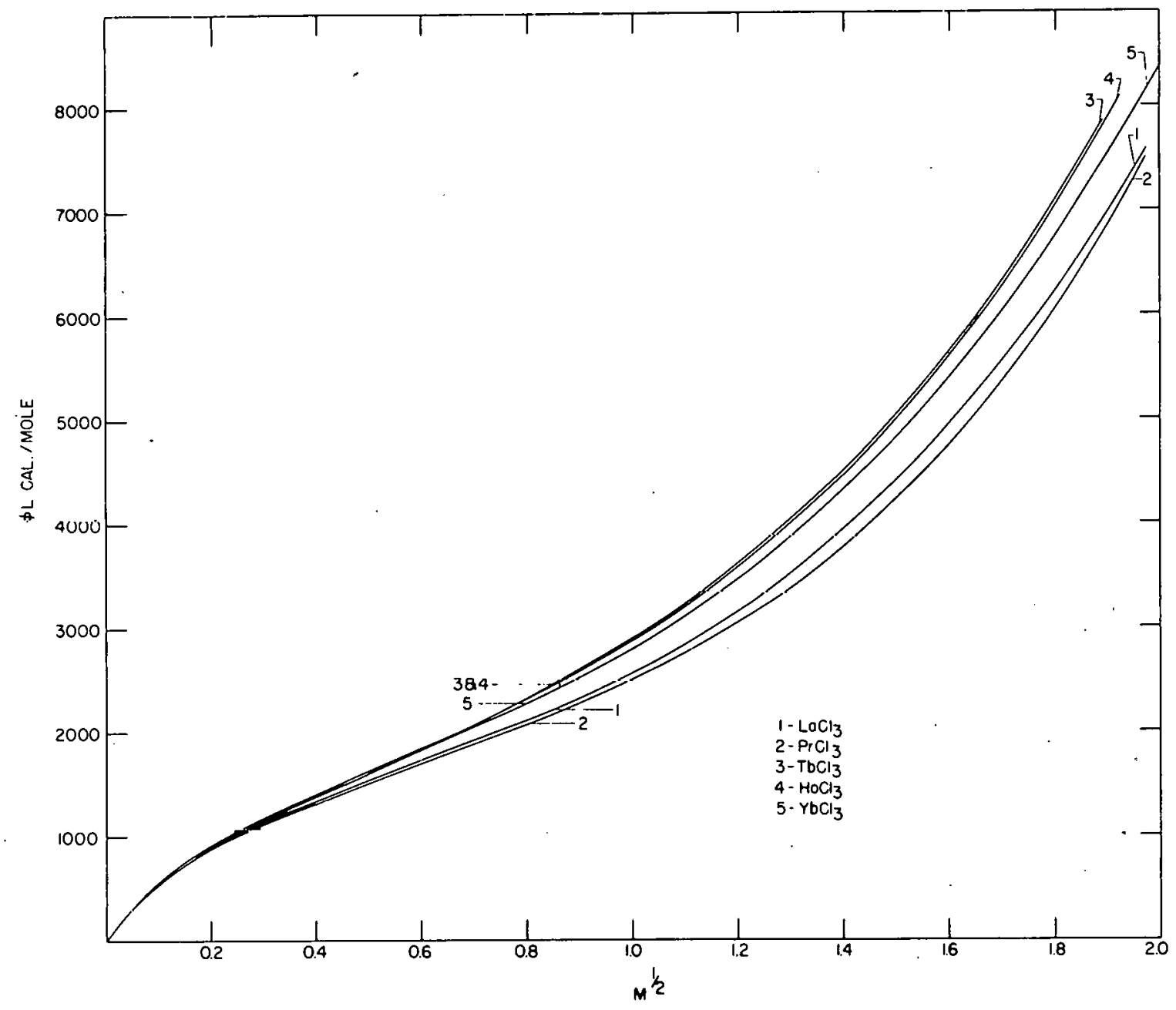

Figure 11. Relative apparent molal heat contents of aqueuus LaCl $3, \mathrm{PrCl}_{3}, \mathrm{TbCl}_{3}, \mathrm{HnCl}_{3}$, and $\mathrm{YbCl}_{3}$ solutions versus $\mathrm{m}^{1 / 2}$ at $25^{\circ} \mathrm{C}$ 
immediately adjacent to the rare-earth ion), and that higher complexes, $\mathrm{RCl}_{2}{ }^{+}$and $\mathrm{RCl}_{3}$, may become very important. The dissociation of these various species may indeed contribute to the rapid rise of $\emptyset_{\mathrm{L}}$. Graphs of $\bar{L}_{1}$ and $\overline{\mathrm{L}}_{2}$ for these five rare-earth chlorides are given in Figures 12 and 13 respectively. The $\bar{L}_{1}$ curves are negative over the entire concentration range and decrease rapidly above two molal. The $\bar{I}_{2}$ curves are positive over the entire concentration range and rise rapidly above one molal. The $\bar{L}_{1}$ and $\bar{L}_{2}$ curves of $\operatorname{PrCl}_{3}$ cross those of $\mathrm{LaCl}_{3}$ and the $\overline{\mathrm{I}}_{2}$ curve of $\mathrm{PrCl}_{3}$ also crosses that of $\mathrm{YbCl}_{3}$. Saeger (62) noted that the $\overline{\mathrm{V}}_{2}$ curve of $\mathrm{NdCl}_{3}$ exhibited the same unusually sharp curvature above one molal. The $\bar{v}_{2}$ curve of $\mathrm{PrCl}_{3}$, determined by spedding and Brown ${ }^{1}$, has this same pronounced curvature. Saeger postulated that the coordination number may shift toward a smaller value for some rare-earth ions as the concentration increases. This would account for the sharp rise in the $\bar{v}_{2}$ curves of $\mathrm{PrCl}_{3}$ and $\mathrm{NaCl}_{3}$. Since a shift in the equilibrium between two coordination numbers appears to occur between $\mathrm{Nd}$ and $\mathrm{Tb}$, it seems reasonable that with $\mathrm{Pr}$ and Nd this shift could also occur as the concentration

${ }^{1}$ Spedding, F. H, and Brown, M., Ames Laboratory of the A.E.C., Ames, Iowa. Apparent molal volumes of aqueous $\mathrm{PrCl}_{3}$ solutions. Private communication. 1963. 


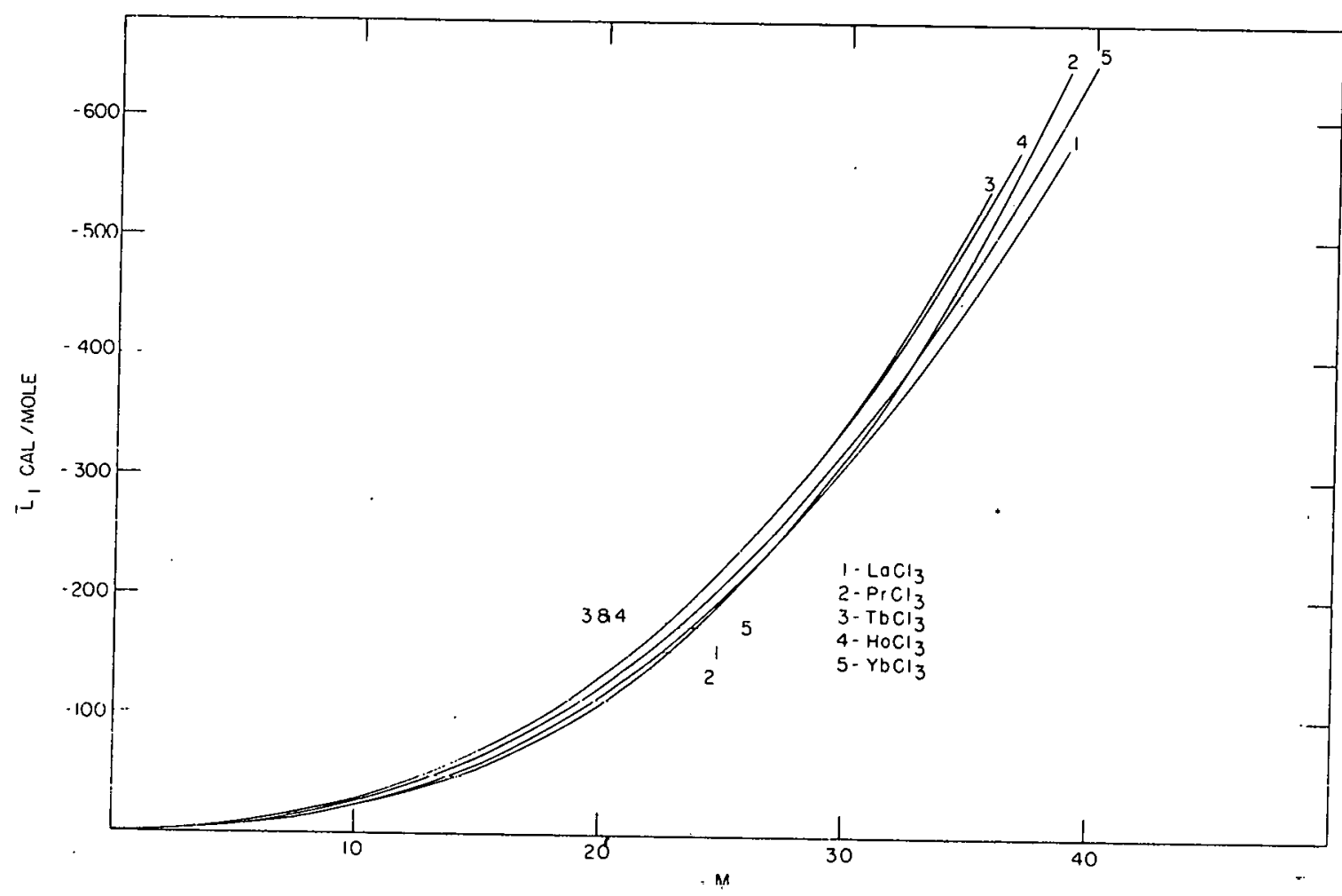

Figure 12. Relative partial molal heat contents of water in aqueous $\mathrm{LaCl}_{3}, \mathrm{PrCl}_{3}, \mathrm{TbCl}_{3}, \mathrm{HoCl}_{3}$, and $\mathrm{YuCl}_{3}$ solutions versus $\mathrm{m}$ at $25^{\circ} \mathrm{C}$ 


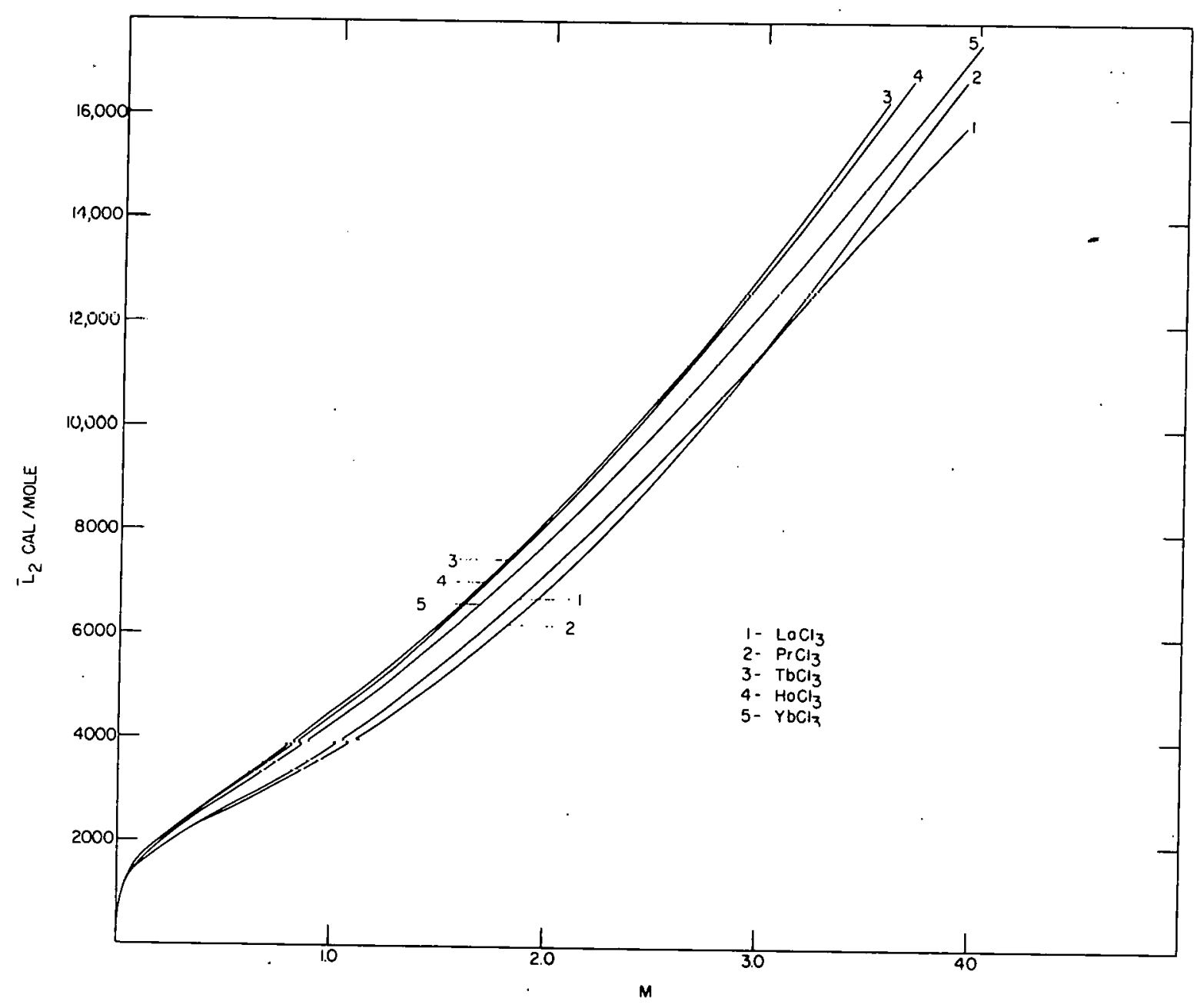

Figure 13. Relative partial molal heat contents of the solute in aqueous $\mathrm{LaCl}_{3}, \mathrm{PrCl}_{3}, \mathrm{TbCl}_{3}, \mathrm{HoCl}_{3}$, and $\mathrm{YbCl}_{3}$ solutions versus $\mathrm{m}$ at $25^{\circ} \mathrm{C}$. 
increases. If hydration is the principal factor in the rapid increase of $\overline{\mathrm{L}}_{2}$ and decrease of $\overline{\mathrm{L}}_{1}$, then the unusually sharp curvature of $\overline{\mathrm{L}}_{2}$ and $\overline{\mathrm{L}}_{1}$ for $\mathrm{PrCl}_{3}$ can be qualitatively explained by a shift in the equilibrium between two coordination numbers as the concentration increases. With a decrease in concentration the equilibrium shifts to the higher coordination number with a concomitant release of energy

Figures 14 and 15 show the behavior of the partial molal excess entropies $\mathrm{T}\left(\overline{\mathrm{S}}_{1}-\overline{\mathrm{S}}_{1}{ }^{0}\right)$ and $\mathrm{T}\left(\overline{\mathrm{S}}_{2}-\overline{\mathrm{S}}_{2}{ }^{0}\right)$ as a function of molality. Since the partial molal heat contents and the activity coefficients obey the Debye-Hückel (9) limiting law, the excess entropies also obey the DebyeHückel limiting law. Friedman (17) has discussed the structural interpretation of the excess entropy in the Debye-Hückel limiting law region. He states that the total excess entropy rises rapidly in this region because "the electric field from an ion is more effective in decreasing the entropy of the solvent when the ion is added to pure solvent than when it is added to a real solution of finite concentration". Frank and Robinson (15) have interpreted the relative partial molal entropies of some $1-1$ and 2-1 electrolytes above the Debye-Hückel limiting law region in terms of structure making and structure breaking effects on the structure of water. They interpreted large positive 


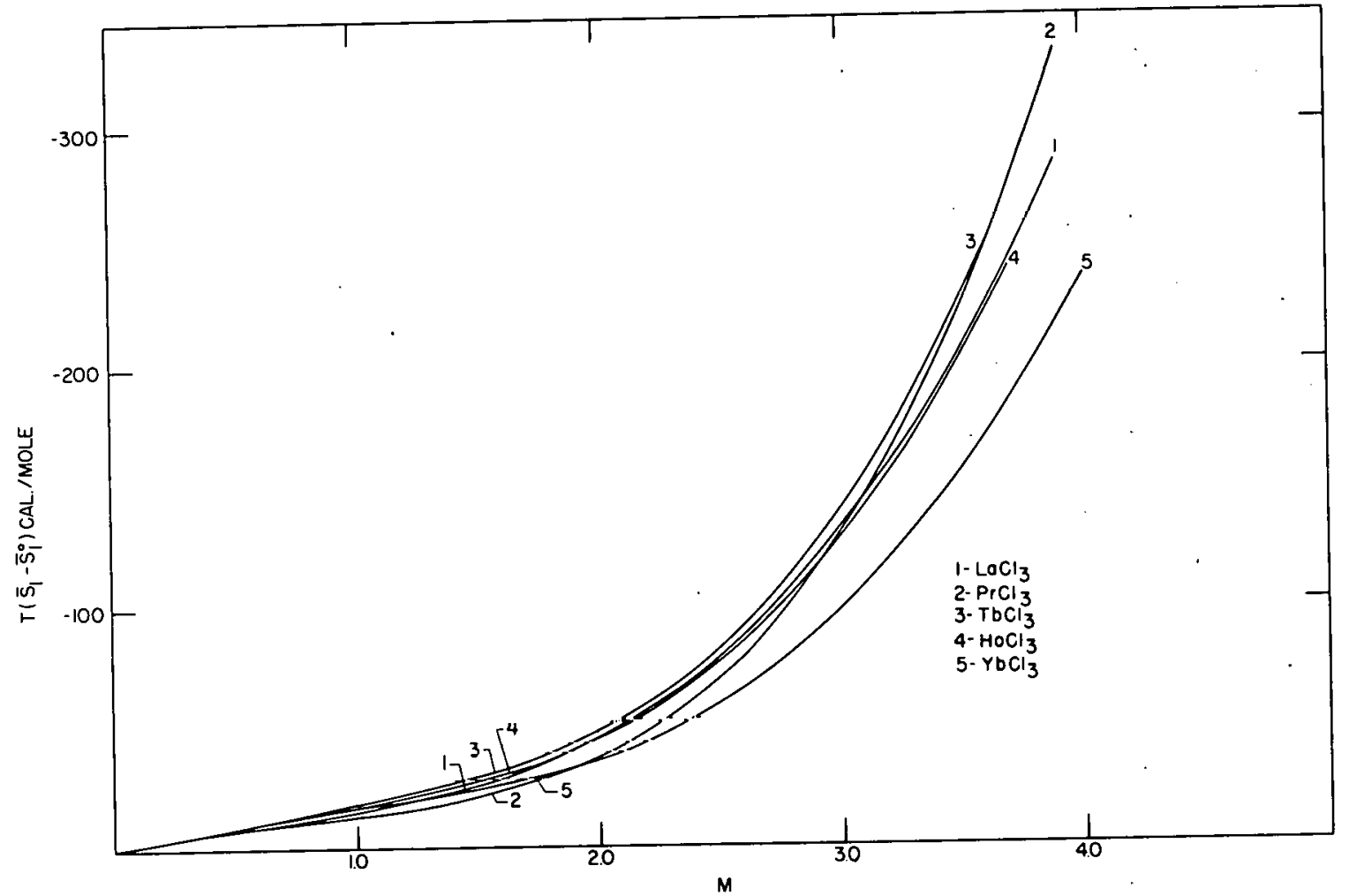

Figure 14. Relative partial molal excess entropies of water in aqueous $\mathrm{LaCl}_{3}, \mathrm{PrCl}_{3}, \mathrm{TbCl}_{3}, \mathrm{HoCl}_{3}$, and $\mathrm{YbCl}_{3}$ solutions versus $\mathrm{m}$ at $25^{\circ} \mathrm{C}$ 


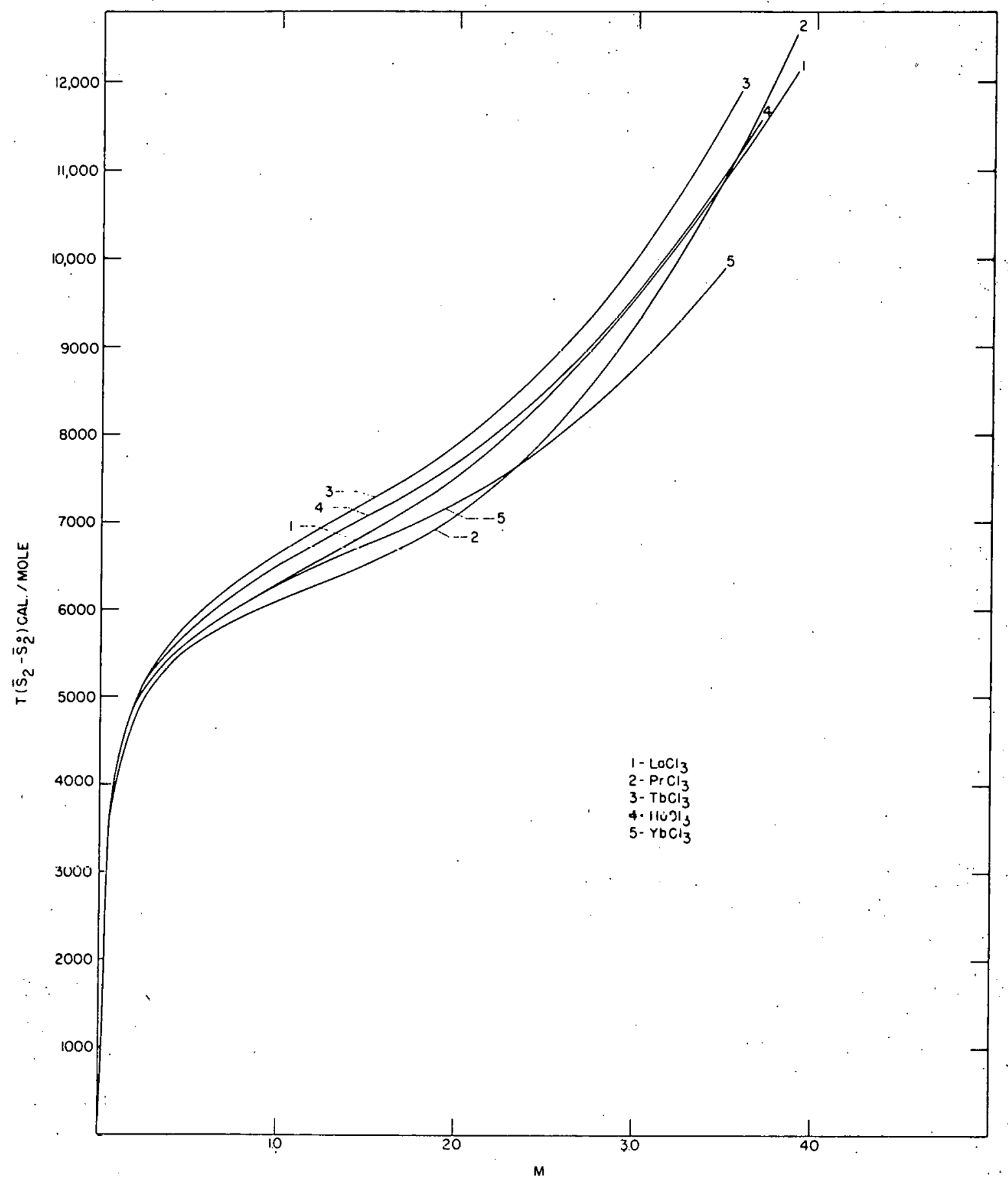

Figure 15. Relative partial molal excess entropies of the solute in aqueous $\mathrm{LaCl}_{3}, \mathrm{PrCl}_{3}, \mathrm{TbCl}_{3}, \mathrm{HoCl}_{3}$, and $\mathrm{YbCl}_{3}$ solutions at $25^{\circ} \mathrm{C}$ 
values of $\mathrm{T}\left(\overline{\mathrm{S}}_{1}-\overline{\mathrm{S}}_{1}{ }^{\circ}\right)$ in terms of the inability of an ion to fit into the water structure.

Above the Debye-Hückel limiting law region, the excess entropies show a complicated series of crossovers. However, from $\mathrm{TbCl}_{3}$ to $\mathrm{YbCl}_{3}$ a definite trend is apparent as the concentration increases. At isomolalities above one molal the magnitude of the excess entropy decreases in the order $\mathrm{TbCl}_{3}>\mathrm{HoCl}_{3}>\mathrm{YbCl}_{3}$. It is difficult to discuss any trends before $\mathrm{Tb}$ because of the shift in the equilibrium between two coordination numbers which occurs from $\mathrm{Nd}$ to $\mathrm{Tb}$. However, if the coordination number of $\mathrm{Pr}$ is shifting toward that of the heavier rare-earths as the concentration increases, then from the previous trend one would expect that the magnitude of the partial molal excess entropies would be $\mathrm{PrCl}_{3}>\mathrm{TbCl}_{3}>\mathrm{HoCl}_{3}>\mathrm{YbCl}_{3}$. From Figures 14 and 15 it can be seen that at the highest isomolality at which they can be compared the magnitude of $\mathrm{T}\left(\overline{\mathrm{S}}_{1}-\overline{\mathrm{S}}_{1}{ }^{0}\right)$ of $\mathrm{PrCl}_{3}$ is equal to that of $\mathrm{TbCl}_{3}$, and $\mathrm{T}\left(\bar{S}_{2}-\bar{S}_{2}{ }^{\circ}\right)$ of $\operatorname{PrCl}_{3}$ is lower than that of $\mathrm{TbCl}_{3}$. This would seem to indicate that the equilibrium has not shifted entirely to the lower coordination number.

It does not seem possible at this time to account for the trend in the partial molal excess entropy of the water in terms of only structure making or structure breaking effects. If this were the explanation, it would seem that 
the ion with the highest charge density, $\mathrm{Yb}^{+} 3$, would produce the most order in the water. Figure 14 shows that the opposite behavior occurs. It is recognized that association may play a very large role in the partial molal excess entropy of dilution, and that the observed trend may be caused both by hydration effects and association. The complexation reaction can be written as follows:

$$
\begin{array}{r}
\mathrm{R}^{+3}\left(\mathrm{H}_{2} \mathrm{O}\right)_{n}+\mathrm{pCl}^{-} \longrightarrow \mathrm{R}\left(\mathrm{H}_{2} \mathrm{O}\right)_{\mathrm{n}} \mathrm{Cl}^{+(3-\mathrm{p})} \longrightarrow \\
\mathrm{R}\left(\mathrm{H}_{2} \mathrm{O}\right)_{\mathrm{m}} \mathrm{Cl}^{+(3-\mathrm{p})}+(\mathrm{n}-\mathrm{m}) \mathrm{H}_{2} \mathrm{O}
\end{array}
$$

Nancollas (45) has observed that for most ions the over-all reaction gives a rather large positive $\Delta S$, while the entropy associated with the first step is much smaller. It will be possible to make quantitative calculations for this contribution when more thermodynamic data, especially heat of formation data, become available for the rare-earth chloride complexes.

The heats of dllution obtained in this research for $\mathrm{PrCl}_{3}, \mathrm{TbCl}_{3}$, and $\mathrm{YbCl}_{3}$ solutions can be compared with those obtained by spedding and Bisbeel and by Spedding and

$I_{\text {Spedding, F. H. and Bisbee, W., Ames Laboratory of }}$ the A.E.C., Ames, Iowa. Heats of solution of some rare-earth chlorides. Private communication. 1964 
Flynn (69) from heat of solution measurements of the anhydrous salts. Although heats of dilution obtained by differences of large heat of solution values are subject to larger errors than heats of dilution obtained directly, nevertheless the two values differ by more than their combined experimental errors. This same discrepancy was also noted by Csejka (8), Eberts (10) and Naumann (46) for their respective heat of dilutions. At a concentration of 0.05 molal, the relative apparent molal heat contents obtained from the heat of solution measurements of $\mathrm{PrCl}_{3}$ and $\mathrm{YbCl}_{3}$ are approximately $300 \mathrm{cal} . / \mathrm{mole}$ larger than those obtained in this research. The discrepancy for $\mathrm{TbCl}_{3}$ is $200 \mathrm{cal}$./mole at the same concentration.

The reason for the discrepancy is not clear. The apparent molal heat contents obtained from the heat of solution data of $\mathrm{NaCl}_{3} \cdot 6 \mathrm{H}_{2} \mathrm{O}(70), \mathrm{DyCl}_{3} \cdot 6 \mathrm{H}_{2} \mathrm{O}(10)$, $\mathrm{TbCl}_{3} \cdot 6 \mathrm{H}_{2} \mathrm{O}$ and $\mathrm{HoCl}_{3} \cdot 6 \mathrm{H}_{2} \mathrm{O}$ support the data obtained from heat of dilution measurements. Eberts (10) proposed two possible explanations. The first is that hydrolysis could occur, since the $\mathrm{pH}$ of the final solutions formed by the anhydrous rare-earth chloride and water was between 6.3 and 6.6. The second explanation is that a slow-type reaction would accompany the dissolution of the anhydrous salt, for example the change from an inner sphere to an outer sphere complex. From the available data it does not seem possible 
to distinguish between these two explanations.

The enthalpy of hydration of $\mathrm{TbCl}_{3}$ and $\mathrm{HoCl}_{3}$ can be calculated from the heat of solution of $\mathrm{TbCl}_{3} \cdot 6 \mathrm{H}_{2} \mathrm{O}$ and $\mathrm{HoCl}_{3} \cdot 6 \mathrm{H}_{2} \mathrm{O}$ obtained in this research, and the heat of solution of the anhydrous $\mathrm{TbCl}_{3}$ and $\mathrm{HoCl}_{3}$ obtained by Spedding and Bisbee. The enthalpy of hydration may be calculated from the equation

$\Delta H$ nydration $=\overline{\mathrm{L}}_{2}\left(\begin{array}{c}\text { hydrated } \\ \text { crystal }\end{array}\right)-\overline{\mathrm{L}}_{2}\left(\begin{array}{c}\text { anhydrous } \\ \text { crystal }\end{array}\right) \cdot$

Bisbee gives $45,980 \mathrm{cal} . / \mathrm{mole}$ and $51,010 \mathrm{cal} . / \mathrm{mole}$ for $\overline{\mathrm{L}}_{2}$ of $\mathrm{TbCl}_{3}$ and $\mathrm{HoCl}_{3}$ respectively. Combining these with the $\overline{\mathrm{I}}_{2} \cdot$ (hydrate) obtained in this research gives $-36,420$ and $-40,580 \mathrm{cal} . /$ mole for $\Delta \mathrm{H}$ hydration of $\mathrm{TbCl}_{3}$ and $\mathrm{HoCl}_{3}$ respectively.

In summary, the heats of dilution of aqueous $\mathrm{PrCl}_{3}$, $\mathrm{TbCl}_{3}$, and $\mathrm{YbCl}_{3}$ solutions were determined from zero molal to saturation and aqueous $\mathrm{LaCl}_{3}$ and $\mathrm{HoCl}_{3}$ solutions from 0.25 molal to saturation at $25^{\circ} \mathrm{C}$. In addition, aqueous heats of solution of $\mathrm{TbCl}_{3} \cdot 6 \mathrm{H}_{2} \mathrm{O}$ and $\mathrm{HoCl}_{3} \cdot 6 \mathrm{H}_{2} \mathrm{O}$ were determined at $25^{\circ} \mathrm{C}$.

From these data empirical least square equations for the relative apparent molal heat contents, $\emptyset_{L}$, were determined as a function of $\mathrm{m}^{1 / 2}$ using an IBM 7074 computer. Expressions for the relative partial molal heat 
content of the water, $\overline{\mathrm{L}}_{1}$, and of the salt, $\overline{\mathrm{L}}_{2}$, were determined from these empirical equations. The relative partial molal excess entropies of the water $\left(\bar{S}_{1}-\bar{s}_{1}{ }^{\circ}\right)$ and of the salt $\left(\bar{S}_{2}-\bar{S}_{2}{ }^{\circ}\right)$ were determined from the $\bar{L}_{1}$ and $\bar{L}_{2}$ data and from the activity coefficient data of these electrolytes. Values for $\bar{L}_{1}, \bar{L}_{2}, T\left(\bar{S}_{1}-\bar{S}_{1}{ }^{0}\right)$ and $\mathrm{T}\left(\overline{\mathrm{S}}_{2}-\overline{\mathrm{S}}_{2}^{\circ}\right)$ were calculated at rounded concentrations. The data show that aqueous $\mathrm{PrCl}_{3}$ and $\mathrm{TbCl}_{3}$ solutions obey the Debye-Hückel limiting law and there is strong indication that aqueous $\mathrm{YbCl}_{3}$ solutions also obey the limiting law. It is postulated that the heat of dilution data below 0.15 molal for all the aqueous rareearth chloride solutions which have been studied can be understood in terms of two serles within the rare earths. These two series have different water coordination numbers with a gradual shift in the equilibrium between these two coordination numbers occurring from beyond Nd to around $\mathrm{Tb}$ or $\mathrm{Dy}$. The lighter rare earths, from La to $\mathrm{Nd}$, favor the higher coordination number, while the heavier rare earths, from around $\mathrm{Tb}$ or $\mathrm{Dy}$ to $\mathrm{Yb}$ favor the lower water coordination number. The data for $\mathrm{PrCl}_{3}$ indicate that for this salt the equilibrium between two water coordination numbers shifts toward the lower coordination number with increasing concentration above 2.0 molal. 


\section{BIBLIOGRAPHY}

1. Adams, E. G., J. Am. Chem. Soc., 48, 621 (1926).

2. Ahrland, S., Acta Chem. Scand., 5, 199 (1951).

3. Arrhenius, S., Z. Physik. Chem., 1, 631 (1887).

4. Ayers, Buell 0., "Apparent and Partial Molal Volumes of Some Rare Earth Salts in Aqueous Solution", Unpublished Ph. D. thesis, Library, Iowa State University of Science and Technology, Ames, Iowa, 1954.

5. Bjerrum, N., Kgl. Danske Vidensk. Selskab., 7, No. 9 (1926). (Original available but not translated; cited in Harned, H. S. and Owen, B. B., "The Physical Chemistry of Electrolytic Solutions", 3rd ed., page 70, Reinhold Publishing Corporation, New York, N.Y., 1958.)

6. Bjerrum, N., Z. Physik. Chem., 119, 145 (1926).

7. Bjerrum, Jannik, Schwarzenbach, Gerold and Sillen, Lars Gunner, "Stability Constants", Part 2, The Chemical Society, London, England, 1958.

8. Csejka, David A., "Some Thermodynamic Properties of Acueous Rare-Earth Chloride Solutions", Unpublished Ph.D. thesis, Library, Iowa State University of Science and Technology, Ames, Iowa, 1961.

9. Debye, P. and Hückel, E., Physik. Z., 24, 185 (1923).

10. Eberts, Robert E., "Relative Apparent Molal Heat Contents of Some Rare-Earth Chlorides and Nitrates in Acueous Solutions", Unoublished Ph. D. thesis, Library, Iowa Statc University if Science and Technology, Ames, Iowa, 1957.

11. Edelin De La Praudiere, P. L. and Staveley, L. A. K., I. Inorg. Nucl. Chem., 26, 1713 (1964).

12. Foulk, C. A. and Hollingsworth, M., I. Am. Chem. Sec., 45, 1220 (1923).

13. Fowler, R. H., Trans. Earaday Sec., 23, 434 (1927). 
14. Fowler, Ralph and Guggenheim, E. A., "Statistical Thermodynamics", Cambridge University Press, Cambridge, England, 1960.

15. Frank, H. S. and Robinson, A. L., J. Chem. Phys., 8 , $993(1940)$.

16. Frank, H. S. and Thompson, P. T., J. Chem. Phys., 31 , 1086 (1959).

17. Friedman, H. L., J. Chem. Phys., 32, 1351 (1960).

18. Friedman, Harold L., "Ionic Solution Theory", Interscience Publishers, Inc., New York, N.Y., 1962.

19. Fuoss, R. M., I. Am. Chem. Sec., 80, 5059 (1958).

20. Fuoss, R. M. and Kraus, C. A., J. Am. Chem. Sec., 55, 1019,2387 (1933); 52, I (1935).

21. Fuoss, R. M. and Onsager, L., Proc. Nat1. Acad. Sci. U. S., 47, 818 (1961).

22. Glueckauf, E., Irans. Earaday Soc., 51, 1235 (1955).

23. Grenthe, I., Acta Chem. Scand., 12, 2487 (1963).

24. Gronwall, T. H., LaMer, V. K. and Sandved, K., Physik. Z., 29, 358 (1928).

25. Gucker, F. T., Jr., Pickard, H. B. and Planck, R. W., J. Am. Chem. Soc., 61, 459 (1939).

26. Guggenheim, E. A., Irans. Faraday Soc., 55, 1714 (1959).

27. Gulbransen, E. A. and Robinson, A. L., I. Am. Chem. Soc., 56, 2637 (1934).

28. Hale, J. D., Izatt, R. M. and Christensen, J. J., J. Phys. Chem., 67, 2605 (1963).

29. Harned, Herbert S. and Owen, Benton B., "The Physical Chemistry of Electrolytic Solutions", 3rd ed., Reinhold Publishing Corporation, New York, N.Y., 1958.

30a. Hearne, J. A. and White, A. G., J. Chem. Sec. (London), 2081 (1957). 
30b. Hearne, J. A. and White, A. G., J. Chem. Soc. (London), 2168 (1957).

31. Helmholtz, L., I. Am. Chem. Soc., 61, 1544 (1939).

32. Hückel, E., Phrsik. Z., 26, 93 (1925).

33. Kirkwood, J. G., J. Chem. Phys., 2, 767 (1934).

34. Kirkwood, J. G. and Poirier, J. C., J. Phys. Chem., 58,591 (1954).

35. Kramers, H. A., Proc. Royal Acad. Sci. Amsterdam, 30, 145 (1927).

36. La Mer, V. K., Gronwall, T. H. and Greiff, L. J., J. Phys. Chem., 35, 2245 (1931).

37. Lange, E., "Heats of Dilution of Dilute Solutions of Strong and Weak Electrolytes". In Hamer, W. J., ed., "The Structure of Electrolytic Solutions", pp. 135-151, John Wiley and Sons, Inc., New York, N.Y., 1959.

38. Lange, E. W. and Messner, G., Z. Electrochem., 33, 431 $(1927)$.

39. Lange, E. W. and Robinson, A. L., Chem. Rev., 2, 89 $(1931)$.

40. Mackey, J. L., Powell, J. E. and Spedding, F. H., J.' Am. Chem. Soc., 84, 2047 (1962).

41. Malmberg, C. G. and Maryott, A. A., I. Res. NatI. Bur. stand., 56, ? $(1.956)$.

42. Marezio, M., Plettinger, H. A. and Zachariasen, W. H., Acta Cryst., 14, 234 (1961).

43. Mayer, J. I., J. Chem. Phys., 18, 1426 (1950).

44. Milner, S. R., Phil. Mag., 23, 551 (1912); 25, 742 (1913).

45. Nancollas, G. H., Quarterly Reviews, 14, 402 (1960).

46. Naumann, Alfred W., "Heats of Dilution and Related Thernodynamic Properties of Aqueous Neodymium Chloride and Erbium Chloride Solutions", Unpublished Ph.D. thesis, Library, Iowa State University of Science and Technology, Ames, Iowa, 1956. 
47. Nelson, Robert A., "Some Thermodynamic Properties of Aqueous Solutions of Terbium", Unpublished M.S. thesis, Library, Iowa State University of Science and Technology, Ames, Iowa, 1960.

48. Nernst, W. and Orthmann, W., Sitzbar. Breuss. Akad. 51 (1926).

49. Nernst, $W_{j}$ and Orthmann, W., Z. Physik. Chem., 235, 199 (1928).

50. Onsager, L., Chem. Rey., 13, 73 (1933).

51. Owen; B. B., Miller, R. C., Milner, C. E. and Cogan, H. L., J. Phys. Chem., 65, 2065 (1961).

52. Petheram, Harry H., "Osmotic and Activity Coefficients of Some Aqueous Rare-Earth Chloride Solutions at $25^{\circ} \mathrm{C}^{\prime \prime}$, Unpublished M.S. thesis, Library, Iowa State University of Science and Technology, Ames, Iowa, 1963.

53. Poirier, J. C., J. Chem. Phys., 21, 965, 972 (1953).

54. Powell, Jack E., "Separation of Rare Earths by Ion Exchange". In Spedding, F. H. and Daane, A. H., eds., "The Rare Earths", pp. 55-73, John Wiley and Sons, Inc., New York, N.Y., 1961.

55. Richards, T. W. and Rowe, A. W., J. Am. Chem. Soc., 42, 1621 (1920).

56. Richards, T. W. and Rowe, A. W., I. Am. Chem. Soc., 43, 770 (1921).

57. Robinson, A. L. and Wallace, W. E., I. Am. Chem. Soc., 63, 1582 (1941).

58. Robinson, A. L. and Wallace, W. E., Chem. Rev., 30, 195 (1942).

59. Robinson, R. A. and Stokes, R. H., "Electrolyte Solutions", 2nd ed., Butterworth's Scientific Publications, London, England, 1959.

60. Rossini, F. D., "Experimental Thermochemistry", Interscience Publishers, Inc., New York, N.Y., 1956. 
61. Rossini, Frederick D., Wagman, Donald D., Evans, William H., Levine, Samuel and Jaffe, Irving, U.S. National Bureau of Standards Circular 500 (1952).

62. Saeger, Victor W., "Some Physical Properties of RareEarth Chlorides in Aqueous Solution", Unpublished Ph.D. thesis, Library, Iowa State University of Science and Technology, Ames, Iowa, 1960.

63. Salman, B. C. L. and White, A. G., I. Chem. Soc. (London), 3197 (1957).

64. Scatchard, G., I. Am. Chem. Sec., 53, 2037 (1931).

65. Scatchard, G., Phys. 2., 33, 22 (1932).

66. Scatchard, G., Chem. Bey. 12, 309 (1936).

67. Skinner, H. A., "Experimental Thermochemistry", Vol.2, Interscience Publishers, Inc., New York, N.Y., 1962.

68. Spedding, F. H. and Dye, J. L., J. Am. Chem. Sec., 26, 888 (1954).

69. Spedding, F. H. and Flynn, J. P., I. Am. Chem. Sos., 26. 1474 (1954).

70. Spedding, F. H., Naumann, A. W. and Eberts, R. E., J. Am. Chem. Soc., 81, 23 (1959).

71. Spedding, F. H., Porter, P. E. and Wright, J. M., I. Am. Chem. Soc., 24, 2781 (1952).

72. Stokes, R. H. and Robinsnn, R. A., I. Am. Chem. Soc., 20, 1870 (1948).

73. Sturtevant, J. M., "Calorimetry", in Weissberger, Arnold, ed., "Technique of Organic Chemistry" 3 rd ed., Vol. I, Part 1, pp. 523-654, Interscience Publistiers, Inc., New York, N.Y., 1959.

74a. Sturtevant, J. M., I. Am. Chem. Sec., 62, 584 (1940). 74b. Sturtevant, J. M., J. Am. Chem. Soc., 62, 2276 (1940). 74c. Sturtevant, J. M., I. Am. Chem. Sec., 62, 3265 (1940). 74d. Sturtevant, J. M., J. Am. Chem. Soc., 64, 762 (1942). 
75. Swietoslawski, W., "Microcalorimetry", Reinhold Publishing Corporation, New York, N.Y., 1946.

76. Vander Zee, C. E. and Myers, R. A., J. Phys. Chem., 65, 153 (1961).

77. Vander Zee, C. E. and Swanson, J. A., J. Phys. Chem., 67. 2610 (1963).

78. Van't Hoff, J. H., Z. Physik. Chem., 1, 481 (1887).

79. Vidulich, G. A. and Kay, R. L., I. Phys. Chem., 66, $383(1962)$.

80. Worthing, A. G. and Geffner, J., "Treatment of Experimental Data", John Wiley and Sons, Inc., New York, N.Y., 1943.

81. Wyman, J., Phys. Rey., 35, 623 (1930).

82. Wyman, J. and Ingalls, E. N., J. Am. Chem. Soc., 60, 1182 (1938).

83. Young, T. F. and Groenier, W. L., J. Am. Chem. Soc., 58, 187 (1936). 84. Young, T. F. and Seligmanin, P., J. Am. Chem. Soc., 60,

85. Young, T. F. and Vogel, O. G., J. Am. Chem. Soc., 54, $3030^{\circ}(1932)$.

86. Young, T. F., Wu, Y. C. and Krawetz, A. A., Discussions Earaday Soc., 24, 37 (1957). 
$\therefore$ DIST MADE $11-4-66$ TD.

\author{
$\underline{E} \underline{R}-\underline{R}-\underline{A}-\underline{T}-\underline{A}$ \\ IS-1356 - Heats of Dilution of Some Aqueous Rare-Earth \\ Chloride Solutions at $25^{\circ} \mathrm{C}$ \\ C. W. DeKock and F. H. Spedding
}

A number of copies of the above report were found to have pages 81-82 missing. Should this be the case with the copies you received, the missing pages are supplied herewith for insertion. 
to obtain an accurate extrapolation function, it was necessary to make many heat of dilution measurements in the dilute range since only small amounts of heat were evolved when the sample was diluted. Usually only two heat of dilution measurements were made on a particular concentration in the second region, since these values were used only to determine the $\emptyset_{L}$ value for that sample concentration.

In the range from zero molal to 0.25 molal two samples of the same concentration were placed in each calorimeter container. When the first sample of molality $m_{1}$, containing $n_{2}$ moles of salt, was diluted into pure water to give a final molality of $m_{2}$, an amount of heat $q_{1}$ was evolved. When the second sample of molality $m_{1}$, containing $n_{2}^{*}$ moles of salt, was diluted into the solution of molality $m_{2}$, a linal solution of molality $m_{3}$ was obtained. The heat associated with this dilution was qa. The heat evolved for each dilution process can be related to the relative apparent molal heat contents by equations 3.33 and 3.34 giving

$$
\mathrm{q}_{1}=\mathrm{n}_{2}\left[g_{L}\left(\mathrm{~m}_{2}\right)-\phi_{L}\left(\mathrm{~m}_{1}\right)\right]
$$

and

$q_{2}=n\left[\emptyset_{L}\left(m_{3}\right)-\emptyset_{L}\left(m_{1}\right)\right]+n_{2}\left[\emptyset_{L}\left(m_{3}\right)-\emptyset_{L}\left(m_{2}\right)\right] \cdot$ (4.8) 
The heat $q$ is positive if heat is absorbed and negative if heat is evolved.

The heats of dilution per mole between two concentrations are given by equation 3.35 and are

$$
\begin{aligned}
& \Delta H_{1,2}=\emptyset_{L}\left(m_{2}\right)-\emptyset_{L}\left(m_{1}\right) \\
& \Delta H_{1,3}=\emptyset_{L}\left(m_{3}\right)-\emptyset_{L}\left(m_{1}\right) \\
& \Delta H_{3,2}=\emptyset_{L}\left(m_{2}\right)-\emptyset_{L}\left(m_{3}\right)
\end{aligned}
$$

where $\Delta H_{1, f}$ is the heat absorbed when one mole of a solution of concentration $m_{i}$ is diluted to concentration $m_{f}$. The quantities $\Delta \mathrm{H}_{1,2}$ and $\Delta \mathrm{H}_{1,3}$ are referred to as "long chord dilutions" and the quantity $\Delta \mathrm{H}_{3,2}$ as a "short chord dilution".

The quantities $\Delta \mathrm{H}_{1,2}$ and $\Delta \mathrm{H}_{1,3}$ can be obtained from the heat of dilution measurements by substituting equations 4.9 and 4.10 into equations 4.7 and 4.8 to obtain

$$
\Delta H_{1,2}=\frac{q_{1}}{n_{2}}
$$

and 